\title{
Psychogenic non-epileptic seizures : the identification of neurophysiological correlates
}

Citation for published version (APA):

Kolfschoten-van der Kruijs, S. J. M. (2014). Psychogenic non-epileptic seizures : the identification of neurophysiological correlates. [Doctoral Thesis, Maastricht University]. Maastricht University. https://doi.org/10.26481/dis.20140624sk

Document status and date:

Published: 01/01/2014

DOI:

10.26481/dis.20140624sk

Document Version:

Publisher's PDF, also known as Version of record

\section{Please check the document version of this publication:}

- A submitted manuscript is the version of the article upon submission and before peer-review. There can be important differences between the submitted version and the official published version of record.

People interested in the research are advised to contact the author for the final version of the publication, or visit the DOI to the publisher's website.

- The final author version and the galley proof are versions of the publication after peer review.

- The final published version features the final layout of the paper including the volume, issue and page numbers.

Link to publication

\footnotetext{
General rights rights.

- You may freely distribute the URL identifying the publication in the public portal. please follow below link for the End User Agreement:

www.umlib.nl/taverne-license

Take down policy

If you believe that this document breaches copyright please contact us at:

repository@maastrichtuniversity.nl

providing details and we will investigate your claim.
}

Copyright and moral rights for the publications made accessible in the public portal are retained by the authors and/or other copyright owners and it is a condition of accessing publications that users recognise and abide by the legal requirements associated with these

- Users may download and print one copy of any publication from the public portal for the purpose of private study or research.

- You may not further distribute the material or use it for any profit-making activity or commercial gain

If the publication is distributed under the terms of Article $25 \mathrm{fa}$ of the Dutch Copyright Act, indicated by the "Taverne" license above, 


\section{PSYCHOGENIC NON-EPILEPTIC SEIZURES}

THE IDENTIFICATION OF NEUROPHYSIOLOGICAL CORRELATES 
ISBN 978-94-6259-228-5

Ipskamp Drukkers, Enschede

\section{(C) Sylvie Kolfschoten - van der Kruijs}

Financial support for the printing of this thesis was kindly provided by Kempenhaeghe's department of Research and Development, the school for Mental Health and Neuroscience (MHeNS) of Maastricht University, Nationaal Epilepsiefonds, ANT Neuro B.V. and UCB Pharma B.V. Breda. 


\section{PSYCHOGENIC NON-EPILEPTIC SEIZURES}

THE IDENTIFICATION OF NEUROPHYSIOLOGICAL CORRELATES

\section{PROEFSCHRIFT}

ter verkrijging van de graad van doctor aan de Universiteit Maastricht,

op gezag van de Rector Magnificus, Prof. Dr. L.L.G. Soete,

volgens het besluit van het College van Decanen,

in het openbaar te verdedigen op dinsdag 24 juni 2014 om 12.00 uur

door

Sylvie Johanna Maria Kolfschoten - van der Kruijs

geboren op 19 augustus 1987 te Eindhoven 


\section{Promotores}

Prof. Dr. A.P. Aldenkamp

Prof. Dr. K.E.J. Vonck, Universiteit Gent

\section{Copromotores}

Dr. J.F.A. Jansen

Dr. R.H.C. Lazeron, Kempenhaeghe

\section{Beoordelingscommissie}

Prof. Dr. R.J. van Oostenbrugge, Universiteit Maastricht

Prof. Dr. Ir. P.H.N. de With, Technische Universiteit Eindhoven

Prof. Dr. F.R.J. Verhey, Universiteit Maastricht

Prof. Dr. J. Arends, Technische Universiteit Eindhoven

Dr. R. Rouhl, Universiteit Maastricht 


\section{Contents}

1. Introduction

1.1 Psychogenic non-epileptic seizures 9

$\begin{array}{lll}1.2 & \text { Dissociation } & 10\end{array}$

1.3 Magnetic resonance imaging 11

$\begin{array}{ll}1.4 \text { Heart rate variability } & 12\end{array}$

$\begin{array}{lll}1.5 & \text { Thesis outline } & 13\end{array}$

2. Review: Psychophysiological biomarkers of dissociation in 15 psychogenic non-epileptic seizures

S.J.M. van der Kruijs, N.M.G. Bodde, A.P. Aldenkamp. Acta Neurologica Belgica 2011,111 , 99-103.

$\begin{array}{lll}2.1 & \text { Abstract } & 15\end{array}$

2.2 Introduction 16

$\begin{array}{lll}2.3 \text { Methods } & 17\end{array}$

$\begin{array}{lll}2.4 \text { Results } & 17\end{array}$

2.5 Conclusion 20

3. Review: Neurophysiological correlates of dissociative symptoms 23

S.J.M. van der Kruijs, N.M.G. Bodde, E. Carrette, R.H.C. Lazeron, K.E.J.

Vonck, P.A.J.M. Boon, G.R. Langereis, P.J.M. Cluitmans, L.M.G. Feijs,

P.A.M. Hofman, W.H. Backes, J.F.A. Jansen, A.P. Aldenkamp. Journal of Neurology, Neurosurgery \& Psychiatry 2014, 85, 174-179.

3.1 Abstract 23

3.2 Introduction 24

$\begin{array}{lll}3.3 \text { Methods } 25 & 25\end{array}$

3.4 Results 25

3.5 Conclusion 32

3.6 Appendix 36 
4. Subgroup classification in patients with psychogenic non-epileptic seizures

N.M.G. Bodde, S.J.M. van der Kruijs, D.M. IJff, R.H.C. Lazeron, K.E.J.

Vonck, P.A.J.M. Boon, A.P. Aldenkamp. Epilepsy \& Behavior 2013, 26,

279-289.

4.1 Abstract 47

4.2 Introduction 48

4.3 Methods 51

4.4 Results 53

$\begin{array}{lll}4.5 & \text { Discussion } & 61\end{array}$

$\begin{array}{lll}4.6 & \text { Appendix } & 67\end{array}$

5. Functional connectivity of dissociation in psychogenic non-epileptic seizures

S.J.M. van der Kruijs, N.M.G. Bodde, M.J. Vaessen, R.H.C. Lazeron, K.E.J. Vonck, P.A.J.M. Boon, P.A.M. Hofman, W.H. Backes, A.P. Aldenkamp, J.F.A. Jansen. Journal of Neurology, Neurosurgery \& Psychiatry 2012, 83, 239-247.

$\begin{array}{lll}5.1 & \text { Abstract } & 73\end{array}$

$\begin{array}{ll}5.2 \text { Introduction } & 74\end{array}$

5.3 Materials and methods $\quad 75$

5.4 Results 80

5.5 Discussion 86 
6. Resting-state networks and dissociation in psychogenic non-epileptic seizures

S.J.M. van der Kruijs, S.R. Jagannathan, N.M.G. Bodde, R.M.H. Besseling,

R.H.C. Lazeron, K.E.J. Vonck, P.A.J.M. Boon, P.A.M. Hofman, W.H.

Backes, A.P. Aldenkamp, J.F.A. Jansen. Journal of Psychiatric Research $2014,54,126-133$.

6.1 Abstract 93

6.2 Introduction 94

6.3 Materials and methods 96

$\begin{array}{lll}6.4 & \text { Results } & 100\end{array}$

$\begin{array}{lll}6.5 & \text { Discussion } & 104\end{array}$

7. Autonomic nervous system functioning associated with psychogenic 109 non-epileptic seizures: Analysis of heart rate variability

S.J.M. van der Kruijs, K.E.J. Vonck, G.R. Langereis, L.M.G. Feijs, N.M.G. Bodde, R.H.C. Lazeron, E. Carrette, P.A.J.M. Boon, W.H. Backes, J.F.A. Jansen, A.P. Aldenkamp, P.J.M. Cluitmans. Submitted for publication.

$\begin{array}{lll}7.1 & \text { Abstract } & 109\end{array}$

$\begin{array}{ll}7.2 \text { Introduction } & 110\end{array}$

$\begin{array}{lll}7.3 \text { Materials and methods } & 111\end{array}$

$\begin{array}{lll}7.4 \text { Results } & 114\end{array}$

$\begin{array}{ll}7.5 \text { Discussion } & 119\end{array}$ 
8. Autonomic nervous system functioning associated with epileptic seizures: Analysis of heart rate variability

S.J.M. van der Kruijs, K.E.J. Vonck, L.M.G. Feijs, N.M.G. Bodde, R.H.C. Lazeron, E. Carrette, P.A.J.M. Boon, W.H. Backes, J.F.A. Jansen, A.P. Aldenkamp, P.J.M. Cluitmans. Submitted for publication.

8.1 Abstract 123

$\begin{array}{ll}8.2 \text { Introduction } & 124\end{array}$

$\begin{array}{ll}\text { 8.3 Materials and methods } & 125\end{array}$

$\begin{array}{lll}8.4 & \text { Results } & 128\end{array}$

8.5 Discussion 133

$\begin{array}{lll}\text { 9. Discussion } & 137\end{array}$

9.1 Rationale 137

9.2 The role of dissociation in PNES 138

$\begin{array}{lll}9.3 & \text { Functional MRI } & 139\end{array}$

9.4 Electrocardiography 139

9.5 Clinical interpretation $\quad 140$

$\begin{array}{lll}9.6 & \text { Future perspectives } & 145\end{array}$

$\begin{array}{ll}\text { Summary } & 147\end{array}$

$\begin{array}{ll}\text { Samenvatting } & 151\end{array}$

$\begin{array}{ll}\text { References } & 155\end{array}$

$\begin{array}{ll}\text { Curriculum Vitae } & 181\end{array}$

$\begin{array}{ll}\text { List of publications } & 183\end{array}$

$\begin{array}{ll}\text { Dankwoord } & 187\end{array}$ 


\section{Chapter 1}

INTRODUCTION

\subsection{Psychogenic non-epileptic seizures}

Psychogenic non-epileptic seizures (PNES) can be defined as paroxysmal behavior patterns that resemble epileptic seizures, but are not caused by epileptiform brain activity or other organic factors. Instead, psychogenic factors are assumed to underlie the seizures (Bodde et al., 2009a). For example, PNES often occur in persons who report traumatic experiences, such as victims of childhood abuse and war veterans (Tojek et al., 2000; Salinsky et al., 2011). Nonetheless, PNES are also present in persons without trauma history (Hingray et al., 2011). Patients often do not recognize that their symptoms result from psychogenic factors and they often cannot reproduce the emotional states which precede the episodes (Reuber et al., 2011). This is understandable as PNES may serve as a mechanism to cope with or suppress emotional distress. As a result, most patients with PNES are initially misdiagnosed as having epilepsy. Differential diagnosis of epilepsy and PNES is often based on video-EEG monitoring (Cragar et al., 2002), which usually occurs in tertiary epilepsy centers. It is estimated that PNES account for as much as $20 \%$ of the definite diagnoses among patients referred to epilepsy centers for untreatable epilepsy (Lesser, 1996) and up to $50 \%$ of the patients admitted to hospital in apparent status epilepticus (Reuber and Elger, 2003), with an estimated prevalence of 2-33/100,000 (Benbadis et al., 2000).

The period between the onset of seizures and the eventual diagnosis of PNES is on average more than 6 years (Alsaadi and Marquez, 2005). The initial misdiagnosis as epilepsy has serious consequences for the patient, such as exposure to unnecessary antiepileptic medication, and considerable delay to the start of appropriate psychological therapy. By the time the correct diagnosis is made, patients will commonly have taken more types of antiepileptic drugs at higher doses and experience more side effects than an equivalent cohort of patients with epilepsy (Krumholtz and Neidermeyer, 1983; Kristensen and Alving, 1992). In addition, 
long duration of undiagnosed PNES seriously affects quality of life (Szaflarski et al., 2003) and is known to be associated with poorer outcome (Selwa et al., 2000). Failure to recognize psychogenic non-epileptic seizures may even cause death (Reuber et al., 2004a). Misdiagnosis as epilepsy also has a substantial societal burden, as it causes the patients to consume a disproportionate amount of scarce medical resources (Kirmayer and Robbins, 1991) and erroneous treatments for intractable epilepsy are expensive (Martin et al., 1998).

For these reasons, early recognition of PNES is highly important. The aim of this thesis is to increase the understanding of psychopathological mechanisms and predisposition factors, which are crucial to facilitate accurate diagnosis of PNES, preventing burden for the patient and society.

\subsection{Dissociation}

Existing theories regarding the underlying pathological mechanisms of PNES are diverse and involve multiple factors that may interact in both the development and prolongation of PNES. One prominent factor in most theories for PNES (Bodde et al., 2009b) and other functional symptoms (Guz et al., 2004 and Spitzer et al., 1999) is dissociation. Dissociation is a broad concept that involves a variety of manifestations. It has been described as "the lack of normal integration of thoughts, feelings, and experiences into the stream of consciousness and memory" by Bernstein and Putnam (1986). Symptoms of derealization, depersonalization, and psychogenic amnesia are considered key features of dissociation. Accordingly, the process of hypnosis can also be positioned in the dissociative spectrum (Kihlstrom, 1998).

A certain degree of dissociation is used by everyone to focus on tasks at hand, to not be distracted by other input. This type of dissociation is perfectly normal and does not interfere with normal daily functioning. In addition, occasional severe dissociation is used by many to cope in isolated, infrequent incidents of extreme stress (e.g. shock after a severe accident, emotional numbing after a significant loss) (Bovin and Marx, 2011).

Pathological chronic dissociation is observed when a person dissociates habitually even to minor stressors, as is often the case in post-traumatic stress disorder (Briere et al., 2005). This type of dissociation may co-occur with flashbacks 
and feelings of numbness and unreality, which may hinder daily functioning. Dissociation may even be used to the extent that significant parts of the person (e.g. traumatic memories) are split into distinct "identities", which occurs in dissociative identity disorder (Dell, 2002). When episodes of pathological dissociation co-occur with somatic manifestations of emotional distress, which seems to be the case in patients with PNES, the additional symptoms even further invalidate the person.

The observations that patients with PNES often demonstrate dissociative symptoms (Goldstein and Mellers, 2006), increased dissociation tendency (Alper et al., 1997; Bowman and Coons, 2000; Prueter et al., 2002) and high hypnotizability (Dienes et al., 2009), and have dissociative disorders in over $90 \%$ of the cases (Bowman and Markand, 1996) strongly suggest dissociation to be part of the psychopathology and psychogenesis of PNES. Since dissociation may be an important factor in the etiology of PNES, better understanding of the mechanism of dissociation might shed light on the pathology of PNES and lead to more specific treatments. However, since patients are not able to report about dissociative episodes, more objective measurements than self-report are needed. The physiological measurements derived from magnetic resonance imaging and electrocardiography that are adopted in this thesis have the potential to reveal the neurobiological mechanism of dissociation in PNES, explaining how information and emotion in patients with PNES or other functional symptoms are processed differently compared to non-affected individuals.

\subsection{Magnetic resonance imaging}

Magnetic resonance imaging (MRI) of the brain is among the most promising techniques to improve the understanding of the etiology of PNES. It provides the opportunity to investigate cerebral changes in several fundamentally different ways (Tofts, 2003). Macroscopic brain abnormalities can be detected by visual examination of structural MRI images. To investigate brain structure in more detail, advanced methods such as voxel-based morphometry and diffusion weighted imaging analysis are available, which respectively explore brain volume (Mechelli et al., 2005) and white matter integrity (Bammer, 2003). However, these methods provide a static view of brain structure rather than function. 
Functional MRI (fMRI) may be a more powerful technique to investigate brain processes that reflect the mechanisms leading to PNES. Functional MRI is a technique that measures brain activity by following the blood oxygen level dependent (BOLD) response. When an area of the brain is activated, blood flow to that region increases, and oxygen-rich blood replaces oxygen-depleted blood around 2 seconds later. The change in magnetization between oxygen-rich and oxygen-poor blood can be used to localize brain activity (Ogawa et al., 1990). FMRI has been used to discover which brain areas are involved in cognitive processes such as perception, memory and language (Matthews and Jezzard, 2004). However, currently it is recognized that cognitive or emotional functions do not result from localized brain activation, but require activation of multiple brain regions that are interconnected (Bassett and Bullmore, 2009; Stam, 2010). The interaction between brain regions can for instance be investigated by means of correlational analyses between activation patterns of separate brain regions, termed functional connectivity analyses (Sun et al., 2004). Another development in the field of neuroimaging is the examination of resting-state brain networks, which are networks that are active while the brain is in relative rest, i.e. when a person is not supposed to focus on a certain task during MRI scanning. The investigation of resting-state brain networks is based on the assumption that neural connections exist whether or not they are functionally active at any given moment (Smith et al., 2009). In fact, restingstate networks represent the functional architecture of the brain. This approach is particularly appropriate for investigation of brain functioning in PNES, since MRI scanning during provoked dissociation and PNES episodes is difficult and comes with ethical considerations.

\subsection{Heart rate variability}

Since many patients fail to recognize the emotional states that are associated with a seizure (Reuber et al., 2011), not much is known about the psychological triggers of PNES. Dissociative symptoms are often regarded as a coping mechanism to reduce the impact of traumatic experiences and other stressors (Gershuny and Thayer, 1999). Accordingly, PNES may serve as a means to prevent confrontation with intolerable feelings, experiences or memories. In line with this assumption is the description of a "warning" uncomfortable feeling and extinguishment of this feeling 
by PNES that is reported by some patients (Stone and Carson, 2013). However, as a general rule, patients fail to report the emotional states that triggered the seizures. Subjective patient reports are therefore inaccurate.

Monitoring of objective physiological parameters which represent states of stress and arousal are considered to be helpful in identifying the emotional state in which PNES occur. Particular cardiovascular parameters such as heart rate and heart rate variability, which represent activation of the sympathetic and parasympathetic nervous system (Malik et al., 1996), are good candidates since these measures reflect whether a patient is calm or in a state of alertness. For example, a shift in cardiac balance in favor of the parasympathetic system reflects the body being in "rest-and-digest" mode rather than the state of vigilance associated with the sympathetic nervous system (Stein et al., 1994). The simultaneous recording of cardiovascular functioning by electrocardiography during video-EEG monitoring facilitates the investigation of the relationship between changes in these cardiovascular parameters and the occurrence of PNES. If PNES are indeed manifestations of a psychological defense mechanism, one would expect the symptoms to be preceded by physiological arousal, and the arousal to be decreased by PNES episodes. However, one must not exclude alternatives for the view of PNES as a defensive maneuver, since dissociative tendencies and PNES have also been related to increased physiological responses to emotional cues (Giesbrecht et al., 2007; Bakvis et al., 2009).

\subsection{Thesis outline}

This thesis starts with a review of the literature in order to identify the possibilities of MRI, cardiovascular, and neuroendocrine measurements in revealing the etiology of PNES (Chapter 2). In Chapter 3, the focus is broadened, and investigations into neurophysiological characteristics of other functional neurological syndromes and symptoms (FNSS) and related dissociative characteristics are included in order to explore potential underlying mechanisms. In Chapter 4, the applicability of a theoretical model for the diagnosis of PNES was studied in order to define a general psychological profile and to specify possible subgroups. One aim of this study was extensive examination of the role of dissociation in the total population of patients with PNES and in specific subgroups. Chapter 5 describes the findings of a study in 
which functional MRI was used to identify differences in resting-state brain networks between patients with PNES and healthy controls. The study described in Chapter 6 applied the data-driven approach of independent component analysis (ICA) on resting-state fMRI data of a larger study population to investigate alterations within four relevant networks, associated with executive, fronto-parietal, sensorimotor, and default mode activation. Chapter 7 describes the results of heart rate variability analyses in patients with PNES and their potential implications. In Chapter 8, peri-ictal heart rate variability parameters of patients with epilepsy were examined and the potential aid of these parameters to differentiate between epilepsy and PNES is discussed. In the general discussion (Chapter 9), the main findings are summarized and several important questions with regard to clinical interpretation are discussed. 


\section{Chapter 2}

REVIEW: PSYCHOPHYSIOLOGICAL BIOMARKERS OF DISSOCIATION IN PSYCHOGENIC NON-EPILEPTIC SEIZURES

S.J.M. van der Kruijs, N.M.G. Bodde, A.P. Aldenkamp. Acta Neurologica Belgica $2011,111,99-103$.

\subsection{Abstract}

Misdiagnosis of patients with psychogenic non-epileptic seizures (PNES) as having epilepsy is a clinical relevant problem. Considerable problems for the patients, such as unnecessary anticonvulsant medication use and delay of suitable therapy, as well as a considerable economic burden are involved. Next to the diagnostic difficulties, there is little scientific evidence for efficient treatment for PNES. Therefore, evaluation of factors that contribute to the etiology is necessary to be able to compose explanatory models for the occurrence of PNES, which should be employed in diagnosis and treatment.

Recent evidence suggests deficiencies in neuronal information processing in multiple mental conditions. The focus in PNES research over the last two decades primarily has been on differential diagnosis and psychological and environmental factors. The current review focuses on neurobiological substrates of PNES and dissociation, a trait which is often associated with PNES, to explore whether such measures could clarify the deviant processing of information and emotion that is involved in the etiology of PNES.

All studies that have examined the relationship between psychophysiological parameters and PNES had an exploratory character. However, the results suggest that neurophysiological characteristics such as brain activity, cardiovascular parameters and neuroendocrine functioning may be abnormal in patients with PNES. Future investigations should therefore elucidate the exact role of neurophysiological abnormalities in the etiology of PNES. 


\subsection{Introduction}

Psychogenic non-epileptic seizures (PNES) are episodes of movement or behavior that resemble epileptic seizures, but are not accompanied by epileptiform brain activity as seen on electroencephalogram (EEG). The underlying cause is assumed to be psychological; the episodes may be the somatic manifestations of emotional distress (Bodde et al., 2009a). PNES is one of the most important differential diagnoses of epilepsy, and most patients with PNES are initially misdiagnosed as having epilepsy. The average period between the onset of seizures and the diagnosis of PNES is typically more than 6 years (Alsaadi and Marquez, 2005). Misdiagnosis as epilepsy has serious consequences for patients with PNES, such as exposure to unnecessary anticonvulsant medication, and considerable delay to start the appropriate psychological therapy. In addition, a substantial economic burden is involved, as erroneous treatment for intractable epilepsy is expensive (Martin et al., 1998). Evaluating the information described above, it is clear that differential diagnosis of PNES is clinically relevant. However, if the emphasis is only on excluding epilepsy, PNES may become a non-disease (Dekkers and Van Domburg, 2000). A positive diagnosis is necessary for appropriate treatment, therefore, the underlying mechanisms must be evaluated and results must be implemented in treatment. To gain more insight in the underlying mechanisms of psychogenic seizures, it is necessary to identify not only causal factors, such as traumatic experiences, but also predisposition factors, which elucidate why certain persons develop PNES symptoms after trauma and others do not. Such predisposition factors may be of influence in the stages of vulnerability, shaping, provocation and prolongation of PNES pathology, and have to be identified in order to organize an explanatory model of PNES (Bodde et al., 2009b).

An important predisposing factor for PNES is an increased dissociation tendency (Kuyk et al., 1999; Bodde et al., 2009b). The process of dissociation is a disruption of the usually integrated functions of identity, memory, consciousness or perceptions of the environment. Dissociation is closely related to the process of hypnosis and essentially shows the ability to distance from reality. It is often regarded as a psychological defense mechanism from stressful events, by altering conscious experience (Erdelyi, 2004). Others assume dissociation to be a constitutional mental weakness that is activated by adverse events (Dell, 2010). The tendency to easily 
dissociate is considered an important factor in the provocation and possibly also the prolongation of PNES (Reuber and Elger, 2003).

Because an increased dissociation tendency may be such a prominent trait of a substantial group of PNES patients, investigation of biological correlates of dissociation is an important step in the attempt to generate an explanatory model for PNES. This review focuses on neurobiological substrates of PNES and dissociation associated with PNES, to explore whether deviant information processing is involved in the etiology of PNES.

\subsection{Methods}

Relevant studies were identified by searching the electronic databases PubMed and ScienceDirect. Articles included in this review were identified by searching the terms "MRI PNES", "fMRI PNES", "fMRI psychiatry", "fMRI hypnosis", "HRV PNES", and "HPA axis PNES". Titles of articles and abstracts extracted during the search were reviewed for relevance, and if found to be applicable, the full-text article was retrieved. Case reports were not considered. Articles were included when published after 1980 up till 2010.

\subsection{Results}

\subsubsection{Structural MRI abnormalities}

Magnetic resonance imaging (MRI) of the brain provides the opportunity to investigate cerebral changes in a number of fundamentally different ways (Tofts, 2003). Structural MRI is one of the techniques most often employed for detection of anatomical brain abnormalities. Some investigations have related PNES with structural MRI abnormalities. For example, Reuber et al. (2002) found structural brain abnormalities more commonly in PNES patients than in the general population. They investigated the proportion of PNES patients having neurological abnormalities on structural magnetic resonance imaging, and found that 27 percent of PNES patients and 78 percent of patients with PNES and epilepsy showed anatomical irregularities. A wide variety of abnormalities was found in the PNES only group, including - in order of frequency - postoperative defects, arachnoid cyst, posttraumatic changes, 
generalized atrophy, gliotic change, white matter lesions, hippocampal sclerosis, and venous angioma. Abnormalities in the PNES plus epilepsy group included hippocampal sclerosis, postoperative defects, migration disorders, signs of previous stroke, gliosis, posttraumatic changes, hemiatrophy, white matter lesions, tumor, cavernoma, and venous angioma.

Devinsky et al. (2001) even report 25 percent of their sample of PNES patients (with and without comorbid epilepsy) having structural abnormalities on MRI. In their sample, neurological features also varied widely, but showed to be significantly more present in the right hemisphere of PNES patients compared to the distribution of pathologies in the brains of epilepsy patients. These results suggest that right hemisphere dysfunction may form a predisposition factor to development of PNES symptoms. This finding is consistent with previous evidence for right hemisphere dominance in emotional regulation and conversion reactions /Cancelliere and Kertesz, 1990; Stern, 1997). Thus, it is possible that neuropathology influences the neuropsychological performance of patients with PNES, and both may, in interaction, constitute the vulnerability factor in PNES patients.

Future research should address the role of microstructural brain abnormalities in the etiology of PNES, for example investigated with voxel-based morphometry (cortical thickness) and diffusion-weighted imaging (white matter integrity).

\subsubsection{Functional MRI abnormalities}

Quantitative information about structural brain abnormalities provides minimal insight into functional organization and reorganization in patients with PNES. To investigate whether deviations in functional brain architecture are predictive of dissociation in patients with PNES, functional imaging is essential. Functional magnetic resonance imaging (fMRI) is a technique frequently used to explore the relationship between brain activation and cognitive functioning. It measures changes in the blood-oxygen-level dependent (BOLD) signal, which are assumed to accompany neural activity in the brain (Nair, 2005). Functional MRI abnormalities have been demonstrated to be related to abnormal information processing in several mental conditions, for example schizophrenia (Hasenkamp et al., 2011; Krawitz et al, 2011), panic disorders (De Carvalho et al., 2010), and bipolar disorder (Dickstein et al, 2010). 
Until now, functional MR imaging techniques have not been used to explain deviant neuronal processing in patients with PNES. However, these techniques have been employed to explore neurophysiological correlates of hypnosis, a process closely linked to dissociation. In a functional MRI investigation of McGeown et al. (2009), the authors demonstrate that induction of hypnosis in highly suggestible individuals causes decreased cerebral blood flow in the anterior parts of the default mode network during rest. Other authors, for example Egner et al. (2005) and Raz et al. (2005), have also associated decreased activation of frontal structures such as the anterior cingulate cortex (ACC) with high suggestibility. Because the process of hypnosis appears to be related to dissociation, similar activation patterns may be observed in patients with PNES who have a high dissociation tendency.

\subsubsection{Brain network abnormalities}

Cognitive and emotional functions result from the interactions of a number of differently localized brain regions rather than single (isolated) regions. In this context, brain connectivity analyses, which examine the integrity and efficiency of cerebral networks, are most appropriate in evaluating information processing deficits of patients with psychiatric conditions such as PNES (Fusar-Poli and Broome, 2006). For example, fMRI facilitates the assessment of the functional connectivity of regional brain activity, based on correlations in dynamic spontaneous fluctuations (Rogers et al., 2007). In addition, graph theoretical analyses provide measures that reflect the integrity and efficiency of regional or global brain networks (Stam and Reijneveld, 2007). These analyses can be applied both on task-related fMRI data, as well as on resting state fMRI (rs-fMRI) data where no explicit stimuli are presented (Buckner and Vincent, 2007). Network analysis of diffusion tensor imaging (DTI) data, using measures of water directionality and diffusivity, can provide information regarding the integrity of structural connectivity of the entire brain (Bullmore and Sporns, 2009).

\subsubsection{Cardiovascular dysfunctioning}

It is hypothesized that patients with PNES experience increased levels of emotional stress. Emotional stress has been proven to be accompanied by physiological changes like increased heart rate, blood pressure, respiration rate and muscle tension, and decreased heart rate variability (HRV) (Brosschot et al., 2007; Henje 
Blom et al., 2010). Heart rate variability in particular is a measure of interest, because it reflects the functioning of the parasympathetic autonomic nervous system, the system responsible for stimulation of activities that occur when the body is at rest. Heart rate variability may be decreased in patients with PNES, suggesting a state of hypervigilance. Indeed, Bakvis et al. (2009) have examined the cardiovascular functioning of patients with PNES, and found that patients with PNES show lower HRV during baseline and recovery of stress compared to healthy controls. However, their study had an experimental design; ambulatory measurements during daily life would provide additional and ecological valid information about the level of emotional arousal and cardiovascular condition of patients with PNES.

\subsubsection{Abnormal neuroendocrine functioning}

An increased state of threat vigilance was confirmed by Bakvis et al. (2010) using endocrinal measurements, which demonstrated a state of hypercortisolism in patients with PNES. Increased cortisol levels are assumed to reflect greater activity of the hypothalamic-pituitary-adrenal (HPA) axis, a major part of the neuroendocrine system that controls reactions to stressors and regulates many body processes including mood and emotions (Herman and Cullinan, 1997; McEwen, 2007). The HPA-axis has been proven to be involved in the neurobiology of mood disorders such as anxiety disorder (Mantella et al., 2008, and Lenze et al., 2011), bipolar disorder (Havermans et al., 2011; Chen et al., 2010), post-traumatic stress disorder (Pervanidou and Chrousos, 2010), borderline personality disorder (Nater et al., 2010), and major depressive disorder (Mclsaac and Young, 2009; Dedovic et al., 2010). Antidepressants, which are routinely prescribed for many of these disorders, serve to regulate HPA axis function (Laakmann et al., 1984). Recently, a pilot randomized controlled trial with Sertraline (a serotonine selective reuptake inhibitor) suggests this pharmacotherapy to be effective for seizure reduction, confirming involvement of the HPA-axis in the etiology of PNES (Lafrance et al., 2010).

\subsection{Conclusion}

To explore whether deviant information processing is involved in the etiology of PNES, this review focused on neurobiological substrates of PNES and of dissociation 
associated with PNES. Better understanding of the mechanisms underlying PNES could eventually improve the clinical management of PNES diagnosis and treatment. Early recognition of vulnerability factors such as dissociation would offer a possibility of earlier diagnosis of PNES, diminishing delay of suitable therapy and unnecessary epilepsy treatment.

Moreover, finding a neurobiological substrate of (dissociation in) PNES would change the concept of psychogenic seizures into being a psychophysiological phenomenon. This change of concept has implications for the development and evaluation of treatment, although direction of causality has to be examined in more detail. It will be difficult to position physiological abnormalities definitely as a predisposition factor, because such abnormalities may both be the cause and the consequence of dissociation and psychogenic non-epileptic seizures. Longitudinal studies should clarify the exact contribution and interaction of dissociation and physiological disturbances in PNES.

The most promising clinical consequence of such studies, in addition to improving knowledge about the etiology of PNES, is the possibility of using neuroimaging data or other physiological findings to identify subgroups of patients, which could allow treatment to be tailored. 



\section{Chapter 3}

NEUROPHYSIOLOGICAL CORRELATES OF DISSOCIATIVE SYMPTOMS

S.J.M. van der Kruijs, N.M.G. Bodde, E. Carrette, R.H.C. Lazeron, K.E.J. Vonck, P.A.J.M. Boon, G.R. Langereis, P.J.M. Cluitmans, L.M.G. Feijs, P.A.M. Hofman, W.H. Backes, J.F.A. Jansen, A.P. Aldenkamp. Journal of Neurology, Neurosurgery \& Psychiatry $2014,85,174-179$.

\subsection{Abstract}

Dissociation is a mental process with psychological and somatoform manifestations, which is closely related to hypnotic suggestibility, and essentially shows the ability to take distance from reality. An increased tendency to dissociate is a frequently reported characteristic of patients with functional neurological symptoms and syndromes (FNSS), which account for a substantial part of all neurological admissions. This review aims to investigate what heart rate variability (HRV), electroencephalography (EEG) and neuroimaging data (Magnetic Resonance Imaging) reveal about the nature of dissociation and related conditions.

The majority of the studies identified by the literature search concerned the physiological characteristics of hypnosis; relatively little investigations have focused on dissociation-related FNSS. General findings were increased parasympathetic functioning during hypnosis (as measured with HRV), and lower HRV in patients with FNSS. The large variety of EEG and functional MRI investigations with diverse results challenges definite conclusions, but evidence suggests that subcortical as well as (pre)frontal regions serve emotion regulation in dissociative conditions. Functional connectivity analyses suggest altered brain networks in patients with FNSS, in which limbic areas have an increased influence on motor preparatory regions.

HRV, EEG and (functional) MRI are sensitive methods to detect physiological changes related to dissociation and dissociative disorders such as FNSS, and can possibly provide more information about their etiology. The use of such measures could eventually provide biomarkers for earlier identification of patients at risk and appropriate treatment of dissociative conditions. 


\subsection{Introduction}

Dissociation is a mental process in which one's consciousness is being detached from thoughts, memories, feelings, and sense of identity. Dissociation is part of normal functioning, allowing us to be able to complete two tasks at once, but extreme forms of dissociation (e.g. shock, fugue) are considered pathological. Dissociation can be regarded as a spectrum, covering distinct but related concepts as suggestibility and fantasy proneness, but also hypnotic states and dissociative disorders (Kirsch and Lynn, 1998). The dissociation involved in hypnosis is considered mild in nature, temporarily decoupling executive control from other functions such as emotional control, sensory perceptions and motor functions (Bowers, 1992). Pathological dissociation, observed as spontaneous and uncontrollable hypnosis-like episodes, is considered a severe and aberrant form of dissociation, and has been related with emotional stress and traumatic experiences (Chu and Dill, 1990; Bremner et al., 1992). However, the exact emotional function of such dissociative episodes remains unclear.

In neurological practice, dissociation is seen as a common mechanism involved in many functional neurological symptoms and syndromes (FNSS) (Bodde et al., 2009b; Bell et al., 2011). Patients with FNSS are often initially misdiagnosed with a neurological condition, since the psychogenicity of FNSS is not always immediately recognized. The relationship between FNSS and dissociation is presumed because patients with FNSS often show a high level of hypnotizability, and a high prevalence of dissociative symptoms and dissociative disorders (Bell et al., 2011). In fact, the symptoms may be considered dissociative episodes with somatoform manifestations (Nijenhuis and Van der Hart, 2011). However, the dissociative nature of FNSS remains matter of debate (Brown et al., 2007). As a consequence, the unraveling of the pathological mechanism and the emotional function of the symptoms is an ongoing challenge.

Since the tendency to dissociate is considered an innate characteristic (Butler et al., 1996), the question rises whether there is a biological basis. Such a biological basis could provide information about the underlying mechanisms and functions of dissociation. Examples of possible biomarkers of dissociation are brain structure (obtained by magnetic resonance imaging (MRI)), brain activation (obtained by electroencephalography (EEG) and functional MRI) and functional networks 
(functional connectivity analyses). Additionally, cardiovascular parameters, measured using electrocardiography (ECG) or photoplethysmography (PPG), could provide information about fluctuations in autonomic function before, during and after dissociative episodes, and as such provide information about the role of (emotional) arousal in dissociation processes. The aim of this narrative review, based on a systematic search strategy, is to summarize and discuss the results and future possibilities of these physiological methods in relation to dissociation disorders and the related FNSS.

\subsection{Methods}

Relevant studies were identified by searching the electronic databases Cochrane, PubMed and ScienceDirect, performed August 1st, 2012. Articles included in this review were identified by searching the Medical Subject Heading (MeSH) terms "hypnosis, dissociation, functional, conversion symptoms", and any combination possible with "HRV, EEG, neuroimaging, MRI, VBM, DTI, fMRI". Titles of articles and abstracts selected from the search were reviewed for relevance, and when regarded applicable, the full-text article was retrieved. Case and small-N $(<5)$ reports were not incorporated. Articles obtained via citation tracking were also included.

\subsection{Results}

\subsubsection{Heart rate variability}

The relationship between emotional distress and dissociative episodes has remained unclear. Even in extreme cases such as in FNSS, patients commonly fail to report the exact feelings (e.g. stress, anxiety) as well as the circumstances that provoke symptoms. Often there is even denial of psychogenicity, which is understandable as the symptoms may serve as a means to avoid confrontation with intolerable feelings (with as a consequence a dissociative episode). Physiological parameters that change in function of emotional arousal, and that are independent of subjective reports, could elucidate the role of emotional stress in the development of the 
symptoms. Examples are cardiovascular functioning, skin conductance and muscle tension.

In particular heart rate variability (HRV) is considered to be a clinically relevant physiological measure for emotional arousal (Thayer and Brosschot, 2005). Heart rate variability is the variation in the beat-to-beat interval between heart beats, also called interbeat interval (IBI). The most widely used HRV analysis methods can be grouped under time-domain and frequency-domain methods. Time-domain methods are based on the analysis of beat-to-beat intervals, with outcome measures such as RMSSD, the root of the mean squared difference of successive interbeat intervals. Frequency-domain methods analyze the frequency domain after Fourier transformation of the time domain, and use the various spectral components of HRV, such as low-frequency (LF) and high-frequency (HF) components. The most frequently used HRV metrics are IBI, RMSSD, the power and amplitude of LF and HF components, their normalized values (LFnu and HFnu), and the LF/HF ratio (Malik et al., 1996). All these measures vary in relation to changes in autonomic modulations of the heart rhythm. An increased HRV reflects a shift in cardiac balance in favor of the parasympathetic system (Stein et al., 1994). This shift reflects the body being in "rest-and-digest" mode rather than the state of vigilance associated with the sympathetic nervous system. One important source of individual variability in HRV is negative emotional wellbeing or worry, which suppresses parasympathetic cardiac control, as confirmed by a variety of studies in healthy and depressed subjects (Pieper et al., 2007; Bosch et al., 2009; Miu et al., 2009).

Studies assessing the relationship between HRV and hypnosis, dissociation and FNSS are summarized in Supplementary Table 1 (Appendix). The general conclusion is that during hypnosis, HRV increases without a concomitant change in heart rate, suggesting an increase in parasympathetic modulation of cardiac activity (Diamond et al., 2008; Aubert et al., 2009; Vandevusse et al., 2010). The two HRV studies that assessed the tendency to dissociate show that a high tendency to dissociate is significantly related with decreased HRV (Latalova et al., 2010; Diveky et al., 2012). This finding corresponds with the results of investigations in patient populations with dissociative symptoms: Patients with FNSS demonstrate lower HRV compared to healthy controls (Bakvis et al., 2009; Ponnusamy et al., 2011). During rest as well as during recovery from a social stress test, patients with psychogenic non-epileptic seizures (PNES) show significantly lower HRV compared to controls 
(Bakvis et al., 2009; Ponnusamy et al., 2011). Within-subject comparisons demonstrate that in patients with dissociative identity disorder (DID), HRV decreases during confrontation with trauma-related memories, with a stronger effect with the participant being in the trauma-related identity state (Reinders et al., 2006).

\subsubsection{Electroencephalography}

To investigate electroencephalographic (EEG) changes during hypnosis, and to identify electrophysiological markers of dissociation and dissociative disorders, frequency band analysis has been performed. The quantity of EEG-based research on physiological indicators of hypnotic responding and hypnotic susceptibility is considerable, and has been summarized repeatedly. For example, already in 1977, Dumas reviewed the literature on EEG alpha (8-12 Hz) indices of hypnotic susceptibility, and concluded that there is no simple correlation in the overall population (Dumas, 1977). In 1991, Perlini and Spados (1991) came to the same conclusion in their literature review. However, in 1997, Ray concluded that the most solid relationship between EEG and hypnotizability exists in the theta frequency range $(4-8 \mathrm{~Hz})$. Highly susceptible individuals show relatively more theta activity in the EEG not only at baseline but also during hypnotic induction. This suggests that EEG theta activity is a characteristic of these individuals rather than an experimentally induced effect. Ray also reports anterior-posterior differences in the theta frequency band to be related with hypnotic susceptibility, with relatively more theta activity in the more frontal areas of the cortex. These results indicate altered frontal-directed strategic control during exploratory choices in reinforcement learning, because neurophysiological processes linking uncertainty and the exploration/exploitation trade-off are reflected in oscillations of the frontal theta rhythm (Cavanagh et al., 2011). The most recent literature review on EEG correlates of hypnosis and hypnotic susceptibility was written by De Pascalis in 1999. He concluded, based mainly on findings from his own laboratory, that differences in occurrence of $40-\mathrm{Hz}$ (about $40-\mathrm{Hz}$ band) activity appear to discriminate high and low hypnotizables both in and outside hypnosis, which was seen as evidence for an alteration of attention.

More recent findings, not previously reviewed in the literature, are summarized in Supplementary Table 2 (Appendix). Especially measures of synchronization or 
synchronicity, which represent cooperation within and between cortical regions, have been reported. For example, during hypnosis, decreases in gamma band (>30 $\mathrm{Hz}$ ) coherence have been reported, which reflect a decrease in frontal connectivity (Egner et al., 2005). Similarly, frontoparietal synchrony has been reported to decrease during hypnosis (Terhune et al., 2011; Lee and Koo, 2012), and lower synchronization of frontal lobe channels during hypnosis has been observed in highly hypnotizable subjects compared with people with medium and low hypnotizability (Lee and Koo, 2012; Baghdadi and Nasrabadi, 2012). In a cohort of psychiatric patients, more random and less correlated fractal dynamics of EEG rhythm have been observed during hypnosis, which also reflect decreased synchronicity (Lee et al., 2007). Decreased global functional coherence has been specifically related to the occurrence of imagery and transcendent experiences during hypnosis (Cardeña et al., 2012).

EEG data can also be analyzed as sequences of maps of the spatial distributions of the electric potential on the scalp, which are called 'microstates'. The classes of microstates may correspond to basic building blocks of human information processing: Microstates of class A are associated with abstract thoughts, class $B$ with visualizing thoughts, $C$ with increased and $D$ with decreased attention (Koenig et al., 2002). Decreased occurrence and duration of microstates of class $B$ and $D$ have been observed during deep hypnosis compared to light hypnosis, while the microstates of classes $A$ and $C$ showed the opposite behavior. These results led to the conclusion that light and deep hypnosis require different types of electrophysiological information processing: The decreased duration and occurrence of class B and D microstates, also observed in schizophrenia, may reflect minimized control/executive functions during deep hypnosis. The changes of the class $\mathrm{A}$ and $\mathrm{C}$ microstates during light hypnosis resemble electrophysiological changes during meditation, which suggests that these microstate changes may be related to mental relaxation and attentional processes (Katayama et al., 2007).

Only one study showed correlations between EEG analyses and FNSS. The investigation was conducted in patients with psychogenic non-epileptic seizures (PNES) and healthy controls, and showed decreased prefrontal and parietal synchronicity in the interictal EEG of patients with PNES. Correlation analysis suggests these synchronicity measures to be related to the frequency of the symptoms (Knyazeva et al., 2011). 


\subsubsection{Neuroimaging}

Neuroimaging can be used to investigate cerebral structure and functioning in various ways. The most accepted technique to detect differences in the brain's soft tissue anatomy is Magnetic Resonance Imaging (MRI). To analyze MR images at a more detailed structural level, for example to investigate cortical thickness and white matter integrity, techniques as voxel-based morphometry (VBM) and Diffusion Tensor Imaging (DTI) are available. Patterns of brain activation can be visualized using Positron Emission Tomography (PET/SPECT) and functional MRI. Furthermore, characteristics of networks in the brain, i.e. brain regions that share structural connections or that functionally interact, can be analyzed using DTI tractography and functional MRI connectivity techniques, respectively.

Cortical thickness and anatomical brain abnormalities have been related to hypnotizability and dissociation (Supplementary Table 3a, Appendix). Corpus callosum size has been positively related to hypnotizability (Horton et al., 2004), and the tendency to dissociate has been shown to correlate negatively with frontal white matter integrity as measured with DTI (Rusch et al., 2007). More investigations have been focusing on cerebral anatomy and functional neurological symptoms. Structural brain abnormalities such as postoperative defects, arachnoid cysts and atrophy were more common in patients with psychogenic non-epileptic seizures (PNES) than in the general population (Reuber et al., 2002). Even 25 percent of a sample of patients with PNES (with and without comorbid epilepsy) has been reported to display structural abnormalities on MRI (Devinsky et al., 2001). More recently, cortical thickness analyses revealed abnormal cortical atrophy of motor and premotor regions in the right hemisphere and in the cerebellum of patients with PNES. Premotor cortex atrophy appeared to be significantly related to depression scores (Labate et al., 2012). In another sample of patients with motor conversion disorder, decreased volumes of the caudate nuclei, lentiform nuclei and thalami have been observed (Atmaca et al., 2006).

Functional neuroimaging has been used to examine brain activation during hypnosis (Supplementary Table 3b, Appendix). The brain regions mostly activated during hypnotic PET imaging are the anterior cingulate cortex (ACC) and the thalamus Maquet et al., 1999; Rainville et al., 2002; Wik et al., 1999). Functional MRI during 
hypnosis also identified the ACC as a region with increased activation (Reinders et al., 2006; Raij et al., 2009; Schlamann et al., 2010), while activation of the somatosensory cortex decreased (Schulz-Stubner et al., 2004; Roder et al., 2007). Conversely, decreased activation of the ACC during hypnosis has also been reported (McGeown et al., 2009; Deeley et al., 2012).

Two studies overlap the fields of hypnosis and dissociative symptoms, using hypnosis to investigate differences in brain activation between subjectively experienced paralysis and intentionally simulated paralysis. Relative increases in PET signal in the prefrontal cortex, thalamus and putamen during subjectively experienced paralysis, and relatively increased activation of prefrontal and posterior cortical regions during intentionally simulated paralysis were identified (Ward et al., 2003). Functional MRI revealed hypoactivation of the sensorimotor cortex and cerebellum, and increased activation of the ACC, frontal gyrus and insula during movement imitation in hypnotic paralysis (Burgmer et al., 2012).

In a sample of patients with borderline personality disorder, acute dissociation was not related with differences in regional (orbitofrontal) brain activation (Wolf et al., 2012). However, in patients with primarily dissociative symptoms, significant differences in brain activation have been reported. For example, in patients with dissociative identity disorder, within-subject analyses of PET imaging during neutral and trauma-related identity states demonstrated widespread changes in subcortical regions, including the insula, during the trauma-related identity state (Reinders et al., 2006). When compared to healthy controls, another group of patients with DID demonstrated decreases in orbitofrontal neuronal activation, and increased activation in median and superior frontal regions and occipital regions (Sar et al., 2007). Similarly, in patients with dissociative amnesia, PET imaging has demonstrated decreased neuronal activity in the right inferolateral prefrontal cortex (Brand et al., 2009).

Functional motor symptoms have been associated with lower activity in the temporoparietal junction (Voon et al., 2010a), supplementary motor area (Voon et al., 2011) and supramarginal gyrus (Van Beilen et al., 2011), and higher activity in right amygdala, left anterior insula, and bilateral posterior cingulate cortices (Voon et al., 2011).

In patients with the dissociative subtype of post-traumatic stress disorder (PTSD), fMRI activation patterns suggest that prefrontal and limbic structures underlie the 
dissociative responses (Lanius et al., 2002; Hopper et al., 2007). Furthermore, comparisons between conscious and non-conscious processing of fear stimuli in patients with dissociative PTSD demonstrate enhanced prefrontal activity to conscious fear and enhanced activity in limbic regions to non-conscious fear processing (Felmingham et al., 2008). These findings support the theory that dissociation is a regulatory strategy invoked to cope with extreme emotional arousal in PTSD.

In contrast, a possibly negative influence of dissociation in trauma survivors has also been reported. A recent study demonstrates a persisting effect of peritraumatic dissociation on brain functioning: Two to four months after acute trauma, individuals who experienced peritraumatic dissociation showed greater activation of the occipital lobe than trauma survivors without dissociation, and a higher incidence of PTSD (Daniels et al., 2012).

Functional connectivity analyses have been employed to investigate the functioning of brain networks during hypnosis. Increased functional connectivity of the prefrontal cortex and precuneus with motor and somatosensory areas has been reported (Coyan et al., 2009; Vanhaudenhuysen et al., 2009; Pyka et al., 2011). Reductions in functional connectivity have been found within the lateral frontoparietal cortex and parahippocampal region (Demertzi et al., 2011).

In patients with borderline personality disorder, acute dissociation has been related with increased functional connectivity in the insula and decreased connectivity in the cuneus (Wolf et al., 2011).

In addition, functional connectivity analyses have identified alterations in functional brain networks in patients with FNSS. One investigation in patients with functional motor symptoms revealed that these patients had a higher functional connectivity between the amygdala and the supplementary motor area during processing of positive and negative emotional stimuli (Voon et al., 2010b). Another investigation identified lower functional connectivity between the supplementary motor and dorsolateral prefrontal cortices during internally generated action (Voon et al., 2011). In patients with psychogenic non-epileptic seizures (PNES), increased resting-state connectivity between the insula and precentral regions has been described (Van der Kruijs et al., 2012). 


\subsection{Conclusion}

This review identified several possible neurobiological substrates of dissociation, the related concept of hypnosis, and some of the functional neurological symptoms and syndromes (FNSS) associated with it. Although the available empirical evidence is modest, some tentative conclusions can be drawn.

Starting with heart rate variability (HRV), it appears that hypnosis significantly activates parasympathetic functioning, reflective of increased relaxation during hypnotic conditions. In contrast, persons with a higher tendency to dissociate and with FNSS demonstrated significantly lower HRV compared to controls. This apparent discrepancy can be explained that dissociation reactions in FNSS are a sign of negative overall emotional well-being, accompanied by decreased HRV. At times this underlying hypervigilance may need temporary relieve, resulting in increased HRV, a phenomenon previously described as bottom-up hijacking. In such situations, adaptive top-down processing is lost, probably resulting in dissociative episodes (Ogden et al., 2006). The positive effects of hypnosis on HRV may provide possibilities for therapeutic intervention in dissociative conditions, for example in the form of mindfulness and meditation (auto-hypnosis) techniques, which also promote a more adaptive and objective manner of responding to emotional triggers as neuroimaging suggests (Taylor et al., 2011).

Measures of EEG synchronicity have been used to evaluate brain network states believed to represent communication within the brain. EEG during hypnosis has provided evidence for decreased functional connectivity, which has been specifically related to the occurrence of imagery and transcendent experiences. Microstate analyses indicate differences between light and deep hypnosis, which may complicate research even further. The only study conducted in patients with FNSS suggests that decreases in prefrontal and parietal synchronicity, indicative of altered brain connectivity, are related to the frequency of the symptoms.

Structural neuroimaging demonstrates that functional neurological symptoms may be associated with decreased frontal white matter density and atrophy within the basal ganglia and motor cortex. Functional imaging during hypnosis and after autogenic (self-hypnosis) training indicates an increase in activity of the anterior cingulate cortex (ACC), thalamus and insula, and decrease in activity of the somatosensory cortex. Hypnotic paralysis activated similar brain areas, while 
simulated paralysis showed different activation patterns, suggesting different neural mechanisms to be involved in the processes of dissociation and malingering.

Functional imaging in patients with dissociative identity disorder suggests frontal cortex activation to be significantly decreased when compared to healthy controls, and subcortical regions to be involved in trauma processing during the traumarelated identity state. Decreased neuronal activity in the prefrontal cortex was also found in patients with dissociative amnesia. These results are comparable with findings in patients with the dissociative subtype of post-traumatic stress disorder (PTSD). FMRI analyses suggest that enhanced prefrontal activity is related to conscious fear processing, and enhanced activity in limbic networks is related to non-conscious fear processing. In brief, these findings suggest that subcortical as well as (pre)frontal regions have a function in a dissociative mechanism that serves emotion regulation in these conditions.

The latter assumption corresponds with the model proposed by Thayer et al. (2009), who describe a possible integration of HRV and neuroimaging findings in emotion regulation. They suggest a positive relationship between activation of prefrontal and limbic areas and heart rate variability, and deactivation of the prefrontal cortex during emotional stress to let automatic and prepotent processes regulate behavior. Although not discussed by the authors, dissociation may be one of such prepotent behaviors, explaining the associations with decreases in prefrontal activation and heart rate variability.

In patients with functional neurological symptoms, functional imaging has revealed lower activity in the temporoparietal junction, supplementary motor area and supramarginal gyrus, and higher activity in limbic and cingulate regions. These results indicate a possible lack of proprioceptive feedback or disturbed higher-order motor control, which would lead to the perception that the functional motor symptoms are not self-generated.

Functional connectivity analyses have revealed altered functional networks in dissociation and FNSS. The available evidence suggests that acute dissociation influences functional connectivity in the insula and cuneus. Functional neurological symptoms have been associated with an increased functional connectivity between the amygdala and supplementary motor areas, or between the insula and premotor cortex. Decreased functional connectivity between the supplementary motor and dorsolateral prefrontal cortices during voluntary action selection has also 
been reported. In order to provide a meaningful clarification of the etiology of functional neurological symptoms, the data must be interpreted relative to a model of the condition. We propose that the increased functional connectivity between limbic and frontal motor areas suggests a "hyperlink" that may underlie the pathophysiology of functional neurological symptoms (Lanius et al., 2002). Decreased functional connectivity between the supplementary motor and prefrontal areas may provide evidence for hijacking of voluntary action selection (Voon et al., 2011). Dissociation might be one of the mechanisms through which an emotional state can influence motor control, resulting in functional neurological symptoms (Figure 1).

Figure 1. Schematic overview of a plausible pathological functional neurological mechanism involved in cognitive-emotional executive control. It appears that normally, motor functions can be controlled without strong influence of emotions, whereas in patients with FNSS emotions can bypass executive control and cause involuntary movement. (Adapted from Van der Kruijs et al., 2012.)

Normal situation

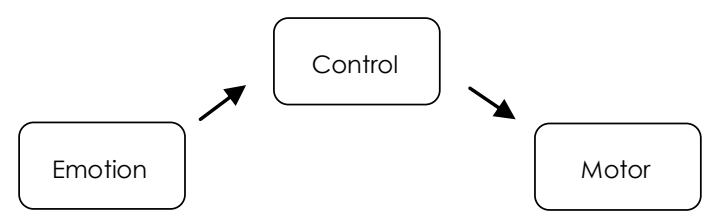

During functional symptoms

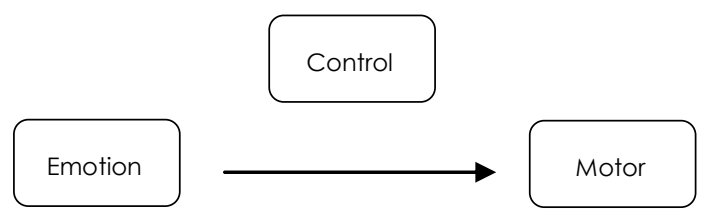

\subsubsection{Future directions}

The search for possible biological substrates of dissociative conditions has provided somewhat more insight into their nature. Future studies are required to address some unanswered questions. Longitudinal (ambulatory) measurements of heart rate variability could assess the relationship between dissociative episodes and arousal, providing more insight in the process of emotional failure underlying the symptoms. 
For example, dissociative episodes and functional neurological symptoms could serve as an escape mechanism or a relaxation technique after build-up of emotions. With longitudinal measurements, preferably in the patient's own environment, the fluctuations in HRV could be assessed in more detail.

EEG and functional MRI should be used to investigate cerebral networks in larger groups of highly dissociative persons or patients with functional neurological symptoms. More sophisticated methodology could help to interpret the findings. For example, Granger causality tests could provide more clarity about the direction of functional connectivity analysis, e.g. identify whether the increased connectivity between amygdala and motor cortex implies increased influence of the amygdala on motor functioning, or whether the effect is in the opposite direction (Smith et al., 2011). The integrity of the identified networks could also be examined in more detail using graph theoretical analyses (Stam and Reijneveld, 2007). For such analyses, functional connectivity data are converted into schematic graphs, in which measures of path length and clustering can be identified that indicate how well integrated a graph is and how efficient information can be exchanged. These techniques could also be addressed to evaluate patients from diagnosis until after remission. Until such longitudinal study designs are used, the nature of altered networks as being a cause or a consequence of the condition cannot be distinguished. Identification of neurophysiological factors contributing to the underlying mechanism of dissociation in functional neurological symptoms might eventually lead to earlier identification and therapeutic intervention in the future. 


\subsection{Appendix}

Supplementary Table 1. Summary of HRV studies of hypnosis, dissociation, and FNSS. AED = antiepileptic drug; $D E S$ = dissociative experience scale; $E C G=$ electrocardiogram; $H F=$ high frequency; HFnu = normalized high-frequency power; $H R=$ heart rate; $H R V=$ heart rate variability; $|B|=$ interbeat interval; $L F=$ low frequency; $L F n u=$ normalized low-frequency power; $P E T=$ positron emission tomography; RMSSD = root mean square of successive differences.

\begin{tabular}{|c|c|c|c|c|c|}
\hline Authors & Field & Method & Participants & Comparison & Findings \\
\hline $\begin{array}{l}\text { Reinders et } \\
\text { al., } 2006\end{array}$ & $\begin{array}{l}\text { Dissociative } \\
\text { identity } \\
\text { disorder }\end{array}$ & $\begin{array}{l}\text { HRV } \\
\text { and } \\
\text { PET }\end{array}$ & $\begin{array}{l}11 \text { patients } \\
\text { with } \\
\text { dissociative } \\
\text { identity } \\
\text { disorder }\end{array}$ & $\begin{array}{l}\text { Listening to a } \\
\text { neutral memory } \\
\text { script vs. trauma- } \\
\text { related memory } \\
\text { script, in neutral } \\
\text { identity state vs. } \\
\text { traumatic identity } \\
\text { state. }\end{array}$ & $\begin{array}{l}\text { When listening to the } \\
\text { trauma-related } \\
\text { memory script, HRV } \\
\text { decreased, with a } \\
\text { significantly stronger } \\
\text { effect for traumatic } \\
\text { identity state. }\end{array}$ \\
\hline $\begin{array}{l}\text { Diamond, } \\
\text { Davis and } \\
\text { Howe, } 2008\end{array}$ & Hypnosis & HRV & $\begin{array}{l}10 \text { healthy } \\
\text { adults }\end{array}$ & $\begin{array}{l}10 \text { minutes } \\
\text { control condition } \\
\text { vs. } 10 \text { minutes } \\
\text { hypnosis }\end{array}$ & $\begin{array}{l}\text { IBI increased during } \\
\text { hypnosis. Self-rated } \\
\text { hypnotic depth } \\
\text { correlated with HF } \\
\text { frequency } \\
\text { (negatively) and HF } \\
\text { amplitude } \\
\text { (positively). }\end{array}$ \\
\hline $\begin{array}{l}\text { Aubert et al., } \\
2009\end{array}$ & Hypnosis & HRV & $\begin{array}{l}12 \text { healthy } \\
\text { subjects }\end{array}$ & $\begin{array}{l}\text { Baseline vs. } \\
\text { hypnosis }\end{array}$ & $\begin{array}{l}\text { LFnu and LF/HF ratio } \\
\text { decreased and, HFnu } \\
\text { increased during } \\
\text { hypnosis. }\end{array}$ \\
\hline $\begin{array}{l}\text { Bakvis et al., } \\
2009\end{array}$ & $\begin{array}{l}\text { Psychogenic } \\
\text { non-epileptic } \\
\text { seizures }\end{array}$ & HRV & $\begin{array}{l}19 \text { patiens with } \\
\text { PNES and } 20 \\
\text { matched } \\
\text { healthy } \\
\text { controls }\end{array}$ & $\begin{array}{l}\text { Baseline vs. Trier } \\
\text { social stress test }\end{array}$ & $\begin{array}{l}\text { Patients had lower } \\
\text { HRV at baseline and } \\
\text { during recovery from } \\
\text { stress compared to } \\
\text { healthy controls. }\end{array}$ \\
\hline $\begin{array}{l}\text { VanDeVusse } \\
\text { et al., } 2009\end{array}$ & Hypnosis & HRV & $\begin{array}{l}30 \text { healthy } \\
\text { female } \\
\text { volunteers }\end{array}$ & $\begin{array}{l}\text { Baseline vs. 30- } \\
\text { minute hypnotic } \\
\text { experience }\end{array}$ & $\begin{array}{l}\text { LF and HF } \\
\text { components of HRV } \\
\text { increased during } \\
\text { hypnosis. }\end{array}$ \\
\hline $\begin{array}{l}\text { Latalova et } \\
\text { al., } 2010\end{array}$ & Dissociation & HRV & $\begin{array}{l}23 \text { bipolar } \\
\text { patients in } \\
\text { remission }\end{array}$ & $\begin{array}{l}\text { Correlate HRV } \\
\text { with tendency to } \\
\text { dissociate } \\
\text { (measured with } \\
\text { DES) }\end{array}$ & $\begin{array}{l}\text { Highly significant } \\
\text { negative correlations } \\
\text { were identified } \\
\text { between DES and } \\
\text { HRV. }\end{array}$ \\
\hline $\begin{array}{l}\text { Ponnusamy, } \\
\text { Marques and } \\
\text { Reuber, } 2011\end{array}$ & $\begin{array}{l}\text { Psychogenic } \\
\text { non-epileptic } \\
\text { seizures }\end{array}$ & HRV & $\begin{array}{l}52 \text { patients } \\
\text { with PNES, } 42 \\
\text { patients with } \\
\text { epilepsy, } 35 \\
\text { healthy } \\
\text { controls }\end{array}$ & $\begin{array}{l}\text { 3-minute ECG } \\
\text { samples of PNES } \\
\text { vs. epilepsy vs. } \\
\text { healthy controls }\end{array}$ & $\begin{array}{l}\text { RMSSD, LF and HF of } \\
\text { patients with PNES } \\
\text { were significantly } \\
\text { lower than those of } \\
\text { healthy controls, but } \\
\text { did not differ from } \\
\text { those of patients with } \\
\text { epilepsy. }\end{array}$ \\
\hline
\end{tabular}




\begin{tabular}{|c|c|c|c|c|c|}
\hline $\begin{array}{l}\text { Diveky et al., } \\
2012\end{array}$ & Dissociation & HRV & $\begin{array}{l}31 \text { patients } \\
\text { with panic } \\
\text { disorder and } \\
20 \text { healthy } \\
\text { controls }\end{array}$ & $\begin{array}{l}\text { Correlate HRV } \\
\text { with tendency to } \\
\text { dissociate } \\
\text { (measured with } \\
\text { DES) }\end{array}$ & $\begin{array}{l}\text { Highly significant } \\
\text { negative correlations } \\
\text { were identified } \\
\text { between DES and } \\
\text { HRV. }\end{array}$ \\
\hline
\end{tabular}


Supplementary Table 2. Summary of recent (1999-2011) EEG studies of hypnosis, dissociation, and FNSS. DFA = detrended fluctuation analysis; $E E G$ = electroencephalogram; $f M R I=$ functional MRl; MPS = multivariate phase synchronisation.

\begin{tabular}{|c|c|c|c|c|c|}
\hline Authors & Field & Method & Participants & Comparison & Findings \\
\hline $\begin{array}{l}\text { Egner, } \\
\text { Jamieson } \\
\text { and } \\
\text { Gruzelier, } \\
2005\end{array}$ & Hypnosis & $\begin{array}{l}\text { fMRI and } \\
\text { EEG }\end{array}$ & $\begin{array}{l}11 \text { highly and } \\
11 \text { low } \\
\text { suggestible } \\
\text { healthy } \\
\text { subjects }\end{array}$ & $\begin{array}{l}\text { Stroop } \\
\text { performance at } \\
\text { baseline vs. } \\
\text { hypnotic } \\
\text { induction }\end{array}$ & $\begin{array}{l}\text { Frontal functional } \\
\text { connectivity (EEG } \\
\text { gamma band } \\
\text { coherence) } \\
\text { decreased in highly } \\
\text { suggestible subjects } \\
\text { after hypnosis. }\end{array}$ \\
\hline $\begin{array}{l}\text { Katayama et } \\
\text { al., } 2007\end{array}$ & Hypnosis & EEG & $\begin{array}{l}7 \text { healthy } \\
\text { subjects }\end{array}$ & $\begin{array}{l}\text { Baseline vs. light } \\
\text { hypnosis vs. deep } \\
\text { hypnosis vs. } \\
\text { eventual } \\
\text { recovery }\end{array}$ & $\begin{array}{l}\text { Microstates of classes } \\
\text { B and D showed } \\
\text { decreased duration } \\
\text { and occurrence in } \\
\text { deep hypnosis } \\
\text { compared to light } \\
\text { hypnosis, in contrast } \\
\text { to the microstates of } \\
\text { classes A and C. }\end{array}$ \\
\hline $\begin{array}{l}\text { Lee et al., } \\
2007\end{array}$ & Hypnosis & EEG & $\begin{array}{l}19 \text { psychiatric } \\
\text { patients }\end{array}$ & $\begin{array}{l}\text { Baseline vs. } \\
\text { Hypnosis }\end{array}$ & $\begin{array}{l}\text { The fractal dynamics } \\
\text { of EEG rhythm were } \\
\text { more random and } \\
\text { less correlated in the } \\
\text { hypnotic condition } \\
\text { than in the waking } \\
\text { condition. }\end{array}$ \\
\hline $\begin{array}{l}\text { Knyazeva et } \\
\text { al., } 2011\end{array}$ & $\begin{array}{l}\text { Psychogen } \\
\text { ic non- } \\
\text { epileptic } \\
\text { seizures } \\
\text { (PNES) }\end{array}$ & EEG & $\begin{array}{l}13 \text { patients with } \\
\text { PNES and } 13 \\
\text { healthy } \\
\text { controls }\end{array}$ & $\begin{array}{l}\text { Between-group } \\
\text { comparison of } \\
\text { multivariate } \\
\text { phase } \\
\text { synchronisation } \\
\text { (MPS) }\end{array}$ & $\begin{array}{l}\text { Only small changes in } \\
\text { MPS survived } \\
\text { conservative testing. } \\
\text { However, negative } \\
\text { correlations between } \\
\text { PNES frequency and } \\
\text { prefrontal and } \\
\text { parietal MPS were } \\
\text { reported. }\end{array}$ \\
\hline $\begin{array}{l}\text { Terhune, } \\
\text { Cardeña } \\
\text { and } \\
\text { Lindgren, } \\
2011\end{array}$ & Hypnosis & EEG & $\begin{array}{l}28 \text { highly and } \\
19 \text { low } \\
\text { hypnotizable } \\
\text { healthy } \\
\text { subjects (Highs } \\
\text { and Lows) }\end{array}$ & $\begin{array}{l}\text { Baseline vs. } \\
\text { Hypnosis }\end{array}$ & $\begin{array}{l}\text { Highs had Lower } \\
\text { frontal-parietal phase } \\
\text { synchrony in the } \\
\text { alpha2 frequency } \\
\text { band during hypnosis } \\
\text { compared with } \\
\text { Lows. }\end{array}$ \\
\hline $\begin{array}{l}\text { Bagdhadi } \\
\text { and } \\
\text { Nasrabadi, } \\
2012\end{array}$ & Hypnosis & EEG & $\begin{array}{l}32 \text { healthy } \\
\text { volunteers with } \\
\text { high, medium, } \\
\text { and low } \\
\text { hypnotizability }\end{array}$ & $\begin{array}{l}\text { Correlation } \\
\text { analysis between } \\
\text { EEG phase } \\
\text { synchronization } \\
\text { and } \\
\text { hypnotizability } \\
\text { levels }\end{array}$ & $\begin{array}{l}\text { Less phase } \\
\text { synchronization } \\
\text { between channels } \\
\text { located at the frontal } \\
\text { lobe was observed in } \\
\text { the highly } \\
\text { hypnotizable group } \\
\text { than in the other } \\
\text { groups. }\end{array}$ \\
\hline
\end{tabular}




\begin{tabular}{|c|c|c|c|c|c|}
\hline $\begin{array}{l}\text { Cardeña et } \\
\text { al., } 2012\end{array}$ & Hypnosis & EEG & $\begin{array}{l}37 \text { healthy } \\
\text { volunteers with } \\
\text { high, medium, } \\
\text { and low } \\
\text { hypnotizability } \\
\text { (Highs, } \\
\text { Mediums, and } \\
\text { Lows) }\end{array}$ & $\begin{array}{l}\text { Correlation } \\
\text { analyses of EEG } \\
\text { frequency band } \\
\text { power and } \\
\text { global functional } \\
\text { connectivity with } \\
\text { hypnotic depth }\end{array}$ & $\begin{array}{l}\text { Hypnotic depth was } \\
\text { correlated with } \\
\text { power and power } \\
\text { heterogeneity in the } \\
\text { beta2, beta3, and } \\
\text { gamma frequency } \\
\text { bands, but only } \\
\text { among Highs. } \\
\text { Imagery and } \\
\text { transcendent } \\
\text { experiences during } \\
\text { hypnosis, primarily } \\
\text { reported by Highs, } \\
\text { were associated with } \\
\text { lower global } \\
\text { functional } \\
\text { connectivity. }\end{array}$ \\
\hline $\begin{array}{l}\text { Lee and Koo, } \\
2012\end{array}$ & Hypnosis & EEG & $\begin{array}{l}10 \text { healthy } \\
\text { volunteers }\end{array}$ & $\begin{array}{l}\text { Correlation } \\
\text { analysis between } \\
\text { detrended } \\
\text { fluctuation } \\
\text { analysis (DFA) } \\
\text { values and } \\
\text { hypnotizability }\end{array}$ & $\begin{array}{l}\text { The DFA values of C3 } \\
\text { and F3 decreased } \\
\text { during hypnosis and } \\
\text { were negatively } \\
\text { correlated with } \\
\text { hypnotizability. }\end{array}$ \\
\hline
\end{tabular}


Supplementary Table 3a. Summary of structural neuroimaging studies of hypnosis, dissociation, and FNSS. CD = conversion disorder; $D E S$ = dissociative experience scale; $D T I=$ diffusion tensor imaging; $M R I=$ magnetic resonance imaging; $\mathrm{VBM}=$ voxel-based morphometry.

\begin{tabular}{|c|c|c|c|c|c|}
\hline Authors & Field & Method & Participants & Comparison & Findings \\
\hline $\begin{array}{l}\text { Devinsky, } \\
\text { Mesad and } \\
\text { Alper, } 2001\end{array}$ & $\begin{array}{l}\text { Psychogenic } \\
\text { non-epileptic } \\
\text { seizures } \\
\text { (PNES) }\end{array}$ & MRI & $\begin{array}{l}79 \text { patients } \\
\text { with PNES } \\
\text { with cerebral } \\
\text { abnormalities } \\
\text { (out of } 311 \text { ) }\end{array}$ & $\begin{array}{l}\text { Frequency of } \\
\text { unilateral } \\
\text { cerebral } \\
\text { physiological or } \\
\text { structural } \\
\text { abnormalities }\end{array}$ & $\begin{array}{l}\text { Among } 60 \text { patients } \\
\text { with unilateral } \\
\text { abnormalities, } 43 \\
\text { (71\%) had right } \\
\text { hemisphere structural } \\
\text { lesions or physiologic } \\
\text { dysfunctions. }\end{array}$ \\
\hline $\begin{array}{l}\text { Reuber et al., } \\
2002\end{array}$ & $\begin{array}{l}\text { Psychogenic } \\
\text { non-epileptic } \\
\text { seizures }\end{array}$ & MRI & $\begin{array}{l}206 \text { patients } \\
\text { with PNES } \\
\text { and } 123 \\
\text { patients with } \\
\text { PNES and } \\
\text { epilepsy }\end{array}$ & $\begin{array}{l}\text { Frequency of MRI } \\
\text { abnormalities }\end{array}$ & $\begin{array}{l}9.7 \% \text { of PNES-only } \\
\text { group showed MRI } \\
\text { abnormalities. ( } 54.9 \% \\
\text { did not undergo MRI.) }\end{array}$ \\
\hline $\begin{array}{l}\text { Horton et al., } \\
2004\end{array}$ & Hypnosis & MRI & $\begin{array}{l}8 \text { highly and } \\
10 \text { low } \\
\text { hypnotizable } \\
\text { healthy } \\
\text { subjects }\end{array}$ & $\begin{array}{l}\text { Between-group } \\
\text { comparison of } \\
\text { anterior corpus } \\
\text { callosum size }\end{array}$ & $\begin{array}{l}\text { Larger anterior } \\
\text { corpus callosum in } \\
\text { highly hypnotizable } \\
\text { group. }\end{array}$ \\
\hline $\begin{array}{l}\text { Atmaca et } \\
\text { al., } 2006\end{array}$ & $\begin{array}{l}\text { Conversion } \\
\text { disorder (CD) }\end{array}$ & $\begin{array}{l}\text { MRI } \\
\text { (VBM) }\end{array}$ & $\begin{array}{l}10 \text { patients } \\
\text { with CD and } \\
10 \text { healthy } \\
\text { controls }\end{array}$ & $\begin{array}{l}\text { Volumetric } \\
\text { analysis in } \\
\text { patients vs. } \\
\text { healthy controls, } \\
\text { and within } \\
\text { patient group, } \\
\text { correlation } \\
\text { analyses } \\
\text { between MRI } \\
\text { and clinical } \\
\text { characteristics } \\
\end{array}$ & $\begin{array}{l}\text { Smaller mean } \\
\text { volumes of the } \\
\text { caudate nuclei, } \\
\text { lentiform nuclei and } \\
\text { thalami in patients. } \\
\text { Significant correlation } \\
\text { between age of } \\
\text { onset and left } \\
\text { caudate volume. }\end{array}$ \\
\hline $\begin{array}{l}\text { Rüsch et al., } \\
2007\end{array}$ & Dissociation & DTI & $\begin{array}{l}20 \text { women } \\
\text { with bipolar } \\
\text { disorder and } \\
20 \text { female } \\
\text { healthy } \\
\text { controls }\end{array}$ & $\begin{array}{l}\text { DTI in patients vs. } \\
\text { healthy controls, } \\
\text { and within } \\
\text { patient group, } \\
\text { correlation } \\
\text { analyses } \\
\text { between DTI and } \\
\text { clinical } \\
\text { characteristics }\end{array}$ & $\begin{array}{l}\text { Frontal diffusivity was } \\
\text { positively correlated } \\
\text { with the tendency to } \\
\text { dissociate (measured } \\
\text { with DES). }\end{array}$ \\
\hline $\begin{array}{l}\text { Labate et al., } \\
2012\end{array}$ & $\begin{array}{l}\text { Psychogenic } \\
\text { non-epileptic } \\
\text { seizures }\end{array}$ & $\begin{array}{l}\text { MRI } \\
\text { (VBM) }\end{array}$ & $\begin{array}{l}20 \text { patients } \\
\text { with PNES } \\
\text { and } 40 \\
\text { healthy } \\
\text { subjects }\end{array}$ & $\begin{array}{l}\text { Cortical thickness } \\
\text { in patients with } \\
\text { PNES vs. healthy } \\
\text { controls. }\end{array}$ & $\begin{array}{l}\text { Abnormal cortical } \\
\text { atrophy of the motor } \\
\text { and premotor regions } \\
\text { in the right } \\
\text { hemisphere and the } \\
\text { cerebellum. } \\
\text { Significant correlation } \\
\text { between depression } \\
\text { scores and premotor } \\
\text { cortex atrophy. }\end{array}$ \\
\hline
\end{tabular}


Supplementary Table 3b. Summary of functional neuroimaging studies of hypnosis, dissociation, and FNSS. $A C C=$ anterior cingulate cortex; $A T=$ autogenic training; $B A=$ Brodmann's area; $B O L D=$ blood-oxygen leven dependent; $C D=$ conversion disorder; $D I D=$ dissociative identity disorder; $D T S=$ dissociation tension scale; $f C-f M R I=$ functional connectivity $f M R l ; f M R I=$ functional MRI; $M R I=$ magnetic resonance imaging; NIS = neutral identity state; $P E T=$ positron emission tomography; $P T S D=$ post-traumatic stress disorder; $r C B F=$ regional cerebral blood flow; RSDI = responses to script-driven imagery; SPECT = single-photon emission computed tomography; TIS = traumatic identity state; TPJ = temporoparietal junction.

\begin{tabular}{|c|c|c|c|c|c|}
\hline Authors & Field & Method & Participants & Comparison & Findings \\
\hline $\begin{array}{l}\text { Maquet et al., } \\
1999\end{array}$ & Hypnosis & PET & $\begin{array}{l}9 \text { healthy } \\
\text { subjects }\end{array}$ & $\begin{array}{l}\text { Baseline vs. } \\
\text { imagination of } \\
\text { autobiographi } \\
\text { cal material in } \\
\text { "normal } \\
\text { alertness" vs. } \\
\text { hypnotic } \\
\text { state. }\end{array}$ & $\begin{array}{l}\text { Hypnosis activated a } \\
\text { mainly left-sided set } \\
\text { of cortical areas } \\
\text { involving occipital, } \\
\text { parietal, precentral, } \\
\text { premotor, and } \\
\text { ventrolateral } \\
\text { prefrontal cortices } \\
\text { and a few right-sided } \\
\text { regions (occipital } \\
\text { and anterior } \\
\text { cingulate cortices } \\
\text { (ACC)). }\end{array}$ \\
\hline Wik et al., 1999 & Hypnosis & PET & $\begin{array}{l}8 \text { women } \\
\text { with } \\
\text { fibromyalgia }\end{array}$ & $\begin{array}{l}\text { Resting state } \\
\text { vs. hypnotic } \\
\text { state. }\end{array}$ & $\begin{array}{l}\text { During hypnosis, rCBF } \\
\text { bilaterally increased } \\
\text { in orbitofrontal and } \\
\text { subcallosial cingulate } \\
\text { cortices, right } \\
\text { thalamus, left inferior } \\
\text { parietal cortex. rCBF } \\
\text { decreased bilaterally } \\
\text { in cingulate cortex. }\end{array}$ \\
\hline Ward et al., 2000 & $\begin{array}{l}\text { Hypnosis / } \\
\text { Simulation }\end{array}$ & PET & $\begin{array}{l}12 \text { healthy, } \\
\text { hypnotized } \\
\text { subjects }\end{array}$ & $\begin{array}{l}\text { Within-group } \\
\text { analysis of } \\
\text { subjectively } \\
\text { experienced } \\
\text { paralysis vs. } \\
\text { intentionally } \\
\text { simulated } \\
\text { paralysis }\end{array}$ & $\begin{array}{l}\text { Increased activation } \\
\text { of orbitofrontal } \\
\text { cortex, cerebellum, } \\
\text { thalamus and } \\
\text { putamen during } \\
\text { subjectively } \\
\text { experienced } \\
\text { paralysis. Increased } \\
\text { activation in } \\
\text { ventrolateral } \\
\text { prefrontal cortex and } \\
\text { posterior cortical } \\
\text { structures during } \\
\text { intentionally } \\
\text { simulated paralysis. }\end{array}$ \\
\hline Lanius et al., 2002 & $\begin{array}{l}\text { Dissociation } \\
\text { in post- } \\
\text { traumatic } \\
\text { stress } \\
\text { disorder } \\
\text { (PTSD) }\end{array}$ & fMRI & $\begin{array}{l}7 \text { subjects } \\
\text { with PTSD } \\
\text { and } 10 \\
\text { controls }\end{array}$ & $\begin{array}{l}\text { Responses to } \\
\text { script-driven } \\
\text { imagery (RSDI) } \\
\text { task } \\
\text { paradigm, } \\
\text { comparing }\end{array}$ & $\begin{array}{l}\text { Patients in } \\
\text { dissociative state } \\
\text { showed more } \\
\text { activation in superior } \\
\text { and middle tempora } \\
\text { gyri, inferior frontal }\end{array}$ \\
\hline
\end{tabular}




\begin{tabular}{|c|c|c|c|c|c|}
\hline & & & & $\begin{array}{l}\text { patients who } \\
\text { relived trauma } \\
\text { vs. patients in } \\
\text { dissociative } \\
\text { state }\end{array}$ & $\begin{array}{l}\text { gyrus, occipital lobe, } \\
\text { parietal lobe, medial } \\
\text { frontal gyrus, medial } \\
\text { cortex, and anterior } \\
\text { cingulate gyrus. }\end{array}$ \\
\hline $\begin{array}{l}\text { Rainville et al., } \\
2002\end{array}$ & Hypnosis & PET & $\begin{array}{l}10 \text { healthy } \\
\text { subjects }\end{array}$ & $\begin{array}{l}\text { Before vs. after } \\
\text { hypnotic } \\
\text { induction }\end{array}$ & $\begin{array}{l}\text { Hypnosis increased } \\
\text { rCBF in anterior } \\
\text { cingulate cortex, } \\
\text { thalamus, and ponto- } \\
\text { mesencephalic } \\
\text { brainstem. }\end{array}$ \\
\hline $\begin{array}{l}\text { Schulz-Stübner et } \\
\text { al., } 2004\end{array}$ & Hypnosis & fMRI & $\begin{array}{l}12 \text { healthy } \\
\text { volunteers }\end{array}$ & $\begin{array}{l}\text { Thermal pain } \\
\text { responses } \\
\text { during } \\
\text { hypnosis vs. } \\
\text { responses } \\
\text { without } \\
\text { hypnosis }\end{array}$ & $\begin{array}{l}\text { Decreased activation } \\
\text { in primary sensory } \\
\text { cortex, middle } \\
\text { cingulate gyrus, } \\
\text { precuneus, and visual } \\
\text { cortex during } \\
\text { hypnosis. Increased } \\
\text { activation in the } \\
\text { anterior basal } \\
\text { ganglia and ACC. }\end{array}$ \\
\hline $\begin{array}{l}\text { Egner, Jamieson } \\
\text { and Gruzelier, } \\
2005\end{array}$ & Hypnosis & $\begin{array}{l}\text { fMRI } \\
\text { and } \\
\text { EEG }\end{array}$ & $\begin{array}{l}11 \text { highly and } \\
11 \text { low } \\
\text { suggestible } \\
\text { healthy } \\
\text { subjects }\end{array}$ & $\begin{array}{l}\text { Stroop } \\
\text { performance } \\
\text { at baseline vs. } \\
\text { hypnotic } \\
\text { induction }\end{array}$ & $\begin{array}{l}\text { ACC activity was } \\
\text { positively related to } \\
\text { hypnosis and } \\
\text { hypnotic } \\
\text { susceptibility. }\end{array}$ \\
\hline $\begin{array}{l}\text { Reinders et al., } \\
2006\end{array}$ & $\begin{array}{l}\text { Dissociative } \\
\text { identity } \\
\text { disorder } \\
\text { (DID) }\end{array}$ & $\begin{array}{l}\text { HRV } \\
\text { and } \\
\text { PET }\end{array}$ & $\begin{array}{l}11 \text { patients } \\
\text { with } \\
\text { dissociative } \\
\text { identity } \\
\text { disorder }\end{array}$ & $\begin{array}{l}\text { Listening to a } \\
\text { neutral } \\
\text { memory script } \\
\text { vs. trauma- } \\
\text { related } \\
\text { memory script, } \\
\text { in neutral } \\
\text { identity state } \\
\text { (NIS) vs. } \\
\text { traumatic } \\
\text { identity state } \\
\text { (TIS) }\end{array}$ & $\begin{array}{l}\text { Exposing TIS to } \\
\text { trauma-related } \\
\text { memory script was } \\
\text { associated with } \\
\text { differences in rCBF in } \\
\text { a wide range of } \\
\text { subcortical areas, } \\
\text { e.g. the insula. In NIS, } \\
\text { no significant } \\
\text { changes in rCBF were } \\
\text { detected. }\end{array}$ \\
\hline $\begin{array}{l}\text { Hopper et al., } \\
2007\end{array}$ & $\begin{array}{l}\text { Dissociation } \\
\text { in post- } \\
\text { traumatic } \\
\text { stress } \\
\text { disorder }\end{array}$ & fMRI & $\begin{array}{l}27 \text { patients } \\
\text { with PTSD }\end{array}$ & $\begin{array}{l}\text { Baseline vs. } \\
\text { responses to } \\
\text { script-driven } \\
\text { imagery (RSDI) } \\
\text { task } \\
\text { paradigm, } \\
\text { correlated } \\
\text { with RSDI } \\
\text { Scale } \\
\text { subscales }\end{array}$ & $\begin{array}{l}\text { Positive correlations } \\
\text { between dissociation } \\
\text { and activation in left } \\
\text { medial prefrontal } \\
\text { cortex and right } \\
\text { superior temporal } \\
\text { cortex. Negative } \\
\text { correlations with } \\
\text { activition in left } \\
\text { superior temporal } \\
\text { cortex, right anterior } \\
\text { insula and right } \\
\text { inferior frontal cortex. }\end{array}$ \\
\hline Röder et al., 2007 & Hypnosis & fMRI & $\begin{array}{l}7 \text { highly } \\
\text { suggestible } \\
\text { healthy } \\
\text { subjects }\end{array}$ & $\begin{array}{l}\text { Pain } \\
\text { perception } \\
\text { during waking } \\
\text { state vs. } \\
\text { hypnotic }\end{array}$ & $\begin{array}{l}\text { Decreased activity of } \\
\text { the pain network in } \\
\text { somatosensory } \\
\text { cortex, parietal } \\
\text { cortex, prefrontal }\end{array}$ \\
\hline
\end{tabular}




\begin{tabular}{|c|c|c|c|c|c|}
\hline & & & & $\begin{array}{l}\text { relaxation vs. } \\
\text { hypnotic } \\
\text { depersonalizat } \\
\text { ion }\end{array}$ & $\begin{array}{l}\text { cortex, putamen and } \\
\text { amygdala during } \\
\text { hypnotic } \\
\text { depersonalization. }\end{array}$ \\
\hline $\begin{array}{l}\text { Sar, Unal and } \\
\text { Ozturk, } 2007\end{array}$ & $\begin{array}{l}\text { Dissociative } \\
\text { identity } \\
\text { disorder } \\
\text { (DID) }\end{array}$ & SPECT & $\begin{array}{l}21 \text { patients } \\
\text { with } \\
\text { dissociative } \\
\text { identity } \\
\text { disorder and } \\
9 \text { healthy } \\
\text { controls }\end{array}$ & $\begin{array}{l}\text { Between- } \\
\text { group } \\
\text { analyses }\end{array}$ & $\begin{array}{l}\text { In patients with DID, } \\
\text { ratio of regional } \\
\text { cerebral blood flow } \\
\text { (rCBF) was } \\
\text { decreased in } \\
\text { orbitofrontal regions, } \\
\text { and increased in } \\
\text { median and superior } \\
\text { frontal regions and } \\
\text { occipital regions. }\end{array}$ \\
\hline $\begin{array}{l}\text { Felmingham et } \\
\text { al., } 2008\end{array}$ & $\begin{array}{l}\text { Dissociation } \\
\text { in post- } \\
\text { traumatic } \\
\text { stress } \\
\text { disorder }\end{array}$ & fMRI & $\begin{array}{l}23 \text { subjects } \\
\text { with PTSD }\end{array}$ & $\begin{array}{l}\text { Non- } \\
\text { dissociative } \\
\text { reactions vs. } \\
\text { dissociative } \\
\text { reactions to } \\
\text { consciously } \\
\text { and non- } \\
\text { consciously } \\
\text { perceived } \\
\text { fear stimuli }\end{array}$ & $\begin{array}{l}\text { Dissociative PTSD } \\
\text { showed more } \\
\text { activation in ventral } \\
\text { prefrontal cortex for } \\
\text { conscious fear, and } \\
\text { in bilateral } \\
\text { amygdala, insula and } \\
\text { left thalamus for non- } \\
\text { conscious fear. } \\
\text { Comparatively } \\
\text { reduced activation in } \\
\text { the dissociative } \\
\text { group in dorsomedial } \\
\text { prefrontal regions for } \\
\text { conscious fear. }\end{array}$ \\
\hline Brand et al., 2009 & $\begin{array}{l}\text { Dissociative } \\
\text { amnesia }\end{array}$ & PET & $\begin{array}{l}14 \text { patients } \\
\text { with } \\
\text { dissociative } \\
\text { amnesia and } \\
19 \text { matched } \\
\text { healthy } \\
\text { controls }\end{array}$ & $\begin{array}{l}\text { Between- } \\
\text { group } \\
\text { analyses }\end{array}$ & $\begin{array}{l}\text { Decreased glucose } \\
\text { utilization in the right } \\
\text { inferolateral } \\
\text { prefrontal cortex was } \\
\text { observed in the } \\
\text { patient group. }\end{array}$ \\
\hline Cojan et al., 2009 & Hypnosis & fC-fMRI & $\begin{array}{l}18 \text { healthy } \\
\text { volunteers }\end{array}$ & $\begin{array}{l}\text { Go-nogo task } \\
\text { in normal state } \\
\text { vs. during } \\
\text { hypnotic left- } \\
\text { hand paralysis } \\
\text { vs. during } \\
\text { simulated left- } \\
\text { hand paralysis }\end{array}$ & $\begin{array}{l}\text { Enhanced functional } \\
\text { connectivity of } \\
\text { precuneus and } \\
\text { angular gyrus with } \\
\text { right motor cortex } \\
\text { during Go-nogo task } \\
\text { in hypnosis. }\end{array}$ \\
\hline $\begin{array}{l}\text { McGeown et al., } \\
2009\end{array}$ & Hypnosis & fMRI & $\begin{array}{l}11 \text { highly and } \\
7 \text { low } \\
\text { suggestible } \\
\text { healthy } \\
\text { subjects }\end{array}$ & $\begin{array}{l}\text { Resting-state } \\
\text { and visual-task } \\
\text { fMRI in and } \\
\text { out of hypnosis }\end{array}$ & $\begin{array}{l}\text { During hypnosis, } \\
\text { highly suggestible } \\
\text { subjects showed } \\
\text { decreased activity in } \\
\text { ACC and superior, } \\
\text { inferior and middle } \\
\text { frontal gyri. }\end{array}$ \\
\hline Raij et al., 2009 & Hypnosis & fMRI & $\begin{array}{l}14 \\
\text { suggestible } \\
\text { subjects }\end{array}$ & $\begin{array}{l}\text { Hypnotic } \\
\text { baseline vs. } \\
\text { hypnotic- } \\
\text { induced pain }\end{array}$ & $\begin{array}{l}\text { Hypnosis increased } \\
\text { activity in bilateral } \\
\text { temporal lobes, } \\
\text { inferior frontal gyrus, } \\
\text { insula, ACC, DLPFC, }\end{array}$ \\
\hline
\end{tabular}




\begin{tabular}{|c|c|c|c|c|c|}
\hline & & & & & $\begin{array}{l}\text { supplementary motor } \\
\text { cortex and } \\
\text { cerebellum. }\end{array}$ \\
\hline $\begin{array}{l}\text { Vanhaudenhuyse } \\
\text { et al., } 2009\end{array}$ & Hypnosis & fc-fMRI & $\begin{array}{l}13 \text { healthy } \\
\text { volunteers }\end{array}$ & $\begin{array}{l}\text { Normal } \\
\text { wakefulness } \\
\text { vs. hypnotic } \\
\text { state }\end{array}$ & $\begin{array}{l}\text { Hypnosis increased } \\
\text { functional } \\
\text { connectivity of the } \\
\text { primary } \\
\text { somatosensory with } \\
\text { anterior insular and } \\
\text { prefrontal cortices. }\end{array}$ \\
\hline $\begin{array}{l}\text { Schlamann et al., } \\
2010\end{array}$ & Hypnosis & fMRI & $\begin{array}{l}19 \text { individuals } \\
\text { trained in AT } \\
\text { and } 19 \\
\text { controls }\end{array}$ & $\begin{array}{l}\text { First steps of } \\
\text { autogenic } \\
\text { training in } \\
\text { trained vs. } \\
\text { untrained } \\
\text { volunteers }\end{array}$ & $\begin{array}{l}\text { Higher activation of } \\
\text { prefrontal and insular } \\
\text { cortex in AT group. }\end{array}$ \\
\hline $\begin{array}{l}\text { Voon et al., } \\
2010 a\end{array}$ & $\begin{array}{l}\text { Conversion } \\
\text { tremor }\end{array}$ & fMRI & $\begin{array}{l}8 \text { patients } \\
\text { with } \\
\text { conversion } \\
\text { tremor }\end{array}$ & $\begin{array}{l}\text { Within-group } \\
\text { analyses of } \\
\text { BOLD } \\
\text { response and } \\
\text { functional } \\
\text { connectivity } \\
\text { during } \\
\text { conversion } \\
\text { tremor and } \\
\text { voluntary } \\
\text { mimicked } \\
\text { tremor }\end{array}$ & $\begin{array}{l}\text { Conversion tremor } \\
\text { compared with } \\
\text { voluntary tremor had } \\
\text { right temporoparietal } \\
\text { junction (TPJ) } \\
\text { hypoactivity and } \\
\text { lower functional } \\
\text { connectivity } \\
\text { between the right } \\
\text { TPJ, sensorimotor } \\
\text { regions, and limbic } \\
\text { regions. }\end{array}$ \\
\hline $\begin{array}{l}\text { Voon et al., } \\
2010 b\end{array}$ & $\begin{array}{l}\text { Motor } \\
\text { conversion } \\
\text { disorder }\end{array}$ & fc-fMRI & $\begin{array}{l}16 \text { patients } \\
\text { with motor } \\
\text { conversion } \\
\text { disorder and } \\
16 \text { matched } \\
\text { healthy } \\
\text { controls }\end{array}$ & $\begin{array}{l}\text { Between- } \\
\text { group } \\
\text { analyses of } \\
\text { BOLD } \\
\text { response and } \\
\text { functional } \\
\text { connectivity } \\
\text { during a face } \\
\text { valence task } \\
\text { paradigm } \\
\end{array}$ & $\begin{array}{l}\text { No differences in } \\
\text { activation maps. } \\
\text { Increased functional } \\
\text { connectivity } \\
\text { between right } \\
\text { amygdala and right } \\
\text { supplementary motor } \\
\text { area in patients. }\end{array}$ \\
\hline $\begin{array}{l}\text { Demertzi et al., } \\
2011\end{array}$ & Hypnosis & fC-fMRI & $\begin{array}{l}\text { Healthy } \\
\text { adults }\end{array}$ & $\begin{array}{l}\text { Resting-state } \\
\text { fMRI during } \\
\text { normal } \\
\text { wakefulness } \\
\text { vs. hypnotic } \\
\text { state vs. } \\
\text { autobiographi } \\
\text { cal mental } \\
\text { imagery }\end{array}$ & $\begin{array}{l}\text { Hypnosis reduced } \\
\text { frontoparietal } \\
\text { functional } \\
\text { connectivity, } \\
\text { increased } \\
\text { connectivity in } \\
\text { bilateral angular and } \\
\text { middle frontal gyri, } \\
\text { and decreased } \\
\text { parahippocampal } \\
\text { connectivity. }\end{array}$ \\
\hline Pyka et al., 2011 & Hypnosis & fc-fMRI & $\begin{array}{l}19 \text { healthy } \\
\text { volunteers }\end{array}$ & $\begin{array}{l}\text { Resting state } \\
\text { vs. hypnotic } \\
\text { left-hand } \\
\text { paralysis }\end{array}$ & $\begin{array}{l}\text { Increased } \\
\text { connectivity of } \\
\text { precuneus with right } \\
\text { dorsolateral } \\
\text { prefrontal cortex, } \\
\text { angular gyrus, and } \\
\text { dorsal precuneus. }\end{array}$ \\
\hline
\end{tabular}




\begin{tabular}{|c|c|c|c|c|c|}
\hline $\begin{array}{l}\text { Van Beilen et al., } \\
2011\end{array}$ & $\begin{array}{l}\text { Conversion } \\
\text { paresis }\end{array}$ & fMRI & $\begin{array}{l}10 \text { patients } \\
\text { with } \\
\text { conversion } \\
\text { paresis, } 13 \\
\text { controls } \\
\text { feigning } \\
\text { paresis, and } \\
21 \text { normal } \\
\text { controls }\end{array}$ & $\begin{array}{l}\text { Between- } \\
\text { group } \\
\text { analyses of } \\
\text { BOLD } \\
\text { response } \\
\text { during } \\
\text { movement } \\
\text { execution and } \\
\text { imagery }\end{array}$ & $\begin{array}{l}\text { Patients showed } \\
\text { significantly } \\
\text { decreased activation } \\
\text { in the supramarginal } \\
\text { gyrus during } \\
\text { movement execution } \\
\text { and imagery. }\end{array}$ \\
\hline Voon et al., 2011 & $\begin{array}{l}\text { Conversion } \\
\text { disorder (CD) }\end{array}$ & fMRI & $\begin{array}{l}11 \text { patients } \\
\text { with } C D \text { and } \\
11 \text { matched } \\
\text { healthy } \\
\text { controls }\end{array}$ & $\begin{array}{l}\text { Between- } \\
\text { group } \\
\text { analyses of } \\
\text { BOLD } \\
\text { response } \\
\text { during } \\
\text { internally and } \\
\text { externally } \\
\text { generated } \\
\text { movement }\end{array}$ & $\begin{array}{l}\text { CD patients had } \\
\text { lower left } \\
\text { supplementary motor } \\
\text { area (SMA) and } \\
\text { higher right } \\
\text { amygdala, left } \\
\text { anterior insula, and } \\
\text { bilateral posterior } \\
\text { cingulate activity. } \\
\text { During internally } \\
\text { generated } \\
\text { movement, the left } \\
\text { SMA had lower } \\
\text { functional } \\
\text { connectivity with } \\
\text { bilateral dorsolateral } \\
\text { prefrontal cortices in } \\
\text { CD patients. }\end{array}$ \\
\hline Wolf et al., 2011 & Dissociation & fc-fMRI & $\begin{array}{l}17 \text { patients } \\
\text { with } \\
\text { borderline } \\
\text { personality } \\
\text { disorder and } \\
17 \text { healthy } \\
\text { controls }\end{array}$ & $\begin{array}{l}\text { Correlation } \\
\text { analyses } \\
\text { between } \\
\text { acute } \\
\text { dissociation } \\
\text { (measured } \\
\text { with DTS) and } \\
\text { functional } \\
\text { connectivity }\end{array}$ & $\begin{array}{l}\text { Dissociation } \\
\text { correlated positively } \\
\text { with connectivity of } \\
\text { the left insula, and } \\
\text { negatively with } \\
\text { connectivity of the } \\
\text { cuneus. }\end{array}$ \\
\hline $\begin{array}{l}\text { Burgmer et al., } \\
2012\end{array}$ & $\begin{array}{l}\text { Hypnosis / } \\
\text { Simulation }\end{array}$ & fMRI & $\begin{array}{l}19 \text { healthy } \\
\text { volunteers }\end{array}$ & $\begin{array}{l}\text { Movement } \\
\text { observation } \\
\text { and imitation } \\
\text { with and } \\
\text { without } \\
\text { hypnotically } \\
\text { induced } \\
\text { paralysis of left } \\
\text { hand }\end{array}$ & $\begin{array}{l}\text { Hypnotic paralysis } \\
\text { during movement } \\
\text { imitation induced } \\
\text { hypoactivation of } \\
\text { sensorimotor cortex } \\
\text { and cerebellum and } \\
\text { increased activation } \\
\text { of anterior ACC, } \\
\text { frontal gyrus and } \\
\text { insula. }\end{array}$ \\
\hline $\begin{array}{l}\text { Daniels et al., } \\
2012\end{array}$ & $\begin{array}{l}\text { Dissociation } \\
\text { in post- } \\
\text { traumatic } \\
\text { stress } \\
\text { disorder }\end{array}$ & fMRI & $\begin{array}{l}21 \text { acutely } \\
\text { traumatized } \\
\text { individuals }\end{array}$ & $\begin{array}{l}\text { Individuals } \\
\text { with } \\
\text { peritraumatic } \\
\text { dissociative } \\
\text { responses vs. } \\
\text { individuals } \\
\text { without }\end{array}$ & $\begin{array}{l}\text { Two to four months } \\
\text { post trauma, } \\
\text { peritraumatic } \\
\text { dissociation was } \\
\text { associated with } \\
\text { greater activation of } \\
\text { the right occipital } \\
\text { lobe. }\end{array}$ \\
\hline $\begin{array}{l}\text { Deeley et al., } \\
2012\end{array}$ & Hypnosis & fMRI & $\begin{array}{l}8 \text { healthy } \\
\text { volunteers }\end{array}$ & $\begin{array}{l}\text { Correlation } \\
\text { analyses of }\end{array}$ & $\begin{array}{l}\text { Hypnotic depth was } \\
\text { negatively correlated }\end{array}$ \\
\hline
\end{tabular}




\begin{tabular}{|c|c|c|c|c|c|}
\hline & & & & $\begin{array}{l}\text { BOLD } \\
\text { response with } \\
\text { hypnotic } \\
\text { depth during } \\
\text { passive visual } \\
\text { stimulation }\end{array}$ & $\begin{array}{l}\text { with activation in } \\
\text { medial frontal gyrus, } \\
\text { anterior cingulate } \\
\text { gyrus, posterior } \\
\text { cingulate gyrus, and } \\
\text { parahippocampal } \\
\text { gyri, and positively } \\
\text { with activation in } \\
\text { middle frontal gyrus, } \\
\text { inferior frontal gyrus, } \\
\text { and precentral gyrus. }\end{array}$ \\
\hline $\begin{array}{l}\text { Van der Kruijs et } \\
\text { al., } 2012\end{array}$ & $\begin{array}{l}\text { Psychogenic } \\
\text { non-epileptic } \\
\text { seizures }\end{array}$ & fc-fMRI & $\begin{array}{l}11 \text { patients } \\
\text { with PNES } \\
\text { and } 12 \\
\text { healthy } \\
\text { volunteers }\end{array}$ & $\begin{array}{l}\text { Between- } \\
\text { group } \\
\text { analyses of } \\
\text { BOLD } \\
\text { response } \\
\text { during Stroop } \\
\text { word-colour } \\
\text { and picture } \\
\text { memory task, } \\
\text { and resting- } \\
\text { state } \\
\text { functional } \\
\text { connectivity }\end{array}$ & $\begin{array}{l}\text { No differences in } \\
\text { activation maps. } \\
\text { Enhanced functional } \\
\text { connectivity } \\
\text { between the right } \\
\text { insula and the left } \\
\text { precentral sulcus in } \\
\text { patients with PNES. }\end{array}$ \\
\hline Wolf et al., 2012 & Dissociation & fMRI & $\begin{array}{l}16 \text { patients } \\
\text { with } \\
\text { borderline } \\
\text { personality } \\
\text { disorder and } \\
16 \text { healthy } \\
\text { controls }\end{array}$ & $\begin{array}{l}\text { Correlation } \\
\text { analyses } \\
\text { between } \\
\text { acute } \\
\text { dissociation } \\
\text { (measured } \\
\text { with DTS) and } \\
\text { cerebral } \\
\text { blood flow }\end{array}$ & $\begin{array}{l}\text { No significant } \\
\text { correlations between } \\
\text { dissociation and } \\
\text { orbitofrontal } \\
\text { activation were } \\
\text { found. }\end{array}$ \\
\hline
\end{tabular}




\section{Chapter 4}

SUBGROUP CLASSIFICATION IN PATIENTS WITH PSYCHOGENIC NON-EPILEPTIC SEIZURES

N.M.G. Bodde, S.J.M. van der Kruijs, D.M. IJff, R.H.C. Lazeron, K.E.J. Vonck, P.A.J.M. Boon, A.P. Aldenkamp. Epilepsy \& Behavior 2013, 26, 279-289.

\subsection{Abstract}

In this open non-controlled clinical cohort study, the applicability of a theoretical model for the diagnosis of psychogenic non-epileptic seizures (PNES) was studied in order to define a general psychological profile and to specify possible subgroups.

Forty PNES patients were assessed with a PNES "test battery" consisting of eleven psychological instruments, e.g., a trauma checklist, the global cognitive level, mental flexibility, speed of information processing, personality factors, dissociation, daily hassles and stress and coping factors.

The total PNES group was characterized by multiple trauma, personality vulnerability (in a lesser extent, neuropsychological vulnerabilities), no increased dissociation, many complaints about daily hassles that may trigger seizures and negative coping strategies that may contribute to prolongation of the seizures. Using factor analysis, specific subgroups were revealed: a 'psychotrauma subgroup', a 'high vulnerability somatizing subgroup' (with high and low cognitive levels) and a 'high vulnerability sensitive personality problem subgroup'.

Using a theoretical model in PNES diagnosis, PNES seem to be a symptom of distinct underlying etiological factors with different accents in the model. Hence, describing a general profile seems to conceal specific subgroups with subsequent treatment implications. This study identified three factors, representing two dimensions of the model, which are essential for subgroup classification: psychological etiology (psychotrauma or not), vulnerability, e.g., the somatization tendency, and sensitive personality problems/characteristics ('novelty seeking'). For treatment, this means that interventions could be tailored to the main underlying etiological problem. Also, further research could focus on differentiating subgroups with subsequent treatment indications and possible different prognoses. 


\subsection{Introduction}

About 25-30\% of the patients referred to tertiary epilepsy centers or specialized hospitals have psychogenic non-epileptic seizures (PNES) (Alper, 1994; Sigurdardottir and Olafsson, 1998; Reuber and Elger, 2003; Witgert et al., 2005). A psychogenic non-epileptic seizure is defined as a clinically observable paroxysmal change in behavior or consciousness that resembles an epileptic seizure but is not accompanied by the typical electrophysiological and behavioral changes that accompany an epileptic seizure. There is also an absence of any known organic etiology for the seizures, whereas there is positive evidence or a strong suspicion for the existence of psychogenic factors (Leis et al., 1992; Reuber and Elger, 2003; Bodde et al., 2009a; Bodde et al., 2009b).

Earlier research in the field of PNES has mainly focused on the differential diagnosis with epileptic seizures. The correct medical diagnosis of PNES remains a challenge, but since the introduction of simultaneous video-EEG monitoring, the differential diagnosis of PNES-epilepsy has greatly improved (Alper, 1994; Alsaadi et al., 2004; Cragar et al., 2005; Ali et al., 2011; Syed et al., 2011). The true challenge in the diagnostic process of PNES, however, is not only to exclude epilepsy and other organic factors but also to avoid that PNES becomes a 'nondisease' (Dekkers and Van Domburg, 2000). A subsequent positive diagnosis is required involving the underlying psychological mechanisms (LaFrance and Devinsky, 2004; Cragar et al., 2005; LaFrance and Barry, 2005; Bodde et al., 2009b). There is consensus that in most patients, multiple underlying psychogenic factors or mechanisms are involved in different combinations and with variable effects on prognosis (Prigitano et al., 2002; Reuber, 2009).

In a small group of PNES patients, the communication of the PNES diagnosis in a clear, empathic way will result in seizure reduction (Bodde et al., 2007; Bodde et al., 2009b; McKenzie et al., 2010; Hall-Patch et al., 2010). However, patients with PNES comprise a very heterogeneous patient group (Brown et al., 1991; Bowman and Markand, 1996; Arnold and Privitera, 1996; Duncan and Oto, 2008; Baslet et al., 2010). Several studies report that for many PNES patients, the long-term prognosis is not good. In about 1/3 to 1/4 of the patients, PNES become chronic (Bodde et al., 2009b; Reuber and House, 2002). Patients often show 'medical shopping' in a search for second opinions. Also, symptom characteristics may shift from seizures to other 
psychosomatic symptoms mimicking e.g., movement disorders (Bodde et al., 2011; McKenzie et al., 2011). As a result, the patients remain in a purely medical environment and are not referred to appropriate psychological therapy (Ettinger et al., 1999; Reuber et al., 2004b).

To achieve optimal therapeutic outcome, the choice of treatment should be adjusted to the individual patient's combination of underlying etiological factors (Prigitano et al., 2002; Galimberti et al., 2003; Reuber et al., 2004b; Cragar et al., 2005; Bodde et al., 2009b). Recently, we have proposed a theoretical model distinguishing five different levels representing specific underlying psychogenic factors (Figure 1) (Bodde et al., 2009a; Bodde et al., 2009b). This model was derived from a literature search on psychological etiology and PNES. The model resembles other models with predisposing, precipitating and perpetuating factors to explain somatoform disorders (Reuber, 2009; LaFrance and Devinsky, 2002; Stone et al., 2004; Reuber et al., 2007), but more specific factors have been added in relation to PNES. Level 1, psychological etiology, refers to factors involved in the causation of PNES, such as sexual abuse or other traumatic experiences (Barry and Sanborn, 2001; Fleisher et al., 2002; Salmon et al., 2003; Fiszman et al., 2004). However, not all people who have had traumatic experiences develop PNES (Mueser et al., 2002; Lally et al., 2010). Many authors have pointed to the specific vulnerability of PNES patients both in terms of their emotional profile and their neuropsychological functioning. Examples are personality factors, gender and age (Wyllie et al., 1991; Thompson et al., 1992; Sirven and Glosser, 1998; Rosenbaum, 2000; Reuber et al., 2004b; Cragar et al., 2005; Harden et al., 2009; Bodde et al., 2011). Also, possible organic factors, such as head trauma, may induce higher vulnerability (Reuber et al., 2002; Fargo et al., 2004; Knyazeva et al., 2011). Level 2, vulnerability, therefore, refers to characteristics that predispose a person to develop psychosomatic symptoms, such as PNES. Level 3, shaping factors, refers to factors that explain why the symptoms are 'seizures' and not for example, functional movement disorders, sleep disorders or "headache-like symptoms'. A shaping factor may be a close friend or a relative with epileptic seizures (symptom modeling) (Brown et al., 1991; Bautista, 2008) or having had epilepsy in the past. Level 4, triggering factors, refers to factors that create circumstances or specific situations that provoke a seizure at a specific moment, such as PNES during school break or after a marital quarrel (Moore and Baker, 1997; Vincentiis et al., 2006). Also, psychological mechanisms that transfer an emotional 
state into a seizure can be part of these triggering factors, such as dissociation and somatization (Alper, 1994; LaFrance and Barry, 2005; Bowman and Markand, 1996; Reuber et al., 2003; Mazza et al., 2009). Such factors explain why seizures occur on a specific day, or in a cluster or why there is a period of remission. This distinguishes PNES from conversion states that generally have a more permanent presentation. Level 5, prolongation, refers to factors that are important in explaining why the seizures persist over time and PNES may become a chronic disorder. These factors determine its frequency and its resistance against therapy. Such modulating factors are, e.g., the coping style of the patient and secondary gain aspects (Cragar et al., 2005; Moore and Baker, 1997; Aldenkamp and Mulder, 1997).

Figure 1 describes the assumed relationship between the factors. The model is not conclusive as some factors can interact at different levels. Coping strategies may be involved in the causation of PNES and may have a role in the vulnerability, whereas family factors may contribute to the prolongation of seizures and not only in the development (Moore et al., 1994).

Figure 1. Diagnostic model of psychogenic factors involved in psychogenic non-epileptic seizures (Bodde et al., 2009a; Bodde et al., 2009b).

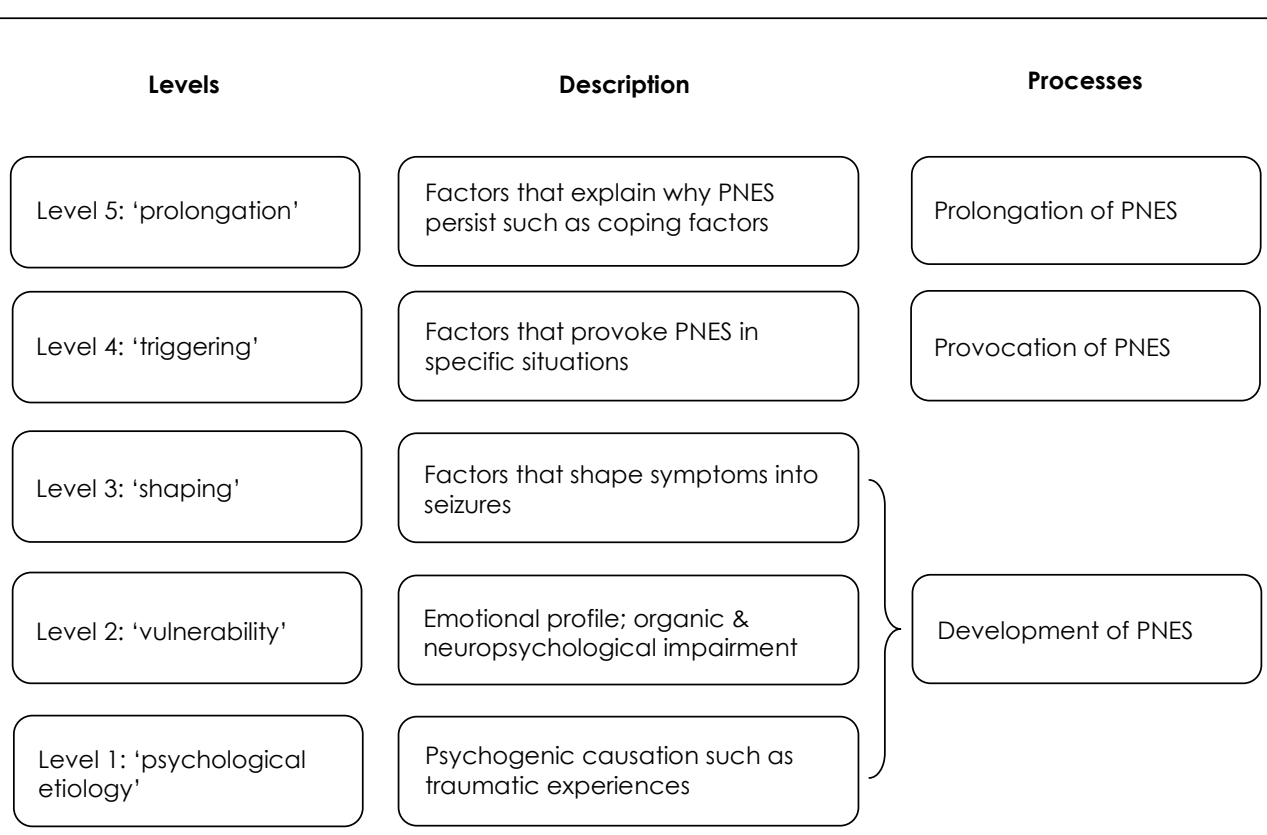


The current study focuses on the applicability of this model in the diagnosis of PNES. Relevant and available tests covering the different factors of the model were used to identify dominant factors for the total group and for specific subgroups. There was a focus on subgroups since many factors have been related to PNES but seldom account for the patient group as a whole (Bodde et al., 2009b; Duncan and Oto, 2008; Baslet et al., 2010; Mazza et al., 2009; Baillès et al., 2004; Hill and Gale, $2011)$. Recent studies increasingly focus on finding criteria to differentiate subgroups in PNES using PNES phenomenology (Cianci et al., 2011), descriptive patient characteristics (Bodde et al., 2012), personality factors and/or cognitive functioning (Cragar et al., 2005; Baslet et al., 2010). As yet, these criteria were not investigated using a diagnostic model. In this study, tests used in clinical practice were integrated in the diagnostic model in order to systematically assess relevant factors and subgroups.

\subsection{Methods}

\subsubsection{Participants}

Patients were included when the PNES diagnosis had been confirmed in the period 2009-2010 in the tertiary referral epilepsy center, using clinical description and additional EEG investigations (such as video-EEG monitoring). The type of EEG investigation was based on clinical indications, such as patient history and seizure semiology. Participants had to be > 15 years of age and normal intelligence levels were required. Mental retardation was an exclusion criterion, as was major psychiatric comorbidity, such as clinical depression. In total, 40 patients were selected that met the inclusion criteria.

\subsubsection{Procedure}

This study was an open non-controlled clinical cohort study. All patients were psychologically assessed by trained clinical psychologists. The history of all patients was taken, and a DSM-IV classification was made. The different levels of the theoretical model were assessed using a psychological PNES "test battery". In this battery, eleven psychological tests/instruments were selected that met the criteria for validity and reliability and had norm scores. For level 1, no norm scores were 
available, but we could use a trauma checklist. Also, level 3, shaping, mostly refers to symptom modeling for which no normed psychological test is available. Since dissociation is supposed to modulate between levels 3 and 4, we used the dissociation questionnaires for this level.

The following tests were selected: For level 1, 'psychological etiology', the Traumatic Experiences Checklist (TEC). For level 2, 'vulnerability', neuropsychological factors and personality factors were assessed. Neuropsychological functioning was examined using Raven's Progressive Matrices, the Trail Making Test (TMT), and a Computerized Visual Searching Task (CVST). Emotional profile and personality factors were tested using the Dutch short version of the Temperament and Character Inventory (short TCl) and the Dutch short version of the Minnesota Multiphasic Personality Inventory (short MMPI). For level 3, 'shaping', the Dissociation Questionnaire (DIS-Q) and Somatoform Dissociation Questionnaire (SDQ-20) were selected. For level 4, 'triggering', the Everyday Problem Checklist (EPCL) was selected to assess daily hassles and stress. For level 5, 'prolongation', coping styles were examined using the Utrecht Coping Scale (UCS) and Cognitive Emotion Regulation Questionnaire (CERQ). An extensive description of the instruments is attached in the Appendix.

\subsubsection{Statistical analysis}

Statistical analyses were performed using SPSS 16.0. (SPSS, Inc., Chicago, IL). The individual results were converted to z-scores to allow comparability among the tests. In a first step of the analyses, we explored whether the scores on the profile of the total group differed significantly from the 'norm z-value' of 0 that represents no difference with the norm population. Secondly, we performed subgroup analysis. In a univariate approach, relevant factors were inspected separately. However, this approach ignores the intercorrelations between the different tests and levels of the model. Subsequently, we, therefore, used a multivariate correlational approach with factor analysis. The significance level was set at $5 \%$. 


\subsection{Results}

Table 1 shows the main demographical and clinical characteristics of the 40 patients. There was a dominance of the female gender, and mean age during assessment was 30 years old. Most patients had only PNES, although about one-third of the patients had PNES in combination with epilepsy. Most patients had at least monthly seizures, and four patients were seizure free in the past three months. Thirteen patients reported no or only a mild impact of the seizures on their daily functioning, whereas eighteen patients reported frequent to severe impact on their daily living. Most patients lived with their parents or with a partner, and only two patients lived alone. Sixteen patients were unemployed or disabled to go to school or work.

Table 1. Demographical and clinical characteristics of the study group.

\begin{tabular}{l|c} 
N & 40 \\
Gender (male:female) & $8: 32$ \\
Mean age (years) & 30 \\
Age range (years) & $15.7-63$ \\
Additional epilepsy (no:yes) & $30: 10$ \\
PNES frequency & \\
- Currently seizure free & 4 \\
- Less than monthly & 2 \\
- Monthly & 3 \\
- Weekly & 15 \\
- Daily & 10 \\
Impact of PNES on daily functioning & \\
- No impact & 3 \\
- Occasionally & 10 \\
- Frequently & 9 \\
- Seriously & 6 \\
- Completely & 3 \\
Social status & \\
- Living with parents & 18 \\
- Living alone & 2 \\
- Married/living with partner & 19 \\
Education/work & \\
- School & 11 \\
- Unemployed & 6 \\
- Disabled & \\
- Employed & \\
- School and employment & \\
&
\end{tabular}




\subsubsection{Profile analysis of the total PNES group}

Figure 2 shows the profile of the total group in z-scores for the different levels in the model: 0 is the average report in the general population; based on reference values, scores of -1 and -2 show deviation of respectively 1 standard deviation and 2 standard deviations from the reference. Vice versa scores of +1 and +2 show scores higher than the reference value. Statistically significant differences with the norm scores are provided in the figure.

Figure 2. Profile of the total PNES group normalized by using z-scores. ${ }^{*}=$ Statistical differences with norm scores.

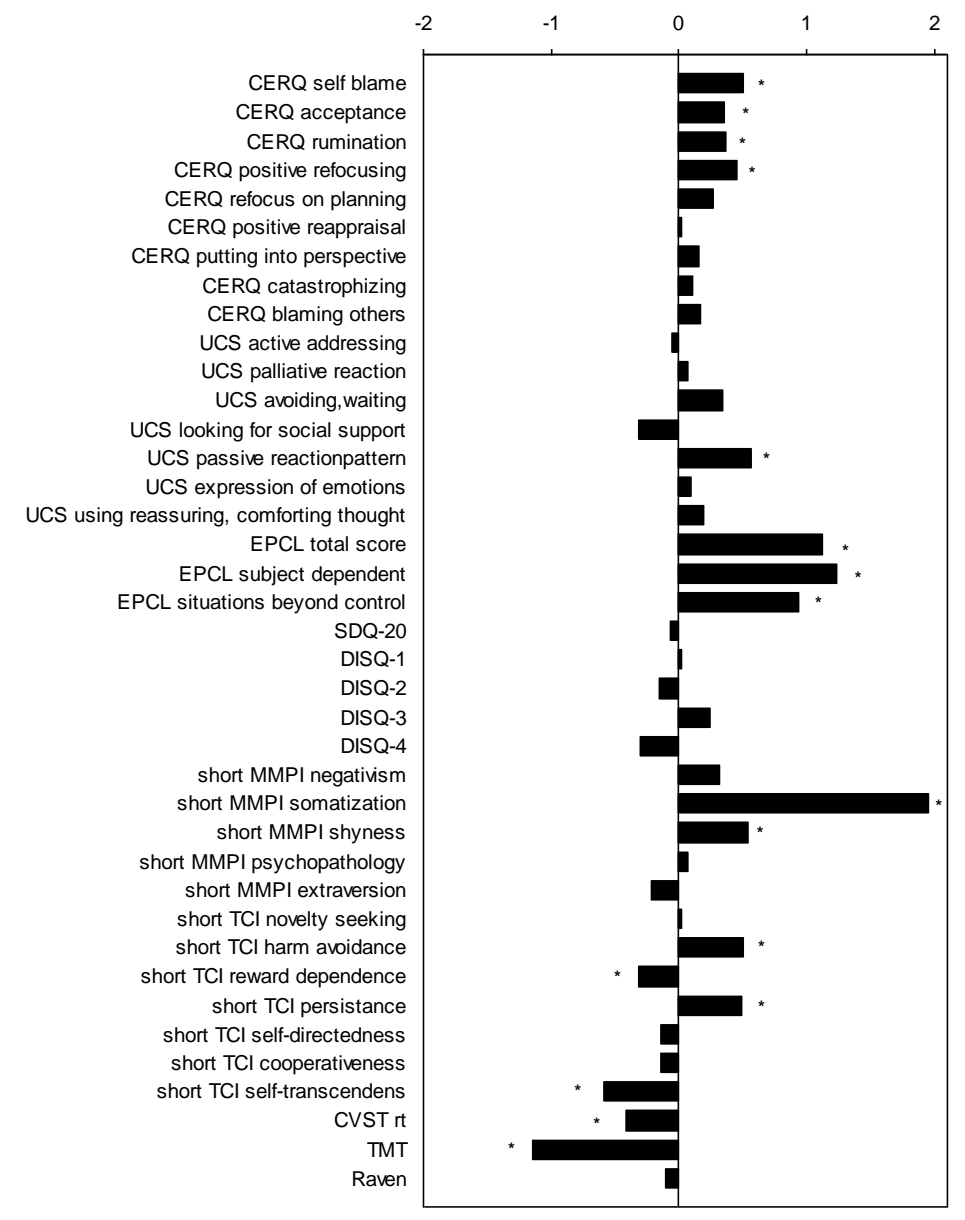


Level 1: 'psychological etiology'

For the Traumatic Experiences Checklist (TEC), no norm scores are defined; therefore, z-values cannot be reported. The TEC was, therefore, not included in the profile. One can argue that any trauma may have an effect and is not 'normal'. Seventy percent of our patients did report a traumatic event, and $52 \%$ reported multiple traumas. These percentages seem to deviate from 'the normal situation'. However, the TEC allows reports over a whole range of situations, some of which actually are more common in the general population, such as 'emotional neglect'. If we only inspect the variables in the TEC 'threat of body/life', 'sexual harassment' and 'sexual abuse' then $42.5 \%$ of our patients reported such traumas.

\section{Level 2: 'vulnerability'}

Global cognitive functioning as assessed with Raven's Progressive Matrices was not significantly different from normal, but PNES patients showed greater rigidity and lacked planning skills (TMT; $\dagger=2.063 ; p=0$.046). Moreover, they were characterized by slowing of central information processing speed (CVST; $\dagger=4.329 ; p=<0.001$ ).

Significant differences on the short version of the Temperament and Character Inventory with the reference values were found on three 'temperament dimensions', e.g., higher 'harm avoidance' $(\dagger=.837 ; p=0.001)$, lower 'reward dependence' $(\dagger=$ 2.057; $p=0.046$ ) and higher 'persistence' ( $t=3.140 ; p=0.003$ ) and on one 'dimension of character': lower 'self-transcendence' ( $t=4.265 ; p=<0.001)$. These results characterized the PNES patients as having a careful, anxious attitude, being vigilant for potential danger (high harm avoidance) in combination with a practical approach of situations and being insensitive for social signals (low reward dependence). The total PNES group was shown to be diligent and perfectionistic despite setbacks (high persistence). They had difficulty tolerating ambiguity and uncertainty and had a strong need to control (low self-transcendence).

On the short MMPI, PNES patients scored relatively high in 'somatization' $(t=$ 8.416; $p=0.001)$ and 'shyness' ( $t=2.558 ; p=0.015)$. This indicated a strong tendency to react with (psycho-)somatic complaints on psychological distress and also a tendency to be introverted, to be less sociable and to attempt to internally control emotions. 
Level 3: 'shaping'

No statistically significant differences were found with the reference values for the Somatoform Dissociation Questionnaire (SDQ-20) and the Dissociation Questionnaire (DIS-Q). The PNES group as a whole did not show increased scores for both forms of dissociation.

\section{Level 4: 'triggering'}

The Everyday Problem Checklist showed a significantly higher number of 'total complaints' $(t=4.497 ; p=<0.001)$, 'subject-dependent complaints' $(t=5.516 ; \mathrm{p}=<$ 0.001 ) and 'situations beyond control of the subjects' ( $t=3.066 ; p=0.004)$. The PNES group as a whole reported having many daily hassles and chronic stressors during the past two months within several life domains.

\section{Level 5: 'prolongation'}

The Utrecht Coping Scale showed a higher tendency towards a passive 'wait-andsee' attitude ( $t=3.129 ; p=0.003)$ when confronted with problems or events requiring adjustment. Furthermore, on a behavioral coping level, the patients tended to avoid problems and tended to avoid looking for social support.

The Cognitive Emotion Regulation Questionnaire (CERQ) showed significantly higher scores for 4 areas: 'acceptance' ( $t=2.510 ; p=0.016)$, 'positive refocusing' ( $\dagger$ $=2.689 ; \mathrm{p}=0.010)$, 'self-blame' $(t=2.665 ; \mathrm{p}=0.011)$ and 'rumination' $(t=2.423 ; \mathrm{p}=$ 0.020).

\subsubsection{Subgroup analysis: Univariate approach and factor analysis}

Some of the total group results were remarkable, such as the lack of dissociation. We therefore investigated whether the overall results were concealing specific subgroups. The total group was divided into subgroups based on a) psychological etiology, b) the tendency to dissociate, c) the tendency to report daily hassles, d) the cognitive level and e) psychopathology. 


\section{Subgroups based on psychological etiology}

The profile was inspected separately for patients who reported a psychotrauma on the TEC total score and patients who did not report a trauma, which is presented in Figure 3. Patients with a reported trauma $(n=28)$ differed from patients without a reported trauma $(n=12)$ on level 2 with more mental slowing on the CVST $(\dagger=-$ 2.690; $\mathrm{p}=0.011)$. The short MMPI showed more 'negativism', indicating more suffering from their problems $(t=2.030 ; p=0.049)$, and more 'shyness', indicating attempting to internally control emotions $(t=-2.891 ; \mathrm{p}=0.006)$. The short $\mathrm{TCl}$ showed more 'harm avoidance' ( $t=-2.304 ; p=0.027$ ) and less 'self-directedness' $(\dagger$ $=2.343 ; p=0.024$ ) for the patients with reported trauma. This showed this subgroup to be more anxious and being vigilant for potential danger (high harm avoidance) in combination with being fragile/immature and having difficulties pursuing meaningful personal goals and values in their lives (low self-directedness). On level 3 , patients with trauma showed increased psychoform dissociation, e.g., scale dl: 'identity confusion and depersonalization', than did patients without trauma ( $t=-$ 2.166; $p=0.037$ ). On level 4, no differences were found. On level 5, there was an increased score on the coping subscale 'blaming others' ( $t=-2.490 ; p=0.018)$, referring to having a cognitive coping strategy of holding other people responsible.

When the group was divided into two subgroups, a) patients with no or one trauma and b) patients with multiple traumas, a similar pattern was found, though less pronounced. Patients with multiple traumas $(n=21)$ differed from patients with no or a single trauma ( $n=19$ ) on level 2 with more 'shyness' ( $t=-2.153 ; p=0.038$ ) on the short MMPI. On level 3, increased dissociation was found for scale d1: 'identity confusion and depersonalization' ( $t=-2.487 ; p=0.019)$. On level 4 , no differences were found, and on level 5, there was again an increased score on the subscale 'blaming others' ( $t=-2.632 ; p=0.012$ ).

\section{Subgroups based on dissociation}

As the average profile did not show increased scores on the dissociation scales, it was explored whether two subgroups would exist. The patients were consequently divided into scores (based on the cut-off score provided by the SDQ-20 manual) that represent higher dissociation tendency (scores > 25; $\mathrm{n}=17$ ) and lower dissociation tendency $(n=23$ ). Patients with higher dissociation showed on level 2 
increased somatization ( $t=-2.293 ; p=0.027)$ on the short MMPI. On level 3, as expected, the dissociation subscales 'loss of control' ( $t=-2.980 ; p=0.005$ ) and 'amnesia' ( $t=-2.485 ; p=0.023$ ) of the DIS-Q were increased. On level 4, 'total complaints' ( $t=-2.743 ; p=0.012)$ and 'subject-dependent complaints' $(t=-2.694$; $\mathrm{p}=0.012$ ) on the EPCL were increased in patients with higher dissociation tendency. On level 5, patients with higher dissociation tendency showed increased scores on the subscale 'blaming others' ( $t=-2.128 ; p=0.042)$.

Figure 3. Profile comparisons of patients with reported trauma versus patients without reported trauma. ${ }^{*}=$ Statistically significant differences between the two groups.

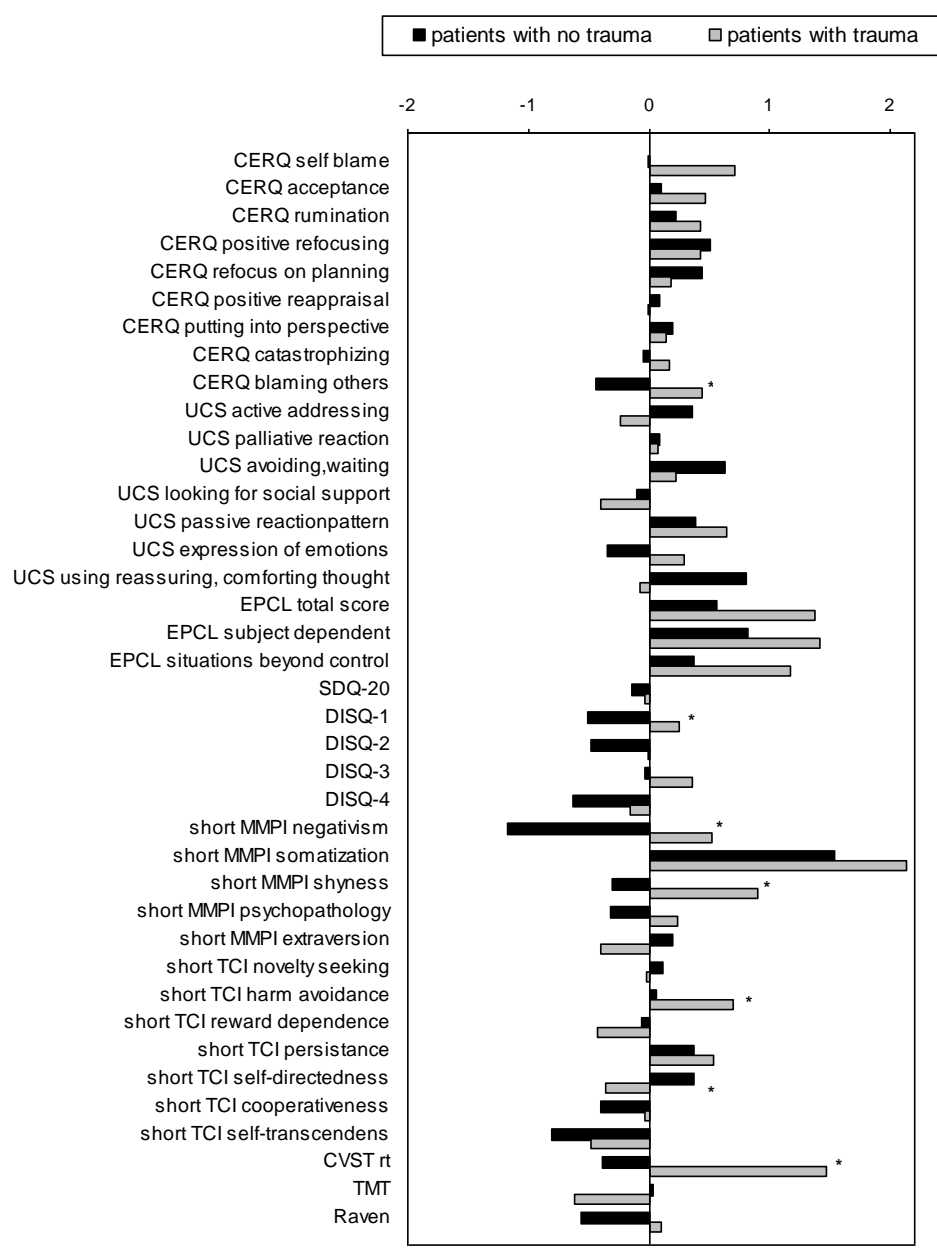


Subgroups based on the tendency to report daily hassles and stressors

As increased levels of daily hassles and complaints on the EPCL were dominant in the average profile, we distinguished patients that reported an extremely high number of complaints over the past two months (scores on the EPCL > z-score 1 ( $n=$ 14)) from the remaining patients. This revealed that patients with a high level of complaints showed on level 2 a higher tendency on the short MMPI towards 'negativism' ( $t=2.661 ; p=0.011)$ and on the short TCl increased 'harm avoidance' $(t=1.997 ; p=0.04)$, less 'persistence' $(t=-2.917 ; p=0.006)$ and less 'selfdirectedness' $(t=-6.692 ; p=<0.001)$. On level 3, all dissociation scales were increased in the patients with a high level of complaints $(S D Q-20 \dagger=3.440 ; p=0.001$; DIS-Q d1: 'identity confusion and depersonalization' $\dagger=3.701 ; p=0.001$; DIS- $Q d 2$ : 'self-control' $t=3.921 ; p=<0.001$; DIS-Q d3: 'amnestic and dissociation features' $t=$ 2.910; $p=0.006$; DIS-Q d4: 'concentration 'absorption' of environmental input' $\dagger=$ $2.212 ; p=0.033)$.

\section{Subgroups based on global cognitive level}

The patients were also divided by those scoring average or higher on the Raven and patients scoring below average. Patients scoring below average showed decreased 'persistence' on the short $\mathrm{TCl}(t=2.299 ; \mathrm{p}=0.03$ ) on level 2 and increased 'positive refocusing' $(t=2.175 ; p=0.043)$ on level 5 .

\section{Subgroups based on psychopathology}

A division based on psychopathology (> or < the z-score 0 on the subscale psychopathology of the short MMPI) did not reveal any significant differences, which may be caused by the fact that only 10 patients had scores higher than zscore 0 . The former step suggests that the total group of PNES patients consisted of subgroups with differential patterns with regard to the factors presented in the model (Figure 1).

In a second step of the subgroup analysis, we used a multivariate correlational approach with factor analysis. Seven variables were entered in the factor analysis. The choice for these variables was based on the highest correlating variables as well as a representation of each level. We entered the following variables: TEC total scores (1) for representation of level 1. CVST scores (2) for the neuropsychological 
factors of level 2, and short TCl 'novelty seeking' scores (3) and short MMPI 'somatization' scores (4) for the personality factors of level 2. SDQ-20 norm scores (5) for representation of level 3, EPCL total complaints (6) for representation of level 4, and CERQ 'self-blame' scores (7) for representation of level 5.

Factor analysis was used, based on principal component analysis. In four steps, the cut-off score of eigenvalue < 1 was reached. At that point, a satisfactory $80 \%$ of the variance was explained. This implicates that the seven variables have sufficient $(80 \%)$ explaining power for the variation in the investigated sample. A four-factor solution was achieved (presented in Table 2).

Factor 1 shows a subgroup characterized by a psychotraumatic origin of PNES without any involvement of level 2 vulnerability. These patients were not necessarily predisposed to develop somatization symptoms based on increased vulnerability; the reported trauma is essential. There was a high level of somatoform dissociation, complaints in daily life and cognitive coping problems (self-blame), which is in line with the results of the former profile analysis. This subgroup may be characterized as the 'psychotrauma subgroup'. This factor alone is valid for $28 \%$ of the study population, so it may represent between $1 / 4$ and $1 / 3$ of the population.

Factor 2 has a high negative loading for the TEC indicating that psychotrauma had no essential role in the psychogenic origin of PNES in these patients. There was, however, on level 2 a high vulnerability with respect to personality factors: a high tendency for somatization. The CVST indicated an undisturbed level of cognitive function. On level 4, there was a high level of complaints in daily life. This factor can be characterized as 'high vulnerability somatization subgroup' representing patients with a strong tendency to react with (psycho-) somatic complaints on psychological distress (without a clear psychotraumatic origin) because of a personality vulnerability. This factor is valid for $21 \%$ of the population.

Factor 3 also shows no loading on psychotrauma. There was again on level 2 a high vulnerability on personality factors, however not focusing on somatization. This factor shows a high loading for 'novelty seeking' on the short $\mathrm{TCl}$, indicating a strong tendency to react impulsively and to have quick tempers. They also loaded on 'selfblame' on the CERQ and had mental slowing/rigidity as a cognitive style on the CVST. This factor can be characterized as the 'high vulnerability sensitive personality problem subgroup' and represents $17 \%$ of this population. 
Factor 4 shows a combination of a high somatization tendency with a rigid and slow cognitive style on level 2 and no stress in daily life. This factor (representing 14\% of this population) seems to be a low cognitive level variant of factor 2 with patients that easily develop somatization symptoms, however, without the burden of daily hassles; the 'high vulnerability somatization subgroup with a low cognitive level'.

In fact, factor analysis shows two dimensions that are essential: the psychological etiology (psychotrauma or not) and the vulnerability e.g., the somatization tendency and the sensitive personality problems ('novelty seeking'), resulting in three subgroups. Subgroups 2 and 4 are similar, except for their cognitive level and for the burden they experience in daily life.

Table 2. Results of the factor analysis. High loadings on a factor (>0.40) are depicted in bold.

\section{COMPONENT}

\begin{tabular}{ll|rrrr} 
& \multicolumn{1}{c}{ Factor 1 } & Factor 2 & Factor 3 & Factor 4 \\
\hline \multirow{2}{*}{ Level 1: } & TEC & $\mathbf{0 . 5 8 6}$ & $\mathbf{- 0 . 6 5 0}$ & -0.017 & 0.096 \\
Level 2: & Short MMPI 'somatization' & 0.041 & $\mathbf{0 . 6 6 3}$ & -0.111 & $\mathbf{0 . 6 5 4}$ \\
& Short TCI novelty seeking & -0.356 & 0.342 & $\mathbf{0 . 7 4 6}$ & -0.182 \\
& CVST & -0.388 & $\mathbf{- 0 . 4 1 7}$ & $\mathbf{0 . 4 0 1}$ & $\mathbf{0 . 6 3 9}$ \\
Level 3: & SDQ-20 norm score & $\mathbf{0 . 8 0 0}$ & -0.018 & 0.043 & 0.237 \\
Level 4: & EPCL total complaints & $\mathbf{0 . 6 6 1}$ & $\mathbf{0 . 5 6 9}$ & 0.071 & -0.078 \\
Level 5: & CERQ 'self-blame' & $\mathbf{0 . 5 1 1}$ & -0.094 & $\mathbf{0 . 6 9 3}$ & -0.073 \\
& & & & & \\
\hline
\end{tabular}

\subsection{Discussion}

\subsubsection{Profile analysis of the total PNES group}

The diagnostic profile of the total group showed some remarkable findings. On level 1 ('psychological etiology'), 70\% of the patients did report one or more traumatic experiences before the age of 18 . Although this percentage was relatively high, it seemed comparable with other studies on PNES (Brown et al., 1991; Fiszman et al., 2004). The psychological instrument we used, the TEC, allowed reports over a whole range of traumatic experiences. When focusing specifically on physical and sexual abuse, than $42.5 \%$ of the patients reported such traumas. To compare, Breslau et al. 
(1998) reported that traumas resulting in a posttraumatic stress disorder occurred in $8 \%$ of the general population. Hence, physical and sexual abuse during childhood is an important etiological factor in PNES.

Level 2 ('vulnerability') effects showed that the neuropsychological impairments were mostly related to a defensive 'avoidance type' of cognitive style (slow, rigid). These effects may be seen as a consequence of personality characteristics and the burden of the seizures rather than as a causal factor. This is in line with the fact that similar neuropsychological impairments in epilepsy and PNES have been reported for many years (Wilkus et al., 1984; Drake, 1993; Hermann; 1993). Drane et al. (2006) also pointed to 'cognitive style characteristics' when they raised the possibility that PNES patients may often make an inadequate effort in taking the tests so that their findings may not be trustworthy. Also, Hill and Gale (2011) mentioned that abnormal neuropsychological functioning in PNES patients has been attributed to psychological and motivational factors. Hence, neuropsychological impairments do not seem to contribute to an increased vulnerability for PNES.

The assessment of personality factors on level 2 showed an increased tendency of somatization, referring to reacting with (psycho-) somatic symptoms on psychological distress, a finding that is often reported in recent PNES studies (Reuber et al., 2003; LaFrance and Barry, 2005; Bodde et al., 2011). The personality profile also showed, in a lesser degree, increased shyness on the short MMPI, referring to being less sociable and to attempt to internally control emotions. The short TCl showed a personality profile of having an anxious, practical and perfectionistic attitude with difficulties tolerating ambiguity and a strong need to control.

Remarkable was the absence of increased scores on tests for level 3 ('shaping'), indicating that dissociation was not increased in the average profile. This is in line with other studies (Reuber et al., 2003; Lawton et al., 2008; Goldstein et al., 2000; Ito et al., 2009) showing that although dissociation scores were higher in PNES patients, these scores did not indicate severe significant dissociative tendencies for the group as a whole.

On level 4 ('triggering'), the total PNES group reported many complaints about possible burdens in daily life in the past two months that may trigger seizures.

Level 5 ('prolongation') showed coping problems that may contribute to prolongation, such as a passive and/or avoidant attitude when confronted with 
problems. These coping problems have been found in other studies as well (Frances et al., 1999; Goldstein et al., 2000; Bakvis et al., 2011).

Although these findings are useful in describing PNES patients as a group, the results might simply represent a 'grand average' concealing specific subgroups. Lally et al. (2010) formulated this different, e.g. there may be no "one fits all" in terms of theory application (see also Mazza et al., 2009) and subgroup analysis might reveal more specific characteristics.

\subsubsection{Subgroup analysis}

Univariate analysis, using dichotomization in low and high scores, showed that subgroups indeed exist. The subgroup of patients with severe (physical and sexual) trauma was characterized by more mental slowing and significantly more 'negativism', more 'shyness', more 'harm avoidance' and less 'self-directedness'. This subgroup, who suffered more from their problems, was more introverted and was trying hard to internally control their emotions. These patients had an anxious attitude and were being vigilant for potential danger. The low 'self-directedness' referred to being immature, fragile and sensitive for external pressure, which can make it difficult to pursue meaningful personal goals and values. Also, in this subgroup, we found a higher tendency for psychoform dissociation on the level of identity confusion. The absence of increased dissociation was, therefore, an average characteristic of the total group but was not true for patients with a reported trauma. Other studies found subgroups in PNES exhibiting more dissociative tendencies related to trauma as well (Kuyk et al., 1997) even in non-clinical samples (Näring and Nijenhuis, 2005). It is remarkable though that somatoform dissociation was not increased in this subgroup, especially since the PNES represent a psychosomatic symptom. The crucial factor is whether there was a reported trauma or not. When the variable 'multiple trauma' was included, the observed pattern did not change. The psychological profile seemed directly linked to the traumatic experiences, and the patients suffered from the consequences. The combination of a high level of distress and an identifiable link to an etiological factor may help these patients to benefit from psychological therapy and to accept the diagnosis since it can be integrated into their personal history (Karterud et al., 2010). 
Subgroup division based on dissociation did not provide new information. This was possibly a result of the high relationship between dissociation and other factors in the model (Lawton et al., 2008). Similarly, a division based on cognitive level did not show new information. The cognitive results primarily reflected a slow and rigid cognitive style and were, therefore, closely related to other factors in the model. This may conceal its effect on subgroup division. Also, psychopathology was not an essential factor. This was probably an effect of sampling bias and test selection, combined with a statistical effect. Severe and/or acute psychiatric comorbidity was an exclusion criterion. Moreover and as a consequence of the previous factor, only 10 patients had a z-score higher than 0 ('normal'), which did not allow sufficient power to detect differences.

One other factor showed new information: reporting daily hassles and complaints, a level 4 ('triggering') factor. Patients with an extremely high level of complaints revealed more 'passive type' of personality characteristics (e.g., increased 'harm avoidance', less 'persistence' and less 'self-directedness') on the short $\mathrm{TCl}$ and an increased tendency to dissociate on both somatoform and psychological forms of dissociation.

Taken as a whole, these univariate analyses suggested that the investigated patients with PNES had some characteristics in common but that a subgroup approach provides more information. Especially, the importance of an underlying traumatic psychological etiology was shown. The effect of other factors was possibly concealed by high intercorrelations between the factors. We, therefore, used a multivariate correlational approach with factor analysis. This generated 4 factors that characterized the subgroups of the patients: A 'psychotrauma subgroup'; about $1 / 4$ and $1 / 3$ of the investigated patients. A 'high vulnerability somatization subgroup'; about 1/5 of the patients. A 'high vulnerability sensitive personality problem subgroup'; less than 1/5 of the patients. A 'high vulnerability somatization, low cognitive level subgroup' with no stress in daily life. This group is a variation of the second subgroup with low cognitive level; a small group of $14 \%$ of the investigated patients.

We concluded that in our study, two dimensions are essential: the psychological etiology (psychotrauma or not) and the vulnerability e.g., the somatization tendency and the sensitive personality problems ('novelty seeking'), resulting in three subgroups. The fact that the first two factors in our model (Figure 1) 
were dominant is in line with the model in which the etiology starts at levels one and two, and subsequent factors are secondary factors.

The concept of subgroups is in line with recent other PNES studies (Bodde et al., 2009b; Baslet et al., 2010; Reuber and House, 2002; Hill and Gale, 2011) in which the chosen classification was based on seizure characteristics and/or psychological criteria. Unfortunately, the distinguished subgroups were not easy to compare since different criteria and psychological tests were used. However, more studies found traumatic experiences and dissociation, cognitive functioning and personality factors, especially somatization, to be discriminatory variables in defining subgroups (Harden et al., 2009; Magaudda et al., 2011). An interesting approach was to define subgroups based on the relationship between PNES and personality disorders, previously presented by Cragar et al. (2005). Psychogenic non-epileptic seizure subtypes had been described on dimensions of psychopathology as measured by the MMPI-2. Three personality clusters emerged. The authors offered tentative descriptions of the clusters: 'depressed neurotics' (1); 'somatic defenders' (2); and 'activated neurotics' (3). Clusters 1 and 3 also differed significantly on neurocognitive testing, with cluster 1 patients scoring lower than cluster 3 on memory functioning, while cluster 2 individuals showed generally average cognition across domains. Reuber and House (2002) distinguished three groups, based on psychiatric comorbidity (present in $70 \%$ of the PNES patients in their study): (a) disorders of mood-depression, anxiety, panic and PTSD; (b) somatization and abnormal illness behavior; and (c) borderline personality. Furthermore, Hill and Gale (2011) recently found two PNES subgroups based on differences in cognitive functioning and seizure semiology. The PNES two-subgroup model (nonmotor and motor), in comparison to patients with temporal lobe epilepsy (TLE), showed a trend towards superior performance across nearly all cognitive measures for the nonmotor PNES subgroup. Conversely, the subgroup with motor PNES symptoms showed performance generally comparable to TLE patients. Finally, a recent study of Magaudda et al. (2011) specifically focused on patients with a combination of both epilepsy and PNES. They showed that this so-called "mixed PNES group" could be divided in three subgroups based on epilepsy type, mental level, comorbid psychiatric disorders, and history of traumatic experiences. In line with our results in their 'group 3', the PNES etiology was not related to epilepsy but to the psychic trauma. 
Our study showed that two dimensions are essential and constitute three subgroups. This is important in clinical practice. In the psychotrauma group, there is the overwhelming impact of psychotrauma, possibly followed by psychological aftermath 'gone wrong', leading to functional somatic symptoms. In this case, there is no specific vulnerability, and the emotions caused by the psychotrauma might be simply too distressing to find another than a somatic channel, leading partially to dissociation. Treatment should focus on the psychotrauma, and in fact these patients seem to be highly comparable with patients with post-traumatic stress disorder (PTSD). So, although PTSD cannot be diagnosed in most PNES patients (Baillès et al., 2004), the role of trauma in this subgroup may be as important. Fiszman et al. (2004) already suggested that PNES may arise as a clinical expression of a hypothetical PTSD subtype, the core symptoms of which are dissociative. For further research, it would be interesting to compare this trauma PNES group (without PTSD) with PTSD patients. Selkirk et al. (2008) also differentiated PNES patients which reported a history of sexual abuse from PNES patients which reported no sexual abuse. Bakvis et al. (2010) also found differences on biological level; basal hypercortisolism was more pronounced in traumatized patients with PNES as compared to non-traumatized PNES patients.

The second and fourth groups are patients with specific personality vulnerability. They are prone to react with somatic symptoms to emotional overload. In these patients, treatment should not only focus on symptom control but also on providing more effective coping strategies to handle critical emotional situations. This is of course more challenging in the fourth subgroup. Finally, the third subgroup has PNES as part of their personality problems, which has been extensively discussed in previously published work (Bodde et al., 2011). 


\subsection{Appendix}

\section{Description of instruments}

\section{Level 1: 'psychological etiology'}

Traumatic Experiences Checklist (TEC): The TEC is a 29-item self-report questionnaire retrospectively assessing potential childhood traumatic experiences in the period of 0 to 18 years of life. The TEC was developed as self-report scale as some patients may be less inhibited to report traumatic experiences on self-report measures than in the context of face-to-face trauma interviews (Carlson, 1997). The TEC includes a wide range of potentially traumatic experiences that are not necessarily traumatizing to every individual. However, experiences that are not traumatic to most individuals can be quite traumatic to others (Nijenhuis et al., 2002). The TEC has a total score and distinguishes 5 subscales: emotional neglect; emotional abuse; threat of body/life; sexual harassment and sexual abuse. Psychometric analysis shows satisfactory reliability (Bracke et al., 2001) and validity (Nijenhuis et al., 2002).

\section{Level 2: 'vulnerability' - Cognitive functions}

- Raven's Progressive Matrices: This non-verbal instrument includes multiple choice tests of abstract reasoning. An assessment with the Raven yields a total and a percentile score. Reliability studies, covering a very wide age range, many cultural groups, and clinical as well as healthy populations, show a good reliability, internal consistency and retest reliability (Court and Raven, 1995; Raven et al., 2003).

- Trail Making Test (adult version): This test consists of two parts, A and B, and is a test for mental flexibility and planning. In fact, this test measures executive function, which is a key cognitive function (Reitan, 1992). Especially, trail B is a good predictor of brain impairment. Although there is a practice effect when the test is administered repeatedly in the same subject, alternate forms of trails $A$ and $B$ have been developed and shown to be reliable (Franzen et al., 1996). In this study, the test was only administered once to the same patient. Furthermore, normative data used nowadays take into account factors such as age and level of education, which makes interpreting the scores very reliable over 
different patient groups (Reitan, 1958; Corrigan and Hinkeldey, 1987; Gaudino et al., 1995).

- Computerized Visual Searching Task (CVST): Assesses central (mental) information processing speed. The CVST is an adaption of Goldstein's Visual Searching Task and gives an indication of the speed of information processing. The test score is the total average searching time of correct answers in seconds (Aldenkamp and Alpherts, 2006).

Level 2: 'vulnerability' - Emotional profile/personality factors

- The Dutch short version of the Temperament and Character Inventory TCl (short TCTI, Dutch: VTCI) was used, including only the main scales (Duijsens et al., 1999; Duijsens et al., 2000; Duijsens et al., 2001): The short $\mathrm{TCl}$ is based on the psychobiological theory of personality of Cloninger (Cloninger, 1987; Cloninger et al., 1993; Cloninger et al., 1994) in which both normal and deviant variations in personality are described. The short TCl has 4 dimensions of temperament: 'novelty seeking'; 'harm avoidance'; 'reward dependence' and 'persistence' and three dimensions of character: 'self-directedness', 'cooperativeness' and 'self-transcendence'. Reliability and validity are acceptable (Maesschalk and Vertommen, 2001; Evers et al., 2002).

- The Dutch short version of the Minnesota Multiphasic Personality Inventory (short MMPI, Dutch: NVM) (Luteijn and Kok, 1985; Eurelings-Bontekoe et al, 1995), which consists of five subscales. Negativism (22 items) refers to passive avoidant behavior, feelings of dissatisfaction and grudge regarding daily life events, and aggressive behavior. This scale is related to the psychopathic deviate, hypomania, lie, depression, masculinity-femininity, and schizophrenia scales of the MMPI. Somatization (20 items) reflects vague physical complaints. This scale is related to the hypochondriasis, hysteria, and depression scales of the MMPI. Shyness (15 items) refers to feelings of shyness and difficulties in interpersonal contacts. This scale is related to the social introversion, hysteria, and psychopathic deviate scales of the MMPI. Psychopathology (13 items) reflects delusional feelings, paranoid thoughts, and bizarre experiences. This scale is related to the paranoia, fake (F), and schizophrenia scales of the MMPI. Extraversion (13 items) refers to an active and energetic attitude towards various 
social contacts. This scale is related to the social introversion and depression scales of the MMPI.

Level 3: 'shaping'

Dissociation is a broad concept that involves both psychological manifestations, such as disturbances of consciousness and/or identity or an altered perception of the environment, as somatoform manifestations, specifically referring to a lack of the normal integration of sensorimotor components of experience, e.g., hearing, speaking, and moving (Van der Hart et al., 2000). Not all types seem to be related to PNES (Lawton et al., 2008; Van der Boom et al., 2010). Therefore, two types of dissociation scales were included: the DIS-Q, which measures more psychological forms of dissociation, and the SDQ-20, which specifically measures somatoform types of dissociation.

- Dissociation Questionnaire (DIS-Q): This scale is based on the Dissociative Experiences Scale (DES) (Bernstein and Putman, 1986), the Perceptual Alteration Scale (PAS) (Sanders, 1986) and the Questionnaire of Experiences of Dissociation (QED) (Riley, 1988), and it has been adapted for the Dutch language (Vanderlinden et al., 1991; Vanderlinden et al., 1993). The scale has four subscales: DIS-Q d1: identity confusion and depersonalization; DIS-Q d2: selfcontrol; DIS-Q d3: amnestic and dissociation features; DIS-Q d4: concentration 'absorption' of environmental input. The DIS-Q is extensively assessed psychometrically. All psychometric studies suggest that the DIS-Q is reliable and is able to differentiate persons with dissociative disorders from other groups (Vanderlinden et al., 1993).

- Somatoform Dissociation Questionnaire (SDQ-20) (Nijenhuis et al., 1996; Nijenhuis, 1998): This self-report questionnaire evaluates the severity of somatoform dissociation. The items pertain to negative (e.g., analgesia) and positive (e.g., site-specific pain) dissociative phenomena (Lally et al., 2010). Several studies showed the psychometric characteristics of the scale to be very satisfactory (Nijenhuis et al., 1996; Nijenhuis et al., 1998a; Nijenhuis et al., 1998b; Sar et al., 2000; El-Hage et al., 2002). 


\section{Level 4: 'triggering'}

The Everyday Problem Checklist (EPCL, Dutch: APL): This self-report questionnaire measures the frequency and the intensity of daily hassles and chronic stressors experienced during the past two months within several life domains (Vingerhoets et al., 1989; Vingerhoets and Van Tilburg, 1994). Two subscales can be distinguished: 1) EPCL-DEP (Dutch: APL-AFH) consisting of items representing events and conditions that are caused by the subjects themselves (subject dependent); and 2) EPCL-IND (Dutch: APL-ONA) containing items referring to situations beyond control of the subject. There is also a total score (TOT-score) indicating the subjective experience of psychosocial stress in the past two months. Test-retest reliability is qualified as satisfactory (Vingerhoets et al., 1989).

\section{Level 5: 'prolongation'}

- Utrecht Coping Scale (UCS, Dutch: UCL): This scale aims at defining characteristic coping behavior confronted with problems or events requiring adjustment (Schreurs et al., 1993). The UCS scales seem to take an intermediate position between "trait" and "state", conforming to the theoretical view on coping as a personality style (Sanderman and Ormel, 1992). There are six subscales: 'actively addressing'; 'palliative reaction'; 'avoiding/waiting'; 'looking for social support'; 'passive reaction pattern'; 'expression of emotions'; and 'using reassuring and comforting thoughts'. Reliability of the UCS is studied in different subject groups and shows sufficient results (Schreurs et al., 1993; Sanderman and Ormel, 1992).

- Cognitive Emotion Regulation Questionnaire (CERQ): The CERQ is a multidimensional questionnaire constructed to identify the cognitive coping strategies someone uses after having experienced negative events or situations. The questionnaire refers exclusively to thoughts (a cognitive level) after having experienced a negative event (Garnefski et al., 2002). The nine conceptually separate emotion regulation strategies described are 'self-blame,' 'acceptance,' 'rumination,' 'positive refocusing,' 'refocus on planning,' 'positive reappraisal,' 'putting into perspective,' 'catastrophizing' and 'blaming others'. Garnefski et al. (2002) showed that the subscales can be grouped into adaptive and less adaptive regulation strategies. Reliability of the scales for 
diverse populations and validity of the CERQ are mentioned as good up to very good (Garnefski et al., 2002; Garnefski et al., 2006). 



\section{Chapter 5}

FUNCTIONAL CONNECTIVITY OF DISSOCIATION IN PSYCHOGENIC NON-EPILEPTIC SEIZURES

S.J.M. van der Kruijs, N.M.G. Bodde, M.J. Vaessen, R.H.C. Lazeron, K.E.J. Vonck, P.A.J.M. Boon, P.A.M. Hofman, W.H. Backes, A.P. Aldenkamp, J.F.A. Jansen. Journal of Neurology, Neurosurgery \& Psychiatry 2012, 83, 239-247.

\subsection{Abstract}

Investigation of resting-state networks may reveal altered routes of information and emotion processing in patients with psychogenic non-epileptic seizures (PNES). This study investigated whether patients with PNES differ from healthy controls in their resting-state functional connectivity characteristics, and whether these connections are associated with the tendency to dissociate.

Eleven patients with PNES without psychiatric comorbidity and twelve healthy controls underwent task-related (picture-encoding and Stroop paradigms) and resting-state functional MRI (fMRI). Global cognitive performance was tested using Raven's Progressive Matrices test and participants completed questionnaires for evaluating dissociation. Functional connectivity analysis on resting-state fMRI was based on seed regions extracted from task-related fMRI activation maps.

Patients displayed a significantly lower cognitive performance and significantly higher dissociation scores. No significant between-group differences were identified between the task-related activation maps. However, resting-state functional connectivity maps were statistically different. For patients with PNES, stronger connectivity values between areas involved in emotion (insula), executive control (inferior frontal gyrus and parietal cortex) and movement (precentral sulcus) were observed, which were significantly associated with dissociation scores.

The abnormal, strong functional connectivity in PNES patients provides a possible neurophysiological correlate for the underlying psychoform and somatoform dissociation mechanism where emotion can influence executive control, resulting in altered motor function (e.g., seizure-like episodes). 


\subsection{Introduction}

Psychogenic non-epileptic seizures (PNES) are paroxysmal episodes that resemble epileptic seizures, but are not based on epileptiform brain activity as recorded by EEGs and have no clinical evidence for epilepsy. Furthermore, no evidence has been found for other somatic causes for the seizures. Instead, psychogenic factors are assumed to cause the seizures (Bodde et al., 2009a).

PNES is one of the most important differential diagnoses of epilepsy. Although the differential diagnosis has been facilitated by the introduction of video EEG, there are as yet no real positive ictal features suggested to be pathognomonic for PNES. Most patients with PNES are initially misdiagnosed as having epilepsy, which has serious consequences for the patient, such as exposure to unnecessary anticonvulsant medication and considerable delay in starting the appropriate psychological therapy (Leis et al., 1992). In addition, misdiagnosis of PNES as epilepsy has a substantial economic burden, as erroneous treatments for intractable epilepsy are expensive (Martin et al., 1998).

More knowledge of PNES etiology is needed to facilitate the process of PNES diagnosis and decide the nature of treatment (Devinsky et al., 2011). Existing theories regarding the underlying psychological mechanisms of PNES are diverse and involve multiple factors that may play a role in the development and prolongation of PNES. One factor that is considered particularly important in most theories for PNES (Bodde et al., 2009b) and other functional symptoms (Spitzer et al., 1999; Guz et al., 2004) is dissociation. Dissociation is a broad concept that involves a variety of manifestations. In the literature on somatoform disorders, psychological and somatoform dissociation are often distinguished, but they can be seen as related constructs (Maaranen et al., 2005). The process of psychological dissociation is a disruption of the integration of a person's conscious functioning by severing the connection to thoughts, memories, feelings and sense of identity. Somatoform dissociation involves the loss of integration of somatic experiences, functions and responses (Näring and Nijenhuis, 2005). Dissociation is postulated to be closely related to the process of hypnosis (Kihlstrom, 1998) and is regarded as a coping strategy in the context of acute or chronic traumatization when the individual lacks the capacity to integrate adverse experiences (Nijenhuis and Van der Hart, 2011). Patients with PNES often demonstrate dissociative symptoms (Goldstein and Mellers, 
2006) and high hypnotizability (Dienes et al., 2009), and dissociative disorders have been reported in over $90 \%$ of the PNES patients (Bowman and Markand, 1996). In fact, PNES may be considered as somatoform symptoms resulting from dissociated mental organization (Nijenhuis and Van der Hart, 2011). Accordingly, the DSM-IV-TR and ICD-10 classifications of PNES as, respectively, conversion disorder and dissociative disorder are still matter of debate (Brown et al., 2007).

Since the tendency to dissociate is considered such an important mechanism in the etiology of PNES, a better understanding of the neurobiological mechanism of dissociation might shed light on the pathophysiology of PNES and lead to more specific treatments. It might explain how information in patients with PNES or other functional symptoms is processed differently compared with non-affected individuals. A previous functional MRI (fMRI) study in patients with a motor conversion disorder identified abnormal functional connectivity (FC) between regions involved in emotion and motor preparation (Voon et al., 2010b). Functional MRI may identify a similar abnormality in patients with PNES, providing evidence for alternative neuronal routes of information and emotion processing in patients with PNES that probably result in dissociative seizure-like episodes (Baslet, 2011; Devinsky et al., 2011; Van der Kruijs et al., 2011). As yet, no fMRI study has been performed in patients with PNES.

We hypothesize that functional connections between networks involved in emotion, sensorimotor, and cognitive processes are abnormal in patients with PNES. Additionally, these abnormal connections are associated with the tendency to dissociate. To test these hypotheses, we performed an fMRI study in patients with PNES and healthy controls.

\subsection{Materials and methods}

\subsubsection{Participants}

Patients were selected by their clinical psychologist or neurologist ( $>10$ years and $>9$ years experience, respectively), on the basis of their seizure characteristics 5 , tendency to dissociate, and the absence of mental retardation and comorbid psychiatric disorders (eg, mood and anxiety disorders, schizophrenia and psychosis, and substance-related disorders), which were determined through (hetero-) 
anamnesis and extensive (neuro-) psychological assessment. Individuals with neurological comorbidity (including epilepsy) and malingering patients were excluded. Patients were only included after the PNES diagnosis was confirmed in a tertiary epilepsy centre by an experienced neurologist/epileptologist, using clinical description and, when available, additional (video) EEG investigations.

The total study population included 13 patients with PNES and 13 healthy volunteers. Two patients with PNES did not complete the study and one healthy control demonstrated periventricular heterotopia on MRI, because of which these patients were excluded from the analysis. The other subjects did not have clinically significant MRI abnormalities (table 1). Analyses were performed on the data obtained from 11 patients and 12 healthy volunteers. All participants gave informed consent to participate in the investigation, which received ethical approval by the Medical Ethical Committee of Maastricht University (ref. 10-3-045).

Table 1. Participant demographics and characteristics. For ID, C = Healthy control. ${ }^{*}=$ Seizure classification according to Abubakr et al. (2003).

\begin{tabular}{|c|c|c|c|c|c|c|c|}
\hline ID & Age & Gender & $\begin{array}{l}\text { PNES } \\
\text { duration } \\
\text { (years) }\end{array}$ & $\begin{array}{l}\text { Nr. attacks } \\
\text { previous } \\
\text { month }\end{array}$ & $\begin{array}{l}\text { Type of } \\
\text { symptoms * }\end{array}$ & Medication & MRI remarks \\
\hline 1 & 39 & $\mathrm{~F}$ & 1 & 3 & Unresponsiveness & - & \\
\hline 2 & 40 & $\mathrm{~F}$ & 13 & 0 & $\begin{array}{l}\text { Major motor } \\
\text { manifestations }\end{array}$ & - & \\
\hline 3 & 50 & $\mathrm{~F}$ & 6 & 5 & $\begin{array}{l}\text { Major motor } \\
\text { manifestations }\end{array}$ & - & \\
\hline 5 & 25 & $\mathrm{~F}$ & 3 & 1 & $\begin{array}{l}\text { Major motor } \\
\text { manifestations }\end{array}$ & - & \\
\hline 6 & 52 & M & 13 & 1 & $\begin{array}{l}\text { Major motor } \\
\text { manifestations }\end{array}$ & $\begin{array}{l}\text { Amitriptyline, } \\
\text { Rosuvastatin, } \\
\text { Oxazepam }\end{array}$ & $\begin{array}{l}\text { Cerebral } \\
\text { atrophy }\end{array}$ \\
\hline 8 & 28 & M & 14 & 0 & $\begin{array}{l}\text { Major motor } \\
\text { manifestations }\end{array}$ & Diazepam & \\
\hline 9 & 37 & M & 3 & 8 & Unresponsiveness & $\begin{array}{l}2008 \text { - } 2010 \\
\text { Valproic acid, } \\
\text { Topiramate, } \\
\text { Sumatriptan, } \\
\text { Naratriptan }\end{array}$ & \\
\hline 10 & 36 & $\mathrm{~F}$ & 27 & 2 & Unresponsiveness & - & \\
\hline 11 & 20 & M & 1 & 2 & Unresponsiveness & - & \\
\hline 12 & 28 & $\mathrm{~F}$ & 2 & 0 & $\begin{array}{l}\text { Major motor } \\
\text { manifestations \& } \\
\text { Unresponsiveness }\end{array}$ & - & \\
\hline 13 & 18 & M & 1 & 0 & $\begin{array}{l}\text { Major motor } \\
\text { manifestations }\end{array}$ & $\begin{array}{l}2009-2010 \\
\text { Valproic acid }\end{array}$ & $\begin{array}{l}\text { Asymmetrical } \\
\text { ventricles }\end{array}$ \\
\hline
\end{tabular}




\begin{tabular}{|c|c|c|c|c|}
\hline $\mathrm{Cl}$ & 55 & $M$ & - & $\begin{array}{l}\text { Diffuse white } \\
\text { matter } \\
\text { abnormalities }\end{array}$ \\
\hline C2 & 52 & $\mathrm{~F}$ & - & \\
\hline C3 & 29 & $\mathrm{~F}$ & - & \\
\hline C4 & 27 & $\mathrm{~F}$ & - & $\begin{array}{l}\text { Small } \\
\text { aspecific } \\
\text { white matter } \\
\text { abnormality }\end{array}$ \\
\hline C5 & 24 & $M$ & - & \\
\hline C6 & 39 & $F$ & - & $\begin{array}{l}\text { Small } \\
\text { lacunair } \\
\text { lesion and } \\
\text { slight atrophy }\end{array}$ \\
\hline C7 & 37 & $\mathrm{~F}$ & - & \\
\hline C8 & 37 & $\mathrm{~F}$ & - & \\
\hline $\mathrm{C} 10$ & 32 & $M$ & - & $\begin{array}{l}\text { Somewhat } \\
\text { plump } \\
\text { ventricular } \\
\text { system }\end{array}$ \\
\hline $\mathrm{C} 11$ & 25 & $\mathrm{~F}$ & - & \\
\hline $\mathrm{C} 12$ & 23 & $\mathrm{~F}$ & - & $\begin{array}{l}\text { Small } \\
\text { arachnoidal } \\
\text { cyst right } \\
\text { temporal } \\
\text { pole }\end{array}$ \\
\hline $\mathrm{Cl3}$ & 23 & $M$ & - & \\
\hline
\end{tabular}

\subsubsection{Questionnaires and neuropsychological investigation}

All participants were asked to complete questionnaires to evaluate their dissociation tendency. These questionnaires included the Dissociation Questionnaire (DIS-Q), Dissociative Experiences Scale (DES) and the Somatoform Dissociation Questionnaire (SDQ-20) (Sno, 2004). Both the psychological forms of dissociation (DES and DIS-Q) as somatoform dissociation (SDQ-20) were assessed. Global cognitive performance was tested using the Raven's Progressive Matrices Test (Raven et al., 2003). We obtained completed questionnaires from 10 patients with PNES and 12 healthy controls, as one patient did not return the questionnaires.

\subsubsection{Neuroimaging}

MRI was performed on a 3.0-tesla unit equipped with an 8-channel head coil (Philips Achieva, Philips Medical Systems, Best, The Netherlands). For anatomic reference, a Tl-weigthed 3D turbo field echo was acquired with the following parameters: 
repetition time (TR) $8.2 \mathrm{~ms}$, echo time (TE) $3.7 \mathrm{~ms}$, flip angle $8^{\circ}$, matrix $240 \times 240$, field of

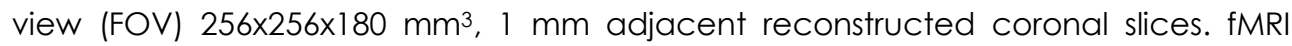
data were acquired using a whole-brain single-shot multi-slice blood oxygen leveldependent echo-planar imaging sequence, with TR $2 \mathrm{~s}$, TE $35 \mathrm{~ms}$, flip angle $90^{\circ}$, voxel size $2 \times 2 \times 4 \mathrm{~mm}^{3}$, matrix 128x128, 32 contiguous slices per volume and 195 volumes per acquisition.

For fMRI, four different scans were performed: (1) first resting-state fMRI (rsfMRI) session, (2) picture encoding, (3) Stroop color naming, and (4) second rsfMRI session. During the rsfMRI sessions, subjects were instructed to close their eyes and think of nothing in particular. The rationale for including a second resting-state session after two task-related paradigms was that attentional effort may provoke dissociative phenomena (Castillo, 1990; Leonard et al., 1999; Cerezuela et al., 2004; Vaitl et al., 2005), which thus may provoke dissociation during the second rsfMRI session.

The picture-encoding task was included in an attempt to stimulate the process of suggestibility by presenting pictures with high positive sentimental value. During this task, subjects viewed five images of real-life outdoor scenes prior to the fMRI scans during acquisition of the T1-weighted scan (Vlooswijk et al., 2011). Each picture was presented 25 times for $3 \mathrm{~s}$. After approximately half an hour, an fMRI examination was performed while variable-length epochs of new pictures (new condition) were demonstrated mixed among variable-length epochs of the five old pictures (old condition). The epochs were mixed into a run of 195 stimuli. A total of 120 new pictures were shown. With each picture, the subjects had to decide whether it was old or new. The activation during the task was contrasted with the resting-state activation for further analysis. Previous studies with this task showed activation of the bilateral medial temporal lobes and other limbic structures (Vlooswijk et al., 2011).

The Stroop task was selected because susceptibility to hypnotic induction (associated with dissociation), has previously been related to Stroop performance and FC changes in the frontal attention system (Kuyk et al., 1999; Egner et al., 2005). In the covert variation of the Stroop test (Stroop, 1935, and Jansen et al., 2008), a word stimulus is presented in green, blue, yellow or red color on a black background. Subjects were instructed to think of the color in which the word was displayed. For example, the word "blue" was written in red letters; the subject had to think "red". Each word was presented for 2 s. In the baseline condition, subjects 
focused on a cross-hair. The paradigm consisted of seven baseline rest condition blocks (30 s each) alternated with six activation blocks, consisting of 15 words. In total, 24 congruent and 66 incongruent stimuli were presented in random order. The contrast between the baseline condition and the activation condition was used for further analysis (Jansen et al., 2008).

\subsubsection{Neuroimaging analysis}

Structural MRI scans were reviewed by an experienced neuroradiologist (> 10 years experience). fMRI data analysis was performed in MATLAB (Mathworks, Natick, Massachusetts, USA) using the statistical parametric mapping software package (SPM8) (Wellcome Department of Cognitive Neurology, London, UK). Task-related paradigms were analyzed using brain activation contrasts according to the general linear model. The blood oxygen level-dependent images were realigned, transformed into the standardized Montreal Neurological Institute space and smoothed with an 8-mm Gaussian kernel. In the general linear model, a standard discrete cosine set was used to correct for (low-frequency) signal drift. Additionally, the paradigms were convolved with the hemodynamic response function. To explore differences in activation between the PNES and control group, a randomeffects analysis was performed. Results were thresholded at the $p<0.05$ level (corrected for family-wise multiple comparisons).

Subsequently, regions of interest with strong activation were defined lof approximately 300 voxels), based on the activation patterns during the tasks averaged for all subjects. This way, we ensured that the created masks were specific for this population, which is preferred over mask definitions available from the literature (Waites et al., 2006). The masks were created in MRIcro (Rorden and Brett, 2000).

For the resting-state FC analysis, the signal time-course data were filtered by applying a bandpass filter $(0.01-0.1 \mathrm{~Hz})$ and corrected for head movement effects by using the six motion correction parameters as a covariate. Seed time courses for each region and subject were then generated by averaging the signal within the region of interest at each time point. Each seed time course then was regressed against all brain voxel time courses to obtain an FC map, which was subsequently transformed using the Fisher-Z transformation (Waites et al., 2006). Multiple regression 
was then performed with subject type (patient or control) and rs-fMRI session (first or second) as covariates. The resulting contrasts were thresholded at the $p<0.05$ level (corrected for multiple comparisons using regional FDR (Langers et al., 2007)). Regions with significant differences in FC between patients and controls (called FC regions hereafter) were identified, and corresponding masks were created in MRIcro (Rorden and Brett, 2000). Subsequently, for these regions individual functional connectivity values (called FC values hereafter) were computed by averaging the FC values over all voxels within each mask.

\subsubsection{Statistical analysis}

Statistical data analyses on summary values were performed in SPSS (PASW Statistics V.18.0, Chicago: SPSS Inc.), whereas analyses on a voxel-by-voxel level were performed in MATLAB (see previous section). Descriptive statistics of relevant variables were obtained, and Mann-Whitney $U$ tests were performed to examine differences between patients with PNES and controls. Additionally, correlation coefficients between dissociation scores, intelligence scores and FC values were obtained over all subjects using the non-parametric Spearman rank-correlation test. Finally, to gain insight to the predictive value of the tested variables for relevant significant correlations from the latter analysis, a linear regression was performed with FC as dependent variable and dissociation and intelligence scores as independent variables. Statistical significance is denoted as $p<0.05$.

\subsection{Results}

\subsubsection{Clinical and neuropsychological assessment}

The study population comprised of 11 patients with PNES ( 6 women, 5 men, age $34 \pm$ 11 years, number of seizures in previous month $2.0 \pm 2.5$ ), and 12 healthy volunteers (8 women, 4 men, age $34 \pm 11$ years) (Table 1). The patients displayed significantly lower performance on the Raven's Progressive Matrices test, and significantly higher dissociation tendency on the dissociation questionnaires, as assessed with MannWhitney $U$ tests $(\mathrm{p}<0.05)$. The patients displayed high scores for both psychological and somatoform dissociations $(p<0.05)$. 


\subsubsection{Neuroimaging analysis}

For both the PNES and control groups, the picture-encoding paradigm yielded significant activation within both hippocampi, the left lateral frontal cortex, the parahippocampal gyrus and fusiform gyrus. The Stroop paradigm activated the inferior frontal, precentral and parietal cortices. These results for both groups are typical activation maps, in accordance with the literature (Mead et al., 2002; Jansen et al., 2008; Vlooswijk et al., 2011). Figure 1 displays the average activation for the picture-encoding and Stroop paradigms for both groups. The random-effects analysis did not reveal any significant differences for picture-encoding and Stroop color-naming activation maps between controls and patients with PNES.

Figure 1. Group averaged fMRI activation maps superimposed on a normalized Tl-weighted MR image. Mean activation patterns for PNES patients are shown in $A$ and $D$ and for healthy controls in $B$ and $E$. Averaged activation patterns over all subjects are shown in $C$ and $F$. For the picture encoding paradigm the characteristic hippocampal activation is shown on coronal (A-B), and axial (C) slices. For the Stroop paradigm (D-F) the characteristic prefrontal activation is shown on coronal (D, E, F) slices. The bar on the top right indicates the $t$-value of the activation level. Slice positions are specified in the MNI coordinate system: $y=-24 \mathrm{~mm}$ for $A$ and $B ; z=-18 \mathrm{~mm}$ for $C$, and $y=6 \mathrm{~mm}$ for $D, E$, and $F$.

A

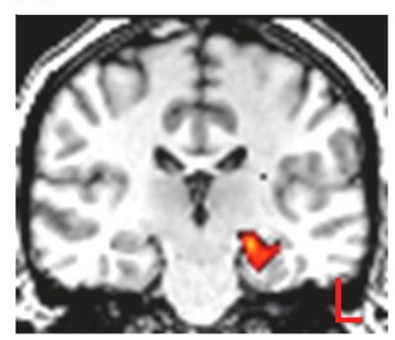

$\mathrm{D}$

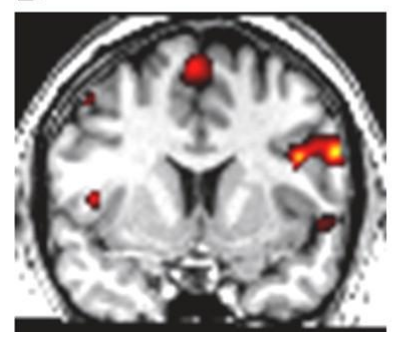

B

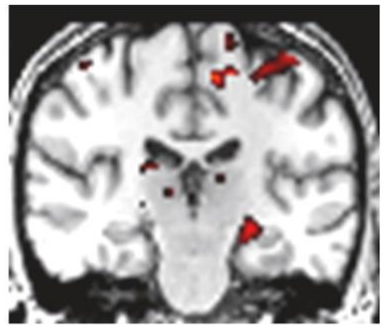

$\mathrm{E}$

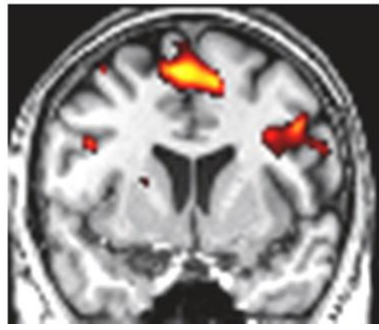

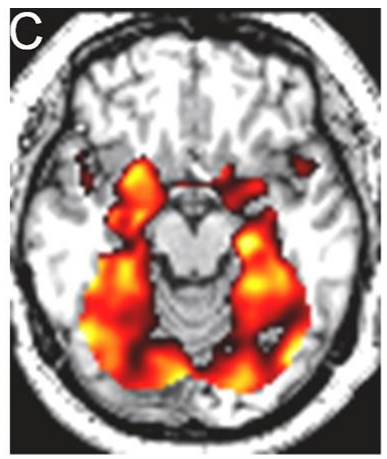

1

5

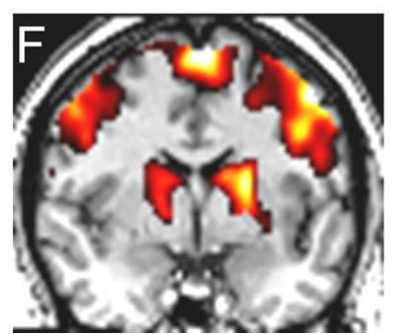


Based on the average activation for the task related paradigms, 9 seed ROIs were created (Figure 2): left parahippocampal gyrus and right parahippocampal gyrus (based on the encode paradigm), and right inferior frontal gyrus, left inferior frontal gyrus, right intraparietal sulcus, left intraparietal sulcus, left supramarginal gyrus, anterior cingulate cortex, and left precentral sulcus (based on Stroop paradigm).

Figure 2. Seed regions obtained from the activation maps from the picture-encoding (8, 9) and Stroop paradigms (1-7), superimposed on a normalised T1-weighted MR image. 1, right inferior frontal gyrus; 2, left inferior frontal gyrus; 3, right intraparietal sulcus; 4, left intraparietal sulcus; 5, left supramarginal gyrus; 6, anterior cingulate cortex; 7, left precental sulcus; 8, right parahippocampus; 9, left parahippocampus. MNI (Montreal Neurological Institute) coordinate system: $z=+46 \mathrm{~mm}$ for $A, y=+6 \mathrm{~mm}$ for $B$ and $y=-42 \mathrm{~mm}$ for $C$.
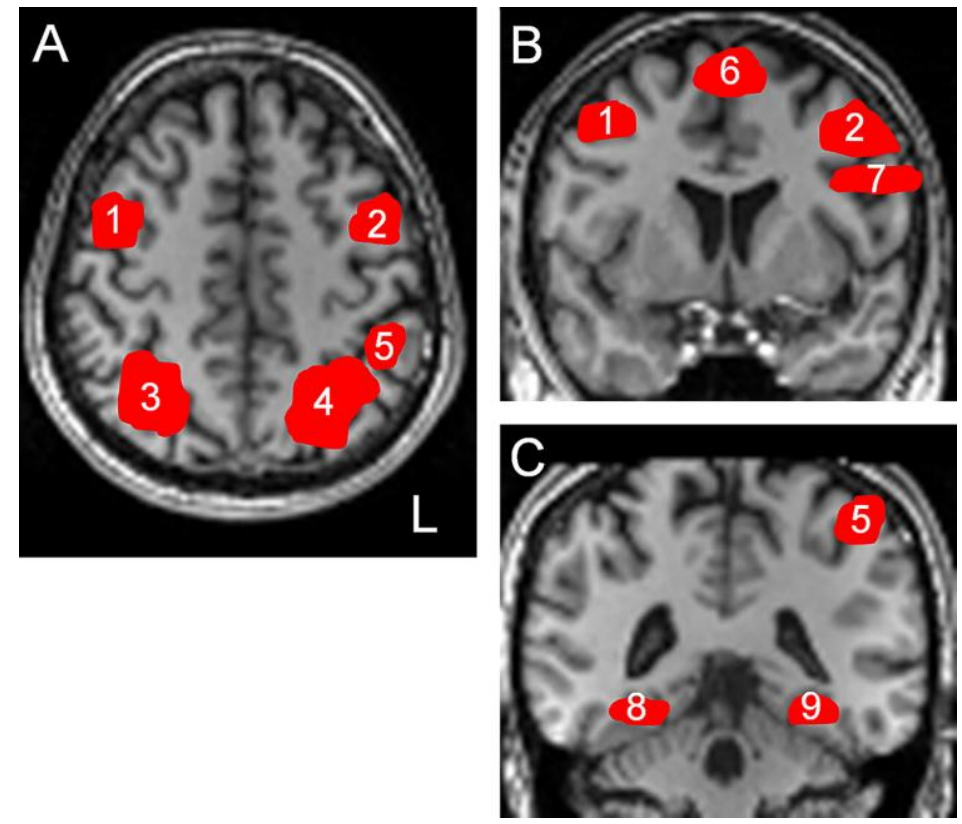

The FC maps based on the seed regions left inferior frontal gyrus, left intraparietal sulcus, left supramarginal gyrus and left precental sulcus yielded significant group differences in connectivity values ( $p<0.05$, corrected) (table 3, figure 3 ). The right intraparietal sulcus yielded similar results as the left intraparietal sulcus (data not shown). The other four seed regions did not yield significant differences in FC values. Multiple regression did not yield statistical significant differences between the two rsfMRI sessions ( $p>0.12)$. 
Table 2. Maximal Z-score and [cluster size] of regions with significant (positive) differences in FC between PNES patients and controls. MNI coordinates are given in italic $(x, y, z) .(L)=$ left, $(R)=$ right.

\begin{tabular}{|c|c|c|c|c|c|c|}
\hline \multirow[b]{2}{*}{$\begin{array}{c}\text { SEED REGION } \\
(x, y, z)\end{array}$} & \multicolumn{6}{|c|}{$\begin{array}{c}\text { FC REGION } \\
(x, y, z)\end{array}$} \\
\hline & $\begin{array}{c}\text { Anterior } \\
\text { insula (R) } \\
(-38,6,-12)\end{array}$ & $\begin{array}{l}\text { Posterior } \\
\text { insula (R) } \\
(-46,-12,6)\end{array}$ & $\begin{array}{c}\text { Central } \\
\text { sulcus (R) } \\
(-44,-20,30)\end{array}$ & $\begin{array}{c}\text { Posterior } \\
\text { cingulate } \\
\text { gyrus (R) } \\
(-2,-58,46)\end{array}$ & $\begin{array}{c}\text { Anterior } \\
\text { cingulate } \\
\text { gyrus (R) } \\
(-4,40,0)\end{array}$ & $\begin{array}{c}\text { Parietal } \\
\text { occipital } \\
\text { fissure (R) } \\
(-24,-56,14)\end{array}$ \\
\hline $\begin{array}{c}\text { Inferior frontal } \\
\text { gyrus (L) } \\
(44,4,46)\end{array}$ & & & $\begin{array}{l}4.26 \\
{[250]}\end{array}$ & $\begin{array}{l}4.09 \\
{[890]}\end{array}$ & $\begin{array}{l}4.13 \\
{[579]}\end{array}$ & $\begin{array}{l}5.17 \\
{[723]}\end{array}$ \\
\hline $\begin{array}{l}\text { Precentral } \\
\text { sulcus (L) } \\
(46,6,26)\end{array}$ & $\begin{array}{l}4.51 \\
{[64]}\end{array}$ & $\begin{array}{l}5.33 \\
{[210]}\end{array}$ & $\begin{array}{l}4.59 \\
{[55]}\end{array}$ & & $\begin{array}{c}4.28 \\
{[789]}\end{array}$ & $\begin{array}{c}4.49 \\
{[634]}\end{array}$ \\
\hline $\begin{array}{c}\text { Supramarginal } \\
\text { gyrus (L) } \\
(46,-40,50)\end{array}$ & & $\begin{array}{l}6.20 \\
{[512]}\end{array}$ & & $\begin{array}{l}5.01 \\
{[897]}\end{array}$ & & $\begin{array}{l}6.30 \\
{[713]}\end{array}$ \\
\hline $\begin{array}{l}\text { Intraparietal } \\
\text { sulcus (L) } \\
(28,-58,50)\end{array}$ & & $\begin{array}{l}4.86 \\
{[313]}\end{array}$ & $\begin{array}{l}5.29 \\
{[79]}\end{array}$ & $\begin{array}{l}6.90 \\
{[795]}\end{array}$ & $\begin{array}{c}4.40 \\
{[653]}\end{array}$ & $\begin{array}{l}4.99 \\
{[806]}\end{array}$ \\
\hline
\end{tabular}

Compared with healthy controls, patients had several significantly stronger functional correlations in the following FC regions: the anterior insular cortex, posterior insular cortex, central sulcus, posterior cingulate cortex, anterior cingulate cortex and parietal occipital fissure (table 2). Interestingly, most FC regions were significantly different in FC maps from more than one seed region (table 3). For example, the posterior insular cortex showed significantly higher correlation values with the precentral sulcus, the supramarginal gyrus as well as the intraparietal sulcus in PNES patients than in controls (average Fisher-Z transformed connectivity values: $0.37 \pm 0.12$ vs $0.25 \pm 0.10,0.31 \pm 0.15$ vs $0.15 \pm 0.13$ and $0.30 \pm 0.15$ vs $0.17 \pm 0.13$, respectively). 
Figure 3. Regions of significant higher functional correlation for seed regions left precentral sulcus (A-C) and left inferior frontal gyrus (D) for PNES patients compared with controls during resting-state fMRI, overlaid on an average normalized TI-weighted MR image generated using MRIcro (A, B, D) or projected on an inflated right hemisphere surface map generated in Freesurfer (MGH, Massachusetts, USA) (C). Contrast is visible in the central sulcus (CS), anterior insular cortex (ICa), posterior insular cortex (ICP), anterior cingulate cortex (ACC), posterior cingulate cortex (PCC) and parietal occipital fissure (POF). The bar on the top right indicates the t-value of the FC map. MNI (Montreal Neurological Institute) coordinate system: $x=-44 \mathrm{~mm}$ for $A, y=+8 \mathrm{~mm}$ for $B$ and $y=50 \mathrm{~mm}$ for $D$.
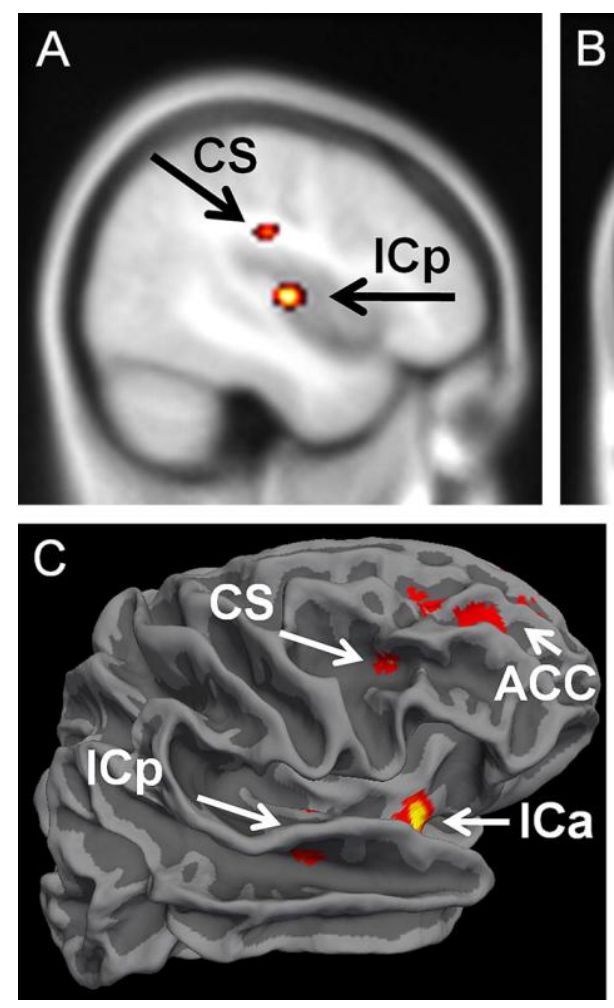

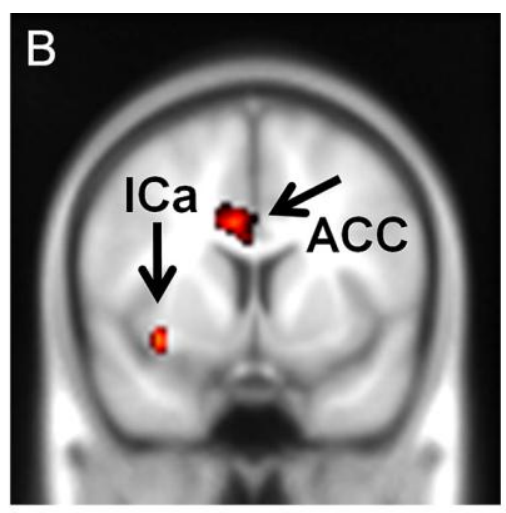

3.5

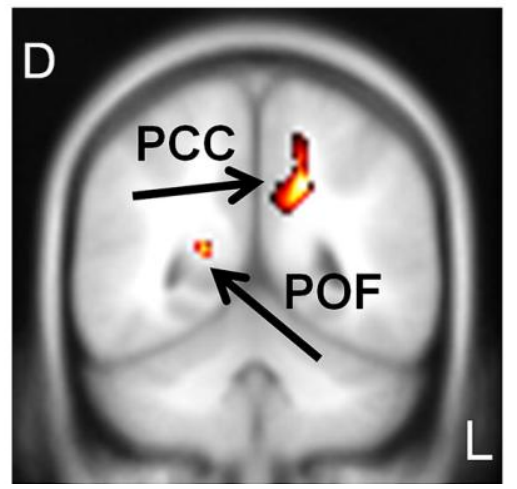

\subsubsection{Correlation analysis}

As the two rsfMRI sessions did not differ, FC values were averaged over the two sessions. Significant correlations $(p<0.05)$ were found between the abnormal FC values and DES, DISQ, SDQ and Raven scores (Table 3). We would like to highlight two correlations that were identified as related to dissociation, especially relevant from the perspective of PNES: precentral sulcus-anterior insula and precentral sulcusposterior insula. For example, the FC value of the precentral sulcus-posterior insula 
correlated significantly with the DES (Spearman's $\rho=0.56, p=0.007$; Figure 4). The FC value of the precentral sulcus-posterior insula connection also negatively correlated significantly with the Raven performance (Spearman's $\rho=-0.56, p=$ 0.005). A linear regression for this $\mathrm{FC}$ value as a dependent variable and DES and Raven test scores as independent variables yielded DES score as significant predictor $(\beta=0.066, p=0.046)$. Raven test score was not a significant predictor $(p=$ 0.37).

Table 3. Spearman's correlation coefficients (over all subjects) between FC values and scores on dissociation questionnaires and Raven's test. $F C=$ functional connectivity value (Fisher-Z transformed); $D E S=$ Dissociative Experiences Scale; DISQ = Dissociation Questionnaire; $S D Q=$ Somatic Dissociation Questionnaire; $P C C=$ posterior cingulate cortex; $A C C$ = anterior cingulate cortex; $P O=$ parieto-occipital. ${ }^{*}=$ Two-tailed $p$-value is statistically significant at the 0.05 level. ${ }^{* *}=$ Two-tailed $p$-value is statistically significant at the 0.01 level.

\begin{tabular}{l|llll} 
& DES & DISQ & SDQ & Raven \\
\hline FC Precentral sulcus - Anterior insula & $0.47^{*}$ & $0.51^{*}$ & 0.39 & $-0.48^{*}$ \\
FC Precentral sulcus - Posterior insula & $0.56^{* *}$ & $0.46^{*}$ & 0.42 & $-0.56^{*}$ \\
FC Supramarginal gyrus - Posterior insula & $0.45^{*}$ & $0.54^{* *}$ & $0.45^{*}$ & -0.38 \\
FC Intraparietal sulcus - Posterior insula & 0.34 & $0.45^{*}$ & 0.37 & -0.32 \\
FC Inferior frontal gyrus - Central sulcus & $0.54^{* *}$ & $0.46^{*}$ & 0.39 & -0.24 \\
FC Precentral sulcus - Central sulcus & $0.58^{* *}$ & 0.39 & 0.34 & -0.27 \\
FC Intraparietal sulcus - Central sulcus & $0.64^{* *}$ & $0.53^{*}$ & $0.43^{*}$ & -0.30 \\
FC Supramarginal gyrus - PCC & $0.46^{*}$ & 0.39 & 0.39 & $-0.50^{*}$ \\
FC Intraparietal sulcus - PCC & $0.59^{*}$ & $0.53^{*}$ & $0.50^{*}$ & $-0.54^{* *}$ \\
FC Inferior frontal gyrus - ACC & $0.43^{*}$ & 0.39 & 0.40 & -0.41 \\
FC Intraparietal sulcus - ACC & $0.54^{* *}$ & $0.43^{*}$ & $0.49 *$ & $-0.47^{*}$ \\
FC Inferior frontal gyrus - PO fissure & 0.40 & 0.39 & $0.46 *$ & $-0.57^{*}$ \\
FC Precentral sulcus - PO fissure & 0.38 & 0.20 & $0.55^{* *}$ & $-0.43^{*}$ \\
FC Supramarginal gyrus - PO fissure & $0.52^{*}$ & $0.46^{*}$ & $0.63 * *$ & $-0.48^{*}$ \\
FC Intraparietal sulcus - PO fissure & 0.37 & 0.28 & $0.44^{*}$ & $-0.55^{*}$ \\
& & & & \\
\hline
\end{tabular}


Figure 4. Scatter plot of distribution of the left precentral sulcus-right posterior insular FC values and DES scores in the whole population. Spearman's $\rho=0.56, p=0.007$. DES $=$ Dissociative Experiences Scale; $F C=$ functional connectivity value.

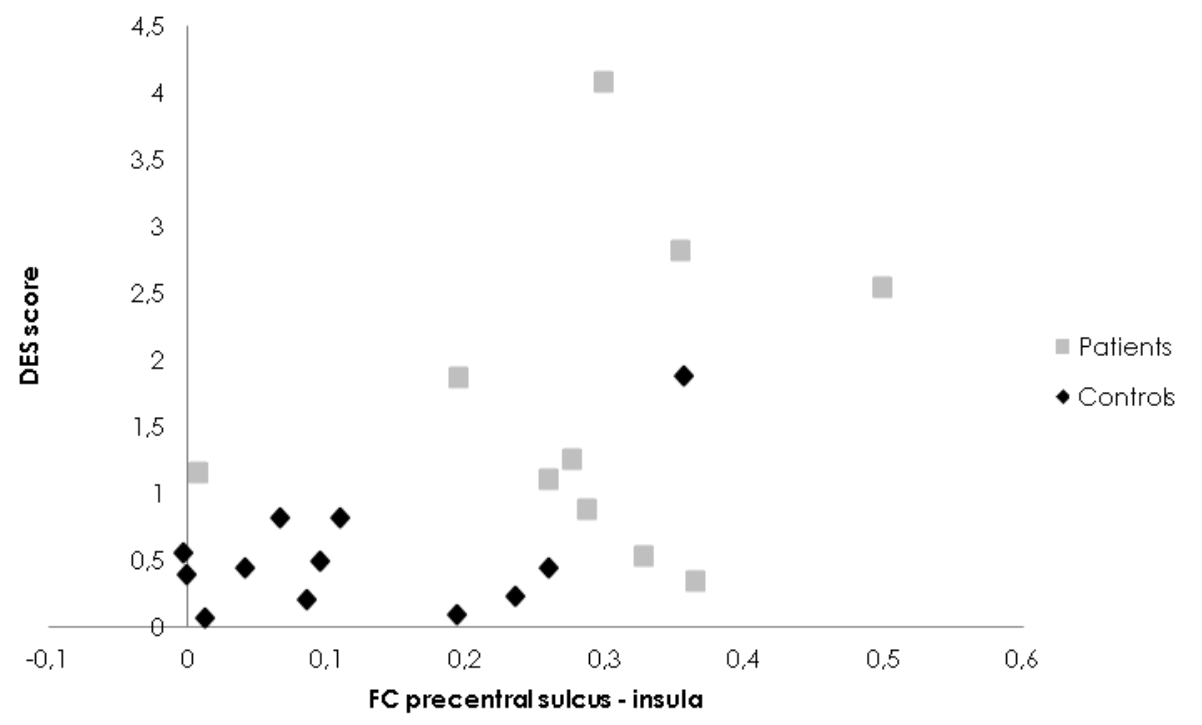

\subsection{Discussion}

In this study, we investigated resting-state networks in PNES patients and healthy controls to potentially reveal PNES-associated neurophysiology in terms of altered routes of information and emotion processing. First, a significantly higher dissociation tendency was observed in patients with PNES. Furthermore, an abnormal functional correlation was observed between the precentral sulcus, which resides in the motor cortex controlling voluntary muscle movement, and the insula, which is part of the limbic system and involved with emotion regulation, visceral sensory perception and self-awareness (Craig, 2009). Additionally, significantly stronger correlations were found between the parietal lobe, which is involved in processing of sensory information and subsequent action organization (Fogassi et al., 2005), and the insula. Moreover, a positive relationship between FC values and dissociation scores was found. 


\subsubsection{Dissociation and PNES}

Our results reconfirm that patients with PNES have in general a higher tendency for dissociation than healthy individuals. This is a general effect concerning both psychological and somatoform dissociation (Bowman and Markand, 1996; Kuyk et al., 1999; Fleisher et al., 2002).

\subsubsection{Dissociation and functional MRI}

The functional connections of the ACC are of interest as the ACC is an area that has been identified to be involved in dissociation and hypnosis (Lanius et al., 2006). The FC value of the IFG with ACC was significantly higher in the PNES group. Furthermore, the strength of this connection was significantly related to DES scores. This might have clinical relevance in PNES, as this connection has been associated with cognitive integration and dissociation (Egner et al., 2005).

Outside the domain of PNES, previous studies have related dissociation with fMRI outcomes. For example, Veltman et al. (2005) have demonstrated increased activation of the dorsolateral and ventrolateral prefrontal cortices, parietal cortex and supplementary motor area during working memory tasks in healthy, highdissociative participants. Similarly, Elzinga et al. (2007) reported increased activation in anterior, dorsolateral and ventrolateral prefrontal cortices and parietal cortex during a working memory task in patients with dissociative disorder. These results suggest that dissociation is associated with an altered working-memory network.

In contrast, the results of the current study do not reveal differences in activation maps of the encoding task (working memory), or in FC based on seeds relevant to memory (hippocampi), between healthy controls and highly dissociative PNES patients. Also, although the picture encoding task employed emotional stimuli, the activation was related to processes of working memory instead of suggestibility. However, we did find abnormalities in FC in highly dissociative patients with PNES based on seed regions obtained by the Stroop task. Previous studies in patients with PNES did indicate only a modest working memory deficiency (Strutt et al., 2011). We propose that the PNES pathology affects the neurobiology of executive control, which underlies dissociation, rather than the networks involved in memory processes. 


\subsubsection{Dissociation and cognition in PNES}

Subjects with lower performance on the Raven's test scored significantly higher on the dissociation scales, which is in accordance with previous literature (Gudjonsson, 1983). Dissociation might exert a perturbing action on individuals, which can negatively influence cognitive performance.

The FC values also correlated significantly with global cognitive functioning scores, as assessed using the Ravens' test. Previously, we showed in patients with chronic epilepsy that FC values, as assessed with fMRI, were strongly correlated with intelligence (i.e., performance on word fluency and text-reading tests). We hypothesized that a reduced performance was related to a reduced synchronization of activity in the brain (Vlooswijk et al., 2010). In the current study, we observed the opposite effect, namely, a negative correlation of FC values with global cognitive performance. However, a linear regression analysis showed that global cognitive performance (i.e., intelligence) was not a significant predictor for FC values, whereas dissociation was. This emphasizes that dissociation, and not intelligence, is a key mechanism underlying abnormal FC values as observed in patients with PNES (Figure 4).

\subsubsection{Conversion disorders and fMRI}

It has been suggested that PNES share a pathophysiological mechanism with conversion disorders (Devinsky et al., 2011; Baslet, 2011). An fMRI study in patients with motor conversion revealed that patients have a higher $\mathrm{FC}$ between the amygdala and the supplementary motor area during processing of positive and negative emotional stimuli (Voon et al., 2010b). It was suggested that this abnormal FC hints at a greater influence of limbic regions over motor preparatory regions (Baslet, 2011). Similarly, in dissociative amnesia, the relationship between memoryrelated areas and executive control areas may be affected (Kikuchi et al., 2010), which also hints at a 'faulty' connection between executive control and areas specifically affected by dissociation (Baslet, 2011).

As we found in PNES, higher FC values between regions involved in emotion and self-perception (insula) and motor preparation (precentral and the sulcus) between these two regions might underlie the pathophysiology for conversion disorders in general, including PNES. The existence of such an unstable cognitive- 
emotional-motor 'hyperlink' is further supported by the fact that PNES is often accompanied by many diffuse psychological, psychiatric and somatoform symptoms (Baslet, 2011; Landgrebe et al., 2008). In addition to the connection pair "insula-precentral sulcus", we also identified other combinations of seed regions and FC regions (originating in the frontal, parietal, and limbic cortices) with higher FC values for patients. The presence of higher $\mathrm{FC}$ in these regions strengthens the assumption that the whole network involved in sensory processing, executive control and emotion regulation in patients with PNES is abnormal. Figure 5 displays a schematic representation of the underlying dysfunctioning in this network in patients with PNES.

\subsubsection{Clinical implications}

Demonstration of a relationship between dissociation and deficient neuronal processing in PNES has substantial implications for the understanding of the etiology. Dissociation is one of the mechanisms through which an emotional state can influence executive control, resulting in a seizure-like episode (Baslet, 2011; Van der Kruijs et al., 2011) (Figure 5). Furthermore, the high FC identified in the current study has potential for the use of functional imaging to aid the differential diagnosis between PNES and epilepsy.

More knowledge of PNES etiology is necessary for the clinical management of PNES diagnosis and treatment (Devinsky et al., 2011). As such, a higher tendency to dissociate, associated with the hyperlink between regions involved in emotion (insula) and motor preparation (precentral sulcus), may be seen as an increased vulnerability to develop PNES. Moreover, identifying a neurobiological substrate of dissociation in PNES changes the concept of psychogenic seizures into being a biopsychological phenomenon, where a psychogenic etiology collides with a specific neurological vulnerability. This has implications for the development and evaluation of treatment, and may eventually improve the clinical management of PNES diagnosis. Moreover, it might aid the patient in accepting diagnosis of PNES. However, it is difficult to consider network abnormalities purely as a predisposition factor, as a diseased network connectivity could either be the cause or the consequence of dissociation and PNES. 
Figure 5. Schematic overview of the circuitry involved in cognitive-emotional executive control. In this study, we found significantly higher functional connectivity strengths between regions involved in emotion (insula) and motor planning (precentral sulcus) for patients with PNES. It appears that healthy controls can control their motor functions without strong influence of emotions, whereas in patients with PNES emotions can bypass executive control and cause involuntary movement.

Normal situation

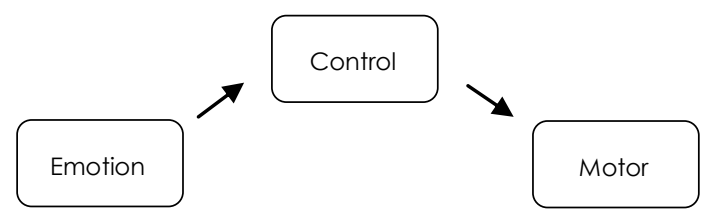

PNES

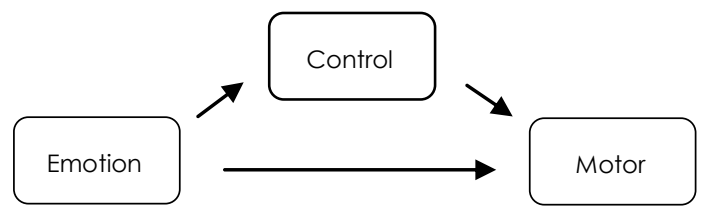

\subsubsection{Study limitations and future considerations}

This study had a limited number of patients. However, even in this small population, statistically significant deviations were demonstrated. These findings should be validated in larger studies, to be able to identify the direction of causality between abnormalities in FC and dissociation and PNES.

Another limitation is that the effect of PNES cannot be disentangled from the effect of dissociation. All of our patients had both PNES and a high dissociation score. To resolve this problem, future studies should include a control group of PNES patients who are not highly dissociative and/or a control group of healthy normal subjects with a high dissociation.

Furthermore, it is not known whether FC abnormalities are accompanied by microstructural (white matter) abnormalities.

\subsubsection{Conclusion}

The abnormal strong functional connectivity found in patients with PNES hints at an underlying psychoform and somatoform dissociation mechanism where emotion can influence executive control, resulting in altered motor function (e.g. seizure-like 
episodes). Future studies should clarify the exact contribution and interaction of the process of dissociation and network disturbances in PNES. 



\section{Chapter 6}

RESTING-STATE NETWORKS AND DISSOCIATION IN PSYCHOGENIC NON-EPILEPTIC SEIZURES

S.J.M. van der Kruijs, S.R. Jagannathan, N.M.G. Bodde, R.M.H. Besseling, R.H.C. Lazeron, K.E.J. Vonck, P.A.J.M. Boon, P.A.M. Hofman, W.H. Backes, A.P. Aldenkamp, J.F.A. Jansen. Journal of Psychiatric Research 2014, 54, 126-133.

\subsection{Abstract}

Psychogenic non-epileptic seizures (PNES) are epilepsy-like episodes which have an emotional rather than organic origin. Although PNES have often been related to the process of dissociation, the psychopathology is still poorly understood. To elucidate underlying mechanisms, the current study applied independent component analysis (ICA) on resting-state fMRI to investigate alterations within four relevant networks, associated with executive, fronto-parietal, sensorimotor, and default mode activation, and within a visual network to examine specificity of between-group differences.

Twenty-one patients with PNES without psychiatric or neurologic comorbidities and twenty-seven healthy controls underwent resting-state functional MR imaging at 3.0T (Philips Achieva). Additional neuropsychological testing included Raven's Matrices test and dissociation questionnaires. ICA with dual regression was used to identify resting-state networks in all participants, and spatial maps of the networks of interest were compared between patients and healthy controls.

Patients displayed higher dissociation scores, lower cognitive performance and increased contribution of the orbitofrontal, insular and subcallosal cortex in the fronto-parietal network; the cingulate and insular cortex in the executive control network; the cingulate gyrus, superior parietal lobe, pre- and postcentral gyri and supplemental motor cortex in the sensorimotor network; and the precuneus and (para-) cingulate gyri in the default-mode network. The connectivity strengths within these regions of interest significantly correlated with dissociation scores. No between-group differences were found within the visual network. 


\subsection{Introduction}

Psychogenic non-epileptic seizures (PNES) are seizures which are assumed to be caused by emotional, rather than organic factors (Bodde et al., 2009a). PNES account for as much as $20 \%$ of the definitive diagnoses among patients referred to tertiary epilepsy centers for untreatable epilepsy (Lesser, 1996). The commonly occurring initial misdiagnosis of PNES as epilepsy has serious consequences for the patients, as it results in unnecessary anticonvulsant treatment and delay of appropriate psychological therapy. In addition, erroneous treatment for intractable epilepsy is expensive, and as such, affects societal costs (Martin et al., 1998). Increased understanding and awareness of the pathological mechanism and predisposition factors are crucial to facilitate accurate diagnosis and treatment of PNES, preventing burden for both patient and economy.

Patients with PNES are often considered to experience a seizure during an episode of severe dissociation, i.e. an episode of altered conscious functioning caused by disrupted connections between thoughts, memories, feelings, and sense of identity (Stone et al., 2005; Bodde et al., 2009b). In addition, patients with PNES often demonstrate dissociative symptoms (Goldstein and Mellers, 2006), increased dissociation tendency (Alper et al., 1997; Bowman and Coons, 2000; Prueter et al., 2002) and high hypnotizability (Dienes et al., 2009), and have dissociative disorders in over $90 \%$ of the cases (Bowman and Markand, 1996), which strongly suggest that dissociation underlies the psychopathology of PNES. Accordingly, the DSM-IV-TR and ICD-10 classifications of PNES as conversion disorder and dissociative disorder, respectively, are still matter of debate (Brown et al., 2007).

The function of dissociation is probably to avoid confrontation with painful or unendurable emotions, which might explain why patients with PNES have difficulties in reporting emotional causes or circumstances of their symptoms (Mellers, 2005; Reuber et al., 2011). Therefore, more objective physiological measures may provide more information about the etiology of PNES and the underlying process of dissociation than psychological self-report instruments (Baslet, 2011). Neuroimaging methods such as functional MRI can be sensitive to detect changes in the processing of information and emotion by patients with pathological conditions, including dissociative conditions such as PNES (Veltman et al., 2005; Felmingham et al., 2008; Bagshaw and Cavanna, 2013; Van der Kruijs et al., 2014a). 
In specific, functional connectivity analyses are useful to examine alterations in interaction between brain regions. In our previous fMRI study we adopted functional connectivity analyses in order to examine altered information processes in a pilot population of patients with PNES (Van der Kruijs et al., 2012). However, in that study we focused on pre-defined regions of interest and therefore needed a priori assumptions. In order to investigate whole-brain networks in patients with PNES, and without making a priori assumptions, the current study examines functional MRI of brain networks that are activated during resting state using a robust data-driven approach, independent component analysis (ICA) (Beckmann et al., 2005; Calhoun et al., 2009). ICA is employed in this study to decompose resting-state fMRI data of patients with PNES and matched healthy controls into a set of statistically maximally independent functional networks. The resting-state networks that are identified are compared with a highly robust set of resting-state networks described by Smith et al. (2009). Smith et al. demonstrated that brain regions that are functionally related also interact during "rest", and identified ten resting-state networks associated with specific functions. We focused on four networks which are of specific relevance with regard to the trait of dissociation. The resting-state network associated with executive control covers several medial-frontal areas, including the anterior cingulate and paracingulate cortex, and is regarded relevant for its function in action-inhibition, emotion, and perception-somesthesis-pain. The fronto-parietal network covers insular regions and is as such also associated with perceptionsomesthesis-pain. The sensorimotor network includes the supplementary motor area, sensorimotor cortex, and secondary somatosensory cortex, and is involved with action-execution and perception-somesthesis. The default mode network, known from task-fMRI to be typically active during rest, covers the precuneal, posterior cingulate and ventromedial frontal cortex, and is selected for its possible function in self-reflection and self-awareness (Gusnard et al., 2001 \& Schneider et al., 2008). To examine the specificity of changes identified in these networks, we also include a resting-state network which is unlikely to be affected by PNES, namely the visual network which covers the visual areas in the occipital lobe. 


\subsubsection{Aims of the study}

Our first aim is to examine alterations in resting-state networks that may underlie PNES psychopathology, comparing adult patients with PNES with matched healthy control subjects. The second goal of the study is to investigate the association of altered resting-state connectivity with indices of dissociation.

\subsection{Materials and methods}

\subsubsection{Participants}

The inclusion of the study population was according to the same criteria as have been described in a previous paper (Van der Kruijs et al., 2012), in which we report on seed-based functional connectivity analyses on a subset 11 patients with PNES and 12 healthy controls) of the current study population. In short, patients were recruited from the outpatient epilepsy clinic of the tertiary referral centre Kempenhaeghe. Patients with a confirmed diagnosis of PNES were screened by their treatment team (consisting of clinical psychologist and neurologist) before study inclusion, which occurred on the absence of psychiatric comorbidity (e.g. mood and anxiety disorders, schizophrenia and psychosis, and cluster B personality disorders), determined through extensive psychological assessment and examination of anamnestic information, which was provided by the patients themselves and often also by family members. Individuals with neurological comorbidities (e.g. epilepsy) and malingering patients were not included. At moment of inclusion and during investigation, none of the patients used antiepileptic medication. Healthy controls were recruited by advertisement. All participants gave written informed consent to participate in the investigation, which received ethical approval by the Medical Ethical Committee of Maastricht University (ref. 10-3-045) and was carried out in accordance with the $7^{\text {th }}$ revision of the Declaration of Helsinki.

\subsubsection{Questionnaires and neuropsychological investigation}

All participants completed the Raven's Progressive Matrices Test (Raven, 1998, updated 2003), which indicates global cognitive performance. We obtained completed dissociation scales (Dissociation Questionnaire (DIS-Q), Dissociative 
Experiences Scale (DES), and the Somatoform Dissociation Questionnaire (SDQ-20) (Sno, 2004)) from 20 patients with PNES and 27 healthy controls, as one patient did not complete the questionnaires. All questionnaires are often used to examine dissociation tendencies of patients with PNES (Kuyk et al., 1999; Reuber et al., 2003; Ito et al., 2009).

\subsubsection{MRI acquisition}

MRI imaging was performed at the epilepsy centre Kempenhaeghe using a 3.0-Tesla unit equipped with a 8-channel head coil (Philips Achieva, Philips Medical Systems, Best, The Netherlands). The scan protocol for structural MRI consisted of a T1weighted 3D turbo field echo with the following parameters: Repetition time (TR) 8.2 ms, echo time (TE) 3.7 ms, inversion time (TI) $1022 \mathrm{~ms}$, flip angle $8^{\circ}$, matrix 240x240,

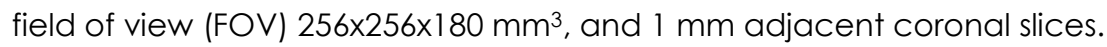

Functional MRI data were acquired using a whole-brain single-shot multi-slice blood oxygen level-dependent (BOLD) echo-planar imaging (EPI) sequence with the following parameters: TR $2 \mathrm{~s}$, TE $35 \mathrm{~ms}$, flip angle $90^{\circ}$, voxel size $2 \times 2 \times 4 \mathrm{~mm}^{3}$, matrix 128x128, 32 contiguous slices per volume, 195 volumes per acquisition. During the resting state $\mathrm{fMRI}$ session, the subjects were instructed to think of nothing in particular. A total of 2 resting-state fMRI sessions was performed per participant, with an interval of 15 minutes (Van der Kruijs et al., 2012).

\subsubsection{Imaging analysis}

Resting state fMRI analysis was performed using Multivariate Exploratory Linear Optimized Decomposition into Independent Components (MELODIC; FMRIB's Software Library, http://fsl.fmrib.ox.ac.uk/fsl). Individual preprocessing comprised motion correction performed using FMRIB's Linear Image Registration Tool (MCFLIRT), brain extraction, spatial smoothing with a Gaussian kernel of full-width-at-halfmaximum (FWHM) of $5 \mathrm{~mm}$, high-pass temporal filtering at $100 \mathrm{~s}(0.01 \mathrm{~Hz})$, intensity normalization, and affine registration to the Montreal Neurological Institute 152 standard space standard template. The preprocessing also consisted of removal of the first $6 \mathrm{~s}$ ( 3 volumes) from each time series to ensure magnetization equilibrium. The absolute head motion (mean) was below $1.9 \mathrm{~mm}$ for all subjects across both the sessions, and not significantly different between patients and controls. As a result, 
the preprocessed functional data contained 192 time-points for each subject per session. The preprocessed data were temporally concatenated across subjects and sessions to create a single 4D data set. This way, the data points of both resting-state fMRI sessions were taken into consideration for computing the independent components. This single 4D data set was then decomposed into spatio-temporal components that represent large-scale patterns of co-activating voxels that are consistent over subjects, taking into consideration the statistically independent sources of variation in the fMRI signal (Beckmann et al., 2005). MELODIC's probabilistic group ICA was used and identified 33 independent components using automatic model-order estimation. From these, we objectively identified the 5 components (Figure 1) based on spatial cross-correlation with a minimum Spearman's correlation of $0.32(p<0.05)$ corresponding to the maps of the restingstate networks associated with executive functioning, fronto-parietal activation, sensorimotor functioning, default mode activation and visual functioning (Smith et al., 2009) using templates from http://fsl.fmrib.ox.ac.uk/analysis/brainmap+rsns/, and overlap was also confirmed by visual inspection.

Figure 1. The five networks which cross-correlated well with the primary functional networks identified by Smith et al. (2009) for default mode (a), sensorimotor (b), executive (c), fronto-parietal (d), and visual functioning (e). Coordinates ( $x$ y z) refer to MNI space.
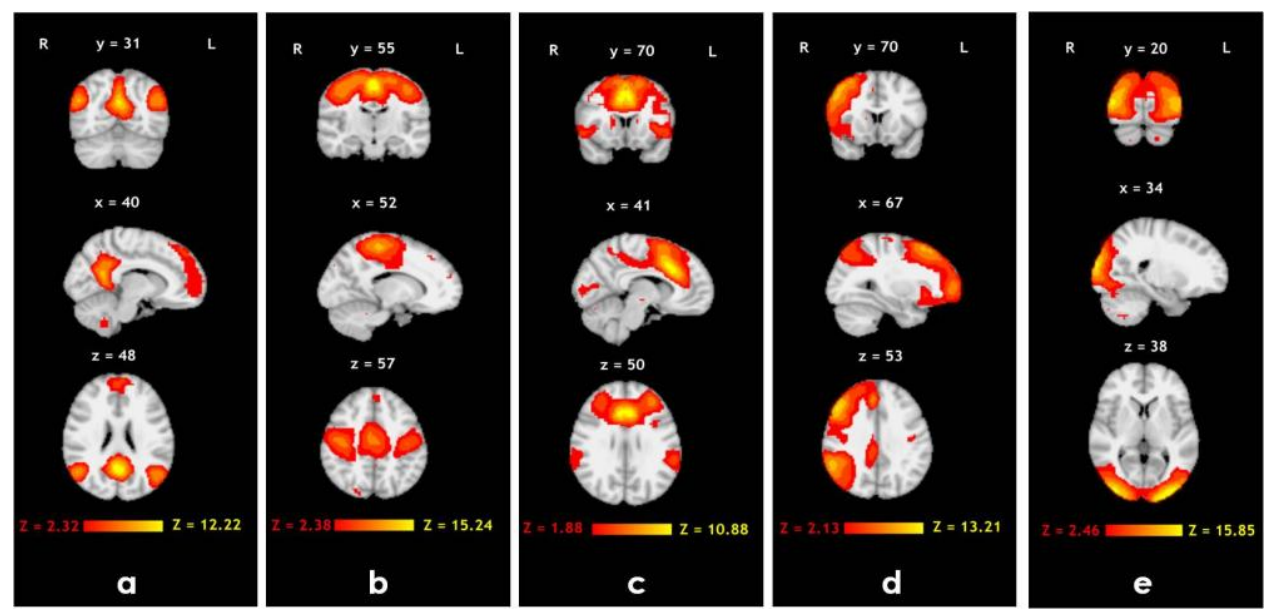
Subsequently, the pooled functional networks (i.e. controls and patients) were mapped to the subject level using the dual regression approach (Filippini et al., 2009). The motivation to perform a pooled analysis of both controls and patients is i) to increase reliability by using a larger subject sample, and ii), since the major ICA components, as indexed by Smith et al. (2009), can be identified in a very robust manner over a large heterogeneous sample of subjects, it is reasonable to assume that these major networks are also present in controls and patients.

Firstly, the full set of group-ICA spatial maps was used in a linear model fit (spatial regression) against the separate fMRI data sets, this creates matrices describing temporal dynamics for each component and subject. Secondly, these time course matrices were used in a linear model fit (temporal regression) against the corresponding fMRI data set to estimate individual subject spatial maps. Thirdly, the different independent component maps were concatenated across subjects into single 4D files (one per original ICA map, with the fourth dimension corresponding to subject identification).

Next, the maps were tested voxel-wise for statistically significant differences between the patient and control group using nonparametric permutation testing (5000 permutations) using FSL's randomize tool. This yielded spatial maps characterizing the group differences. Lastly, these spatial maps were thresholded based on an alternative hypothesis test by fitting a Gaussian/gamma mixture model to the distribution of voxel intensities within spatial maps and controlling the local false discovery rate at $\mathrm{p}<0.05$ to yield multiple-comparisons corrected group difference maps (Beckmann et al., 2005).

The temporal weight of an independent component in a particular voxel is ideally the correspondence of a voxel's time-course to the time signature of the resting-state network under investigation, and can be interpreted as a measure of functional connectivity with the component under investigation. In order to reveal a potential relationship between the weight of the independent components that differ significantly across patients and controls and known clinical (psychological) parameters, the following procedure was carried out. ROls were drawn on the independent component maps in the networks where significant differences in the functional connectivity between the patients and controls were found (i.e. the aforementioned spatial maps). The weight of the independent components in both the sessions was averaged across these ROIs to produce mean connectivity values 
for each patient and control, which could then be correlated with clinical parameters.

\subsubsection{Statistical analysis}

Statistical data analysis was performed in SPSS (PASW Statistics 18.0, Chicago: SPSS Inc.). Descriptive statistics of clinical and neuropsychological variables were obtained, and Mann-Whitney U-tests were performed to examine differences between patients with PNES and controls. Additionally, correlation coefficients between regional variations in functional connectivity with neuropsychological scores were obtained using the non-parametric Spearman rank correlation test. $\mathrm{P}<$ 0.05 was considered statistically significant.

\subsection{Results}

\subsubsection{Clinical and neuropsychological assessment}

Twenty-eight patients with PNES and 30 healthy volunteers were enrolled in the study. All structural MRI scans were interpreted for incidental findings by an experienced neuroradiologist. Ten participants had to be excluded from the MRI analyses: Four patients with PNES did not complete the study, two patients showed large cysts on MRI, one patient had parahippocampal gliosis, and three healthy controls demonstrated callosal white matter abnormalities, unclear contouring of the ventricles, and periventricular heterotopia on MRI. The other subjects did not have clinical significant MRI abnormalities. The final analysis included 27 healthy volunteers (21 females, 6 males, age $36 \pm 12$ y) and 21 patients with PNES (13 females, 8 males, age $34 \pm 12 \mathrm{y}$, number of seizures in previous month $12.3 \pm 34.1$, disease duration $5.7 \pm 6.7 \mathrm{y}$ ). Gender and age were not statistically different between both groups ( $p>0.25$ ). According to the classifications of Abubakr et al. (2003), PNES were classified as episodes of major motor symptoms (during which patients are often unresponsive) in 7 patients, as episodes of unresponsiveness without major motor symptoms in 12 patients, and as the two types of PNES episodes combined in 2 patients. The patients demonstrated significantly higher dissociation tendency on all dissociation questionnaires; the DES (1.7 \pm 1.27 vs $0.6 \pm 0.58$ [ctrl], $p<$ $0.001)$, DISQ (1.6 \pm 0.38 vs $1.4 \pm 0.22, p=0.007)$, and SDQ-20 (28.0 \pm 6.80 vs $21.5 \pm 4.74$, 
$\mathrm{p}<0.001$ ), and significantly lower performance on the Raven's Progressive Matrices test (Raven nr correct: $46 \pm 7$ vs $51 \pm 5, p=0.017$ ), as assessed with Mann-Whitney $U$ tests.

All patients with PNES had a scheduled consult with their psychotherapist directly after the scanning session, to evaluate whether the patients experienced tension, anxiety or recall of memories during the procedure, and to examine whether dissociative phenomena took place. Also, all patients were instructed to use the alarm button in case of aversive feelings. However, none of the patients used the alarm button or reported negative experiences after the scanning session. There were also no indications of pathological dissociative experiences during the scanning sessions. However, since we have no systematic data on what the patients experienced in the scanner, we cannot be certain that minor dissociation or anxiety did not occur.

\subsubsection{Imaging analysis}

Pooled probabilistic group ICA identified 33 components. Of these, we selected 5 components for further analysis based on neuroanatomical correspondence with the consistently identified resting-state networks described in the literature (Smith ef al., 2009). Based on the regions involved, these networks have been associated with fronto-parietal activation, executive control, sensorimotor functioning, default-mode activation and visual functioning.

Compared to healthy controls, patients with PNES showed increased coactivation of the orbitofrontal, insular and subcallosal cortex in the resting-state network associated with fronto-parietal activation; the cingulate and insular cortex in the resting-state network associated with executive control; the cingulate gyrus, superior parietal lobe, pre- and postcentral gyri and supplemental motor cortex in the resting-state network associated with sensorimotor functioning; and the precuneus and (para-) cingulate gyri in the default-mode network. On the other hand, patients with PNES showed relatively decreased coactivation of the orbitofrontal cortex in the resting-state network associated with executive control, and of the precuneus in the resting-state network associated with sensorimotor functioning (Figure 2). There were no significant differences between patients and controls in the resting-state network associated with visual functioning. 
Figure 2. Regions of increased network contribution in patients within the networks for default mode (a), sensorimotor (b), executive (c), and fronto-parietal (d), and regions of decreased network contribution in patients within the sensorimotor network (e). In order to aid visualization, a stronger p-value has been selected in Figure 2c.
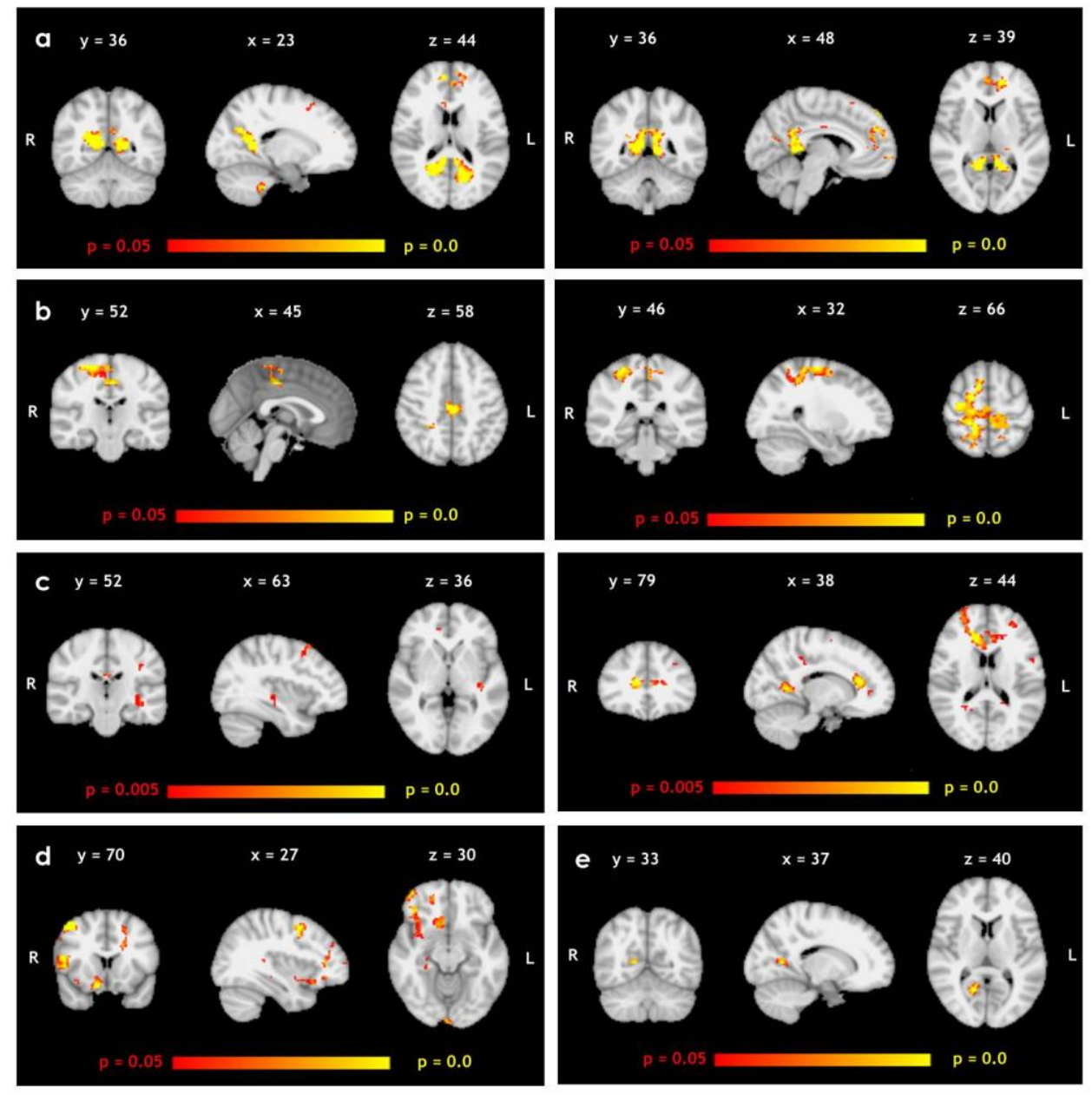

\subsubsection{Correlation analyses}

The connectivity values within the areas of significant between-group differences were all significantly correlated with all dissociation scales within both groups (patients and controls) combined (Table 1). Within the healthy control group, significant correlations were found between connectivity strengths within the executive control network and DES scores $(\rho=0.43, p=0.024)$, and connectivity 
strengths within the sensorimotor network and DISQ scores $(\rho=0.45, p=0.020)$ and SDQ scores $(\rho=0.55, p=0.003)$. Other correlations within both groups separately showed similar trends with regards to the combined group regarding direction of correlation, but did not yield statistical significance ( $p>0.080)$.

Correlations were positive between dissociation scores and functional connectivity values within areas where patients showed higher connectivity than controls, and negative between dissociation scores and connectivity values within areas where patients showed lower connectivity. Figure 3 illustrates these findings by showing the relationship between connectivity values within the executive functioning network and scores on the Dissociative Experiences Scale. Correlations with results on the Raven's Matrices test were only significant for the connectivity values within the default mode network and the sensorimotor network, in opposite directions as found with dissociation scores. No significant correlations between disease duration and connectivity strengths were found ( $p>0.174)$.

Table 1. Spearman's correlation coefficients between functional connectivity values in aberrant regions (ROIs), dissociation scores, and scores on Raven's Progressive Matrices Test. ${ }^{*}=p<0.050$ and ${ }^{* *}=p<0.010$. Correlations coefficients are shown for regions in which patients with PNES showed relatively increased (Patients > Controls) and decreased (Controls > Patients) network contribution.

Patients > Controls

Fronto-parietal network Default mode network Sensorimotor network Executive control Visual network

Controls > Patients Sensorimotor network

$\begin{array}{cccc}0.40^{* *} & 0.34^{*} & 0.58^{* *} & -0.18 \\ 0.38^{* *} & 0.35^{*} & 0.56^{* *} & -0.38^{* *} \\ 0.41^{* *} & 0.38^{* *} & 0.47^{* *} & -0.10 \\ 0.54^{* *} & 0.39^{* *} & 0.47^{* *} & -0.19 \\ \mathrm{~N} / \mathrm{A} & \mathrm{N} / \mathrm{A} & \mathrm{N} / \mathrm{A} & \mathrm{N} / \mathrm{A} \\ & & & \\ & & & \\ & & & \\ -0.39^{* *} & -0.29^{*} & -0.43^{* *} & \\ & & & \end{array}$


Figure 3. Scatter plot of functional connectivity values in the aberrant regions of the executive functioning network and DES scores in the whole population ( $r=0.54, p<0.001)$.

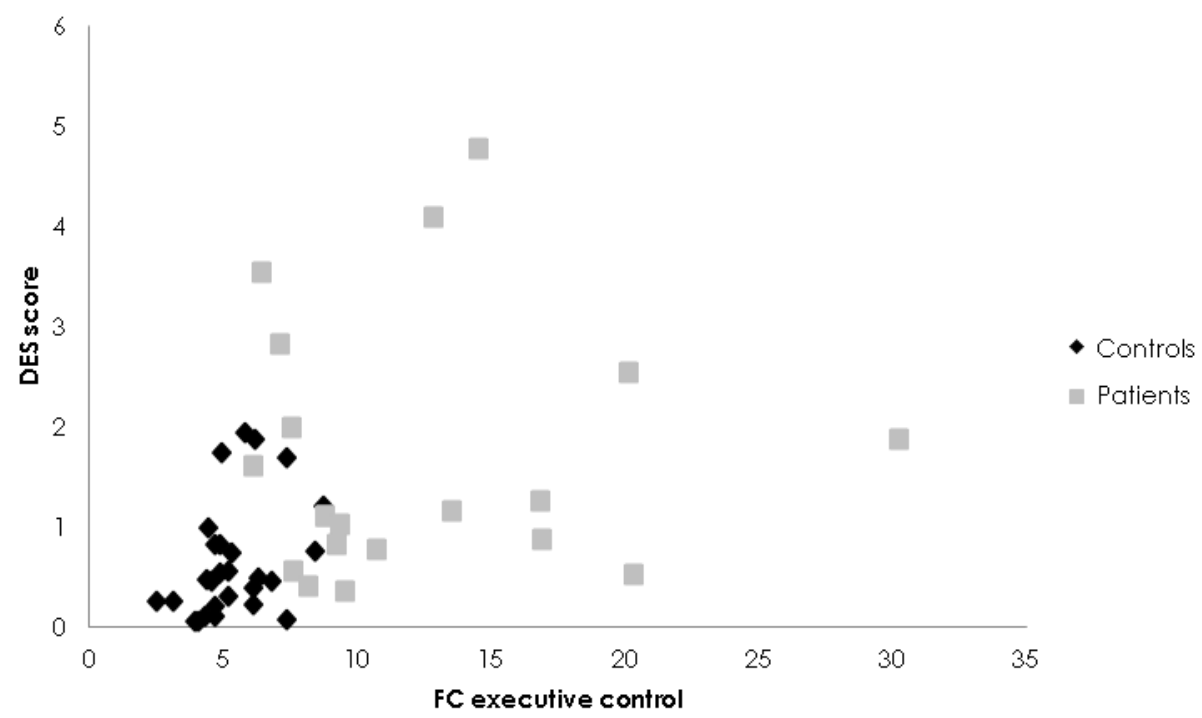

\subsection{Discussion}

\subsubsection{Main findings}

Using a data-driven approach, we have shown that patients with PNES have an increased coactivation of several regions in the resting-state networks associated with fronto-parietal activation, executive control, sensorimotor functioning, and the default mode. Decreases in network contribution were identified within the networks associated with executive control and sensorimotor functioning. The connectivity values within the regions of interest were significantly correlated with dissociation scores. No differences were found for the control resting state network associated with visual functioning, which confirms that visual behavior is most likely not affected by PNES or dissociation. 


\subsubsection{Resting-state networks and dissociation in PNES}

The alterations identified in the resting-state networks could all contribute to the process of dissociation in patients with PNES in a distinctive way (see Figure 4 for a schematic overview). The fronto-parietal network corresponds strongly to perception, somesthesis, and pain (Smith et al., 2009); alterations in this network may be associated with the observation that self-generated movements are not voluntary. In particular altered connectivity of the insula, as was found within this network, has been related to impairments in conscious error perception (Klein et al., 2013). Impaired error awareness may prevent patients with PNES to recognize incorrect (dissociative) behavior and to adjust future behavior, as has been suggested in other psychiatric conditions, e.g. schizophrenia (Mathalon et al., 2002), autism spectrum disorder (Vlamings et al., 2008; Sokhadze et al., 2010) and ADHD (Schachar et al., 2004; Wiersema et al., 2009).

Similar conclusions can be drawn from the abnormalities located in the sensorimotor network, the primary functions of which, next to motor preparation, also are perception, somesthesis, and pain. The abnormalities associated with PNES found in this network, especially within the cingulate gyrus, might be related to altered (motor) response selection (Devinsky et al., 1995).

The network for executive control also covers perception-somesthesis-pain, as well as action-inhibition and emotion; alterations in this network might contribute to the manifestation of emotional triggers as motor symptoms. As both the insular and cingulate cortex show abnormal functional connectivity in this network, this behaviour might be explained from impaired action selection and/or decreased response-inhibition (Devinsky et al., 1995; Klein et al., 2013).

The default-mode network has been linked to self-referential or introspectively oriented mental activity (Gusnard et al., 2001 \& Schneider et al., 2008). It has also been related to the sense that one controls one's own actions and self-reflection processes, which is important for motor intentions and subsequent action monitoring (Tsakiris et al., 2010; Cavanna and Trimble, 2006; Cavanna, 2007). These findings suggest that abnormalities in the default mode network in patients with PNES could reflect abnormal coping styles (e.g. dissociation) and lack of motor control. Furthermore, studies employing neuroimaging techniques indicate the default mode network to play a central role in sustaining consciousness (Demertzi et al., 2013). This 
network may be important for the specific alterations of consciousness, in addition to dissociative experiences, that have been identified in patients with PNES (Ali et al., 2010).

Previous research also suggests altered connectivity of the precuneus within the default mode network to be of influence in maintaining hypnosis (Pyka et al., 2011). Since hypnosis is an altered state of consciousness in the same spectrum as dissociation, these findings might explain the increased coactivation of the precuneus found in patients with PNES.

Besides significant correlations between functional connectivity and dissociation scales, we also identified an association between global cognitive functioning as assessed with the Raven's Progressive Matrices Test and functional connectivity values within the sensorimotor and default mode networks. However, only one of them was significant at the $\mathrm{p}<0.01$ level, whereas most other networks showed no significant correlation, suggesting that the aberrations in resting-state networks of patients with PNES are likely to be caused by other factors than intelligence. However, other factors besides dissociation, e.g. anxiety, may also contribute to the observed network alterations.

The results of this study are consistent with previous findings in a pilot study which was based on a priori assumptions, in which we identified higher functional connectivity values between regions in the frontal, parietal, and limbic cortices in patients with PNES, e.g. between the insula and the precentral sulcus (involved in motor preparation) (Van der Kruijs et al., 2012). Due to the data-driven approach in the current study, the search window of potential abnormal brain regions was increased to include the whole brain. As the current study located abnormal network function in regions beyond the abnormal regions found in the pilot study (e.g. the precuneus), the current study provides a more complete picture of the implications of PNES and dissociation on brain function. Our findings are also coherent with alterations in functional connectivity that have been identified in other populations with functional symptoms: between the motor cortex and posterior cingulate cortex, precuneus and ventromedial prefrontal cortex in conversion paralysis (Cojan et al., 2009), between the supplementary motor cortex and the amygdala in conversion disorder (Voon et al., 2010), between the prefrontal and sensorimotor cortices in conversion paralysis (De Lange et al., 2010), between supplementary motor and dorsolateral prefrontal cortices in conversion 
disorder (Voon et al., 2011). Also, altered topological properties of whole-brain networks as increased clustering coefficient, but also increased path length and decreased connection strength have been reported in PNES (Ding et al., 2013). These findings suggest that brain networks in patients with PNES lack optimal information-integration abilities, which is possibly reflected in the abnormal coping style of these patients.

Figure 4. Schematic representation of the investigated resting-state networks and their potential contributions to the occurrence of PNES.

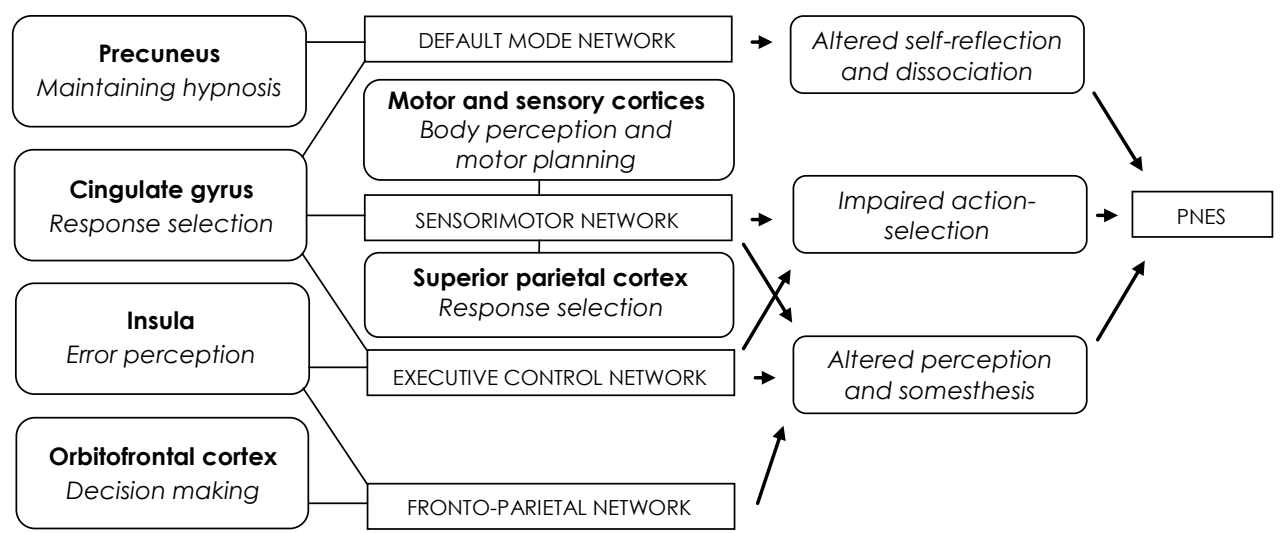

\subsubsection{Limitations and future considerations}

One drawback of our study was that significant correlations between connectivity strengths and dissociation scores were obtained within both groups (patients and healthy controls) combined. There is a risk that these correlations are explicable by group differences in connectivity strengths and dissociation scores (Kriegeskorte et al., 2009). However, all within-group correlation analyses displayed similar, though not always significant outcomes, which is indicative of the robustness of the findings. The lack of statistical significance is possibly due to the relatively small group sizes.

Another difficulty was the inability to disentangle the effects of PNES and dissociation, because most included patients had both PNES and high dissociation scores, and not enough healthy controls demonstrated high dissociation scores to be able to split groups based on dissociation scores. Future studies should focus on 
dissociation scores at moment of inclusion, although ethical considerations may complicate the handling of such criteria. Moreover, the causal direction of the relationship between dissociation and brain network alterations is not known. In addition, the dissociation scales which are currently available and which were used in this study only measure dissociation as a trait, not as a state. Future studies could focus on patients who do not show increased dissociation tendencies, but who may dissociate during PNES episodes.

Furthermore, the current study, though preliminary in nature, yields promising steps towards an objective diagnosis of PNES using functional MRI. However, at present, the technique should only be used to supply complementary information for the current clinical practice, in which video-electroencephalography procedures are considered the gold standard for differential diagnosis between epilepsy and PNES (Eddy and Cavanna, 2014). Future longitudinal studies are warranted to investigate these issues.

Future studies are also needed to investigate whether a structural substrate for the resting network abnormalities can be found. Diffusion tensor imaging (DTI) and voxel-based morphometry are examples of techniques which could be useful to examine the microstructural integrity of the brain. Additionally, molecular and/or "imaging genetics" studies might yield more insight into the underling molecular mechanism of the observed differences in resting-state functionality.

\subsubsection{Conclusion}

Abnormalities in resting-state networks associated with fronto-parietal activation, executive control, sensorimotor functioning, and default-mode activation have been identified in patients with PNES. Significant correlations suggest the network alterations to be related to the process of dissociation. The changes in resting-state networks could contribute to the underlying dissociation mechanism in various ways. 


\section{Chapter 7}

AUTONOMIC NERVOUS SYSTEM FUNCTIONING ASSOCIATED WITH PSYCHOGENIC NON-EPILEPTIC SEIZURES: ANALYSIS OF HEART RATE VARIABILITY

S.J.M. van der Kruijs, K.E.J. Vonck, G.R. Langereis, L.M.G. Feijs, N.M.G. Bodde, R.H.C. Lazeron, E. Carrette, P.A.J.M. Boon, W.H. Backes, J.F.A. Jansen, A.P. Aldenkamp, P.J.M. Cluitmans. Submitted for publication.

\subsection{Abstract}

Psychogenic non-epileptic seizures (PNES) resemble epileptic seizures but originate from psychogenic rather than organic causes. Patients with PNES are often unable or unwilling to reflect on underlying emotions. For gaining more insight in the internal states of patients during PNES episodes, this study explored the time course of heart rate variability (HRV) measures, which provide information about autonomic nervous system functioning and arousal.

HRV measures were extracted from electrocardiography data collected during video-electroencephalography monitoring of 20 patients with PNES, in whom a total number of 118 PNES was recorded. Heart rate (HR) and HRV measures in time and frequency domains (standard deviation of average beat-to-beat intervals (SDANN), root mean square of successive differences (RMSSD), high frequency (HF) power, low frequency (LF) power and very low frequency (VLF) power) were averaged over consecutive five-minute intervals. Additionally, quantitative analyses of Poincaré plot parameters (SD1, SD2 and SD1/SD2 ratio) were performed.

In the five-minute interval before PNES, HR significantly increased whereas SDANN and VLF power significantly decreased. During PNES, significant increases in HF power, SD1 and SD2 were observed. In the five minute interval immediately following PNES, SDANN and VLF power significantly increased and HR and SDI/SD2 ratio decreased, compared to the interval preceding PNES.

The results suggest PNES to be preceded by increased sympathetic functioning, followed by an increase in parasympathetic functioning after PNES. Future research needs to identify the exact nature of the increased arousal that precedes PNES. 


\subsection{Introduction}

Psychogenic non-epileptic seizures (PNES) are episodes of movement, behavior or sensations that resemble epileptic seizures, but are not accompanied by epileptiform brain activity on electroencephalogram (EEG). The underlying cause is assumed to be of psychogenic origin. The current diagnostic manuals (DSM-IV-TR, ICD-10) classify PNES as dissociative or conversion symptoms. Hence, PNES are considered as involuntary somatic manifestations of emotional distress (Bodde et al., 2009a; Reuber, 2009). However, patients often fail to report the feelings (e.g. stress, anxiety) that are associated with an episode as well as possible stressors. Nevertheless, some patients describe a "warning" uncomfortable feeling that can last up to hours, followed by a relief from this feeling by the PNES (Stone and Carson, 2013).

Investigation of more objective physiological parameters that reflect arousal, which possibly reflects (negative) emotional well-being, could elucidate the circumstances of the episodes, which would facilitate diagnosis and treatment in patients with PNES (Van der Kruijs et al., 2014a). In specific, measures of heart rate variability (HRV) have often been applied in behavioral science and medicine. Changes in HRV measures reflect changes in (co-)activation of the sympathetic and parasympathetic branches of the autonomic nervous system (Malik et al., 1996). Stress and anxiety - which elicit the sympathetic branch of the autonomic nervous system to initiate a fight or flight response - counteract the parasympathetic (vagal) branch, that is considered important for reacting appropriately to external stressors (Ogden et al., 2006; Thayer et al., 2009). Patients with PNES are expected to demonstrate decreased vagal functioning, as is found in patients with posttraumatic stress disorder (Shah et al., 2013), major depression (Berger et al., 2012), panic disorder (Diveky et al., 2012), and schizophrenia (Chang et al., 2009). Indeed, between-group analyses of patients with PNES and healthy controls indicate a reduced resting vagal tone in patients with PNES (Bakvis et al., 2009; Ponnusamy et al., 2011; Ponnusamy et al., 2012). In addition, vagal tone is demonstrated to decrease during PNES episodes compared to rest (Ponnusamy et al., 2012).

Ictal changes in HRV have been described in some detail by Ponnusamy et al. (2012), who compared two 3-minute ECG samples, one ictal ECG interval and one interictal ECG interval that was chosen regardless of its occurrence in time in relation 
to the seizure, in order to elucidate differences in autonomic functioning between patients with epilepsy and patients with PNES. They identified decreased vagal tone during PNES episodes, but an even larger decrease of vagal tone during epileptic attacks. However, based on their study design, no conclusions can be drawn about the peri-ictal pattern of autonomic nervous system functioning that accompanies a PNES episode. Examination over consecutive recording periods may provide more information about gradual changes in measures of HRV. The current study used a within-subject design to investigate the relationship between gradual changes in HRV and the occurrence of PNES.

\subsection{Materials and methods}

\subsubsection{Study population}

The study population consisted of twenty patients $(2 \mathrm{M} / 18 \mathrm{~F})$ with a confirmed diagnosis of PNES. All patients who had been previously monitored with video-EEG for 1-7 consecutive days between July 2010 and February 2012 in the Reference Centre for Refractory Epilepsy of Ghent University Hospital in Belgium for differential diagnosis of PNES and epilepsy were considered for inclusion. The diagnosis of PNES was based on the analysis of at least two episodes captured on video-EEG by two epileptologists with extensive experience in this field (KEV and PAB, > 10 years experience). Patients with dual pathology (epilepsy and PNES), were also included when epileptic seizures were controlled and when the PNES were confirmed by video-EEG monitoring. Exclusion criteria were uncertainty about the diagnosis of PNES and comorbid psychiatric disorders (e.g. mood and anxiety disorders, schizophrenia and psychosis, and substance-related disorders). The investigation received ethical approval by the Medical Ethical Committee of Ghent University.

\subsubsection{Electrocardiogram recordings}

The ECG was recorded via precordial electrode positions V1-V4 throughout the video-EEG monitoring period (1-7 days) with a two-lead channel of the Micromed EEG system (Micromed S.p.A., Mogliano Veneto, Treviso, Italy). For the monitoring period, patients were in supine position in bed or on a chair during the day, and lying down in bed during the night. The start and end of a PNES were defined by the 
associated motor symptoms (verified by the video recordings), which were often accompanied by unresponsiveness.

\subsubsection{Heart rate variability analysis}

HRV measures were derived according to the recommendations of the task force of the European Society of Cardiology and the North American Society of Pacing and Electrophysiology (Malik et al., 1996). ECG data were exported from the Micromed reporting system and imported in Matlab (Mathworks Inc., Natick, MA, USA). Custom-built Matlab scripts were used to subsequently carry out R-peak detection, model-based validation and - if necessary - correction of the list of subsequent RR intervals (tachogram) and HRV parameter calculation.

Two time-domain measures of HRV were calculated: SDANN (standard deviation of the average beat-to-beat intervals) and RMSSD (square root of the mean squared difference of successive beat-to-beat intervals). SDANN in general reflects the overall cyclic nature of HRV (the more sinusoidal the tachogram is, the higher SDANN), and is considered to be a measure for overall variability. RMSSD is considered to be a measure for vagal control of heart rate but also includes respiratory sinus arrhythmia, i.e., the local, intra-thoracic effect in HR fluctuations caused by respiratory pressure change during breathing.

Frequency-domain measures of HRV were calculated, using Fast Fourier Transformation to derive the spectral distribution. Indices included high-frequency (HF) power (0.15-0.40 Hz), low-frequency (LF) power (0.04-0.15 Hz), and very low frequency (VLF) power (3-30 mHz). Efferent vagal activity is a major contributor to the HF component, as has been consistently demonstrated by clinical and experimental observations (Akselrod et al., 1981; Pomeranz et al., 1985; Malliani et al., 1991). Consequently, HF power can be seen as a reliable index of parasympathetic nervous system activity. The interpretation of the LF component is more controversial; some studies suggest LF power to be a marker of sympathethic modulation (Malliani et al., 1991; Kamath and Fallen, 1993; Rimoldi et al., 1990; Montano et al., 1994), while others conclude LF power to be a parameter that includes both sympathetic as vagal influences (Akselrod et al., 1981; Appel et al., 1989). As a result, it is unclear whether the ratio of the latter two indices (LF/HF), can be regarded as a measure of sympathovagal balance or of sympathetic 
modulations. The physiological correlates of lower frequency components (VLF) of HRV are still unknown (Malik et al., 1996).

Quantitative analyses of Poincaré plot parameters were also performed. The Poincaré plot (Figure 1) is a plot of $R R(n)$ on the $x$-axis versus $R R(n+1)$ on the $y$-axis; it plots the duration of each RR interval against the duration of the next RR interval. The technique most commonly used to quantify a Poincaré plot is fitting an ellipse to the plot (Marciano et al., 1994; D' Addio et al., 1998; Huikuri et al., 1996; Tulppo et al., 1996). We obtained the standard deviation of instantaneous inter-beat interval (IBI) variability, SDl (which measures the width of the Poincaré cloud) (Tulppo et al., 1996; Kamen and Tonkin, 1995; Kamen et al., 1996, Kamen 1996), the standard deviation of continuous long-term IBI variability, SD2 (which measures the length of the Poincaré cloud) (Tulppo et al., 1996; Kamen and Tonkin, 1995; Kamen et al., 1996, Kamen 1996), as well as the SD1/SD2 ratio. SD1, as a measure of instantaneous changes in |B|, is assumed to reflect vagal efferent activity (Tulppo et al., 1996), whereas SD2 expresses the overall variability in heart rate (Brunetto et al., 2005).

Figure 1. An example Poincaré plot.

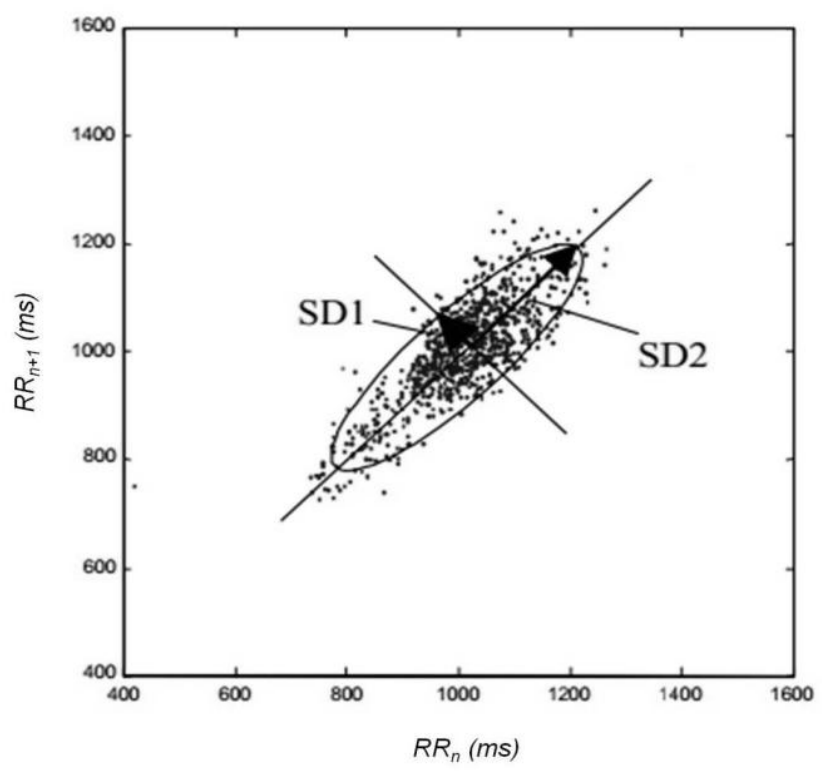




\subsubsection{Statistical analysis}

To examine the patterns of HRV measures circa 1 hour before and circa 1 hour after a PNES, 12 intervals (of approximately 5 minutes each) that preceded and followed the episodes were selected. Since it was not possible to select 25-26 intervals in total for all PNESS (12 intervals before the PNES, 1-2 intervals during the PNES, and 12 intervals after the PNES) due to the occurrence of another PNES in a short time window or the removal of intervals which were disturbed by artifacts, $n$ differed per interval. Therefore, confidence intervals were calculated and non-parametric tests were used. To prevent patients with a high number of seizures from dominating the average, the intervals were first averaged per patient before entered in the withinsubject analysis, resulting in an $n$ of 20 . After visual inspection of the plotted averages of the HRV parameters, related-samples Wilcoxon signed-rank tests were used to test for statistical differences between all selected intervals. P-values $<0.05$ were considered statistically significant.

\subsection{Results}

\subsubsection{Demographic and clinical characteristics}

The study population included 20 patients with PNES (18 women, 2 men, age $35.7 \pm$ 10.4, number of seizures during registration $5.9 \pm 5.7$ ), who had a total number of 118 PNES episodes during video-EEG monitoring. All patients had motor signs during the PNES episodes; none of the patients only experienced unresponsiveness during the episodes, although unresponsiveness frequently co-occurred. Information about medication and comorbidity is summarized in Table 1.

\subsubsection{Heart rate and linear heart rate variability parameters}

The average heart rate and linear heart rate variability measures are summarized in Table 2 and Figure 2. Non-parametric related-samples testing demonstrated significant changes in the intervals directly preceding and following PNES. Between interval -2 and -1 (the two intervals preceding a PNES), there was a significant increase in HR and a significant decrease in SDANN and VLF. Between interval -1 and PNES interval il (the first interval of a PNES episode), there was a significant 
increase in HF. Between interval -1 and interval +1 (the interval following a PNES), there was a significant increase in SDANN and VLF, and a significant decrease in HR.

Table 1. Participant demographics and characteristics.

\begin{tabular}{|c|c|c|c|c|c|}
\hline ID & Age & Gender & $\begin{array}{l}\text { Nr. attacks } \\
\text { during } \\
\text { registration }\end{array}$ & Medication & Comorbidity \\
\hline 1 & 40 & $\mathrm{~F}$ & 14 & $\begin{array}{l}\text { Levetiracetam, carbamazepine, interferon } \\
\text { beta-1b, paracetamol, omeprazole }\end{array}$ & Multiple sclerosis \\
\hline 2 & 41 & $\mathrm{~F}$ & 6 & $\begin{array}{l}\text { Valproate, venlafaxine, escitalopram, } \\
\text { clorazepate, alpralozam }\end{array}$ & \\
\hline 3 & 26 & $\mathrm{~F}$ & 2 & Levetiracetam, paroxetine & \\
\hline 4 & 52 & $\mathrm{~F}$ & 4 & $\begin{array}{l}\text { Levetiracetam, topiramate, lorazepam, } \\
\text { glucosamine sulfate, levothyroxine }\end{array}$ & \\
\hline 5 & 50 & $\mathrm{~F}$ & 2 & $\begin{array}{l}\text { Acetylsalicylic acid, bisoprolol, } \\
\text { oxcarbazepine, pregabaline, ticlopidine, } \\
\text { diltiazem, omeprazole, escitalopram }\end{array}$ & $\begin{array}{l}\text { CREST syndrome, } \\
\text { temporal lobe } \\
\text { epilepsy (seizure } \\
\text { free by } \\
\text { oxcarbazepine) }\end{array}$ \\
\hline 6 & 23 & $\mathrm{~F}$ & 3 & Mirtazapine, salmeterol/fluticasone & \\
\hline 7 & 51 & $\mathrm{~F}$ & 3 & $\begin{array}{l}\text { Trazodon, duloxetine, tramadol, } \\
\text { metformin, alpralozam, fentanyl, } \\
\text { pantoprazol, topiramate, paracetamol }\end{array}$ & $\begin{array}{l}\text { Fibromyalgia, } \\
\text { migraine }\end{array}$ \\
\hline 8 & 39 & $\mathrm{~F}$ & 2 & Paracetamol & $\begin{array}{l}\text { Narcolepsy } \\
\text { (attack free) }\end{array}$ \\
\hline 9 & 37 & M & 16 & Lacosamide, pregabaline & \\
\hline 10 & 24 & M & 19 & Clonazepam & $\begin{array}{l}\text { Posttraumatic } \\
\text { brain damage } \\
\text { (left hemisphere) }\end{array}$ \\
\hline 11 & 34 & $\mathrm{~F}$ & 2 & Levetiracetam, clonazepam & $\begin{array}{l}\text { Juvenile } \\
\text { myoclonic } \\
\text { epilepsy (seizure } \\
\text { free), mental } \\
\text { retardation }\end{array}$ \\
\hline 12 & 23 & $\mathrm{~F}$ & 5 & $\begin{array}{l}\text { Levetiracetam, carbamazepine, } \\
\text { lacosamide, clonazepam, } \\
\text { methylphenidate }\end{array}$ & $\begin{array}{l}\text { Generalized } \\
\text { tonic-clonic } \\
\text { epilepsy }\end{array}$ \\
\hline 13 & 48 & $\mathrm{~F}$ & 3 & $\begin{array}{l}\text { Levetiracetam, lamotrigine, baclofen, } \\
\text { sertraline, paracetamol, clonazepam }\end{array}$ & \\
\hline 14 & 22 & $\mathrm{~F}$ & 5 & $\begin{array}{l}\text { Aldactazine, levetiracetam, lamotrigine, } \\
\text { sodium bicarbonate, escitalopram, } \\
\text { tetrazepam, lorazepam, paracetamol }\end{array}$ & $\begin{array}{l}\text { Interictal } \\
\text { epileptic spikes }\end{array}$ \\
\hline 15 & 34 & $\mathrm{~F}$ & 18 & $\begin{array}{l}\text { Valproate, levetiracetam, lacosamide, } \\
\text { lormetazepam, prazepam, clorazepate, } \\
\text { venlafaxine }\end{array}$ & Insomnia \\
\hline 16 & 45 & $\mathrm{~F}$ & 2 & $\begin{array}{l}\text { Pantoprazol, hydroxychloroquine, } \\
\text { piroxicam, prednisone }\end{array}$ & \\
\hline 17 & 22 & $\mathrm{~F}$ & 3 & Propanolol, carbamazepine & $\begin{array}{l}\text { Migraine, } \\
\text { trigeminal } \\
\text { neuralgia }\end{array}$ \\
\hline 18 & 42 & $\mathrm{~F}$ & 3 & $\begin{array}{l}\text { Levetiracetam, phenytoin, lacosamide, } \\
\text { venlafaxine, simvastatine, fenprocoumon, } \\
\text { nadroparine }\end{array}$ & \\
\hline 19 & 35 & $\mathrm{~F}$ & 3 & $\begin{array}{l}\text { Valproate, benzodiazepine, montelukast, } \\
\text { omeprazole, metoprolol, escitalopram }\end{array}$ & Migraine \\
\hline 20 & 26 & $\mathrm{~F}$ & 3 & $\begin{array}{l}\text { Escitalopram, pantoprazol, clobazam, } \\
\text { pregabaline }\end{array}$ & \\
\hline
\end{tabular}




\subsubsection{Poincaré plot parameters}

Non-parametric related-samples tests indicated significant increases in SD1 $(\mathrm{P}=$ $0.010)$ and SD2 ( $p=0.019$ ) between interval -1 and PNES interval 1. The SD1/SD2 ratio significantly decreased between interval -1 and interval $+1 \quad(p=0.044)$. Example Poincaré plots for interval -1 and interval +1 are shown in Figure 3.

Table 2. Descriptive statistics of heart rate and heart rate variability parameters. Results are reported as Mean (SD) [95\% CI]. Abbreviations: HR = heart rate, RMSSD = root mean square of successive differences, SDANN = standard deviation of average beat-to-beat intervals, VLF = very low frequency, LF = low frequency, $\mathrm{HF}=$ high frequency, $S D=$ standard deviation, $\mathrm{Cl}=$ confidence interval.

\begin{tabular}{|c|c|c|c|c|c|}
\hline & Interval -2 & Interval -1 & Interval i1 & Interval i2 & Interval +1 \\
\hline$H R$ & $\begin{array}{l}75.1(8.2) \\
{[71.25-78.91]}\end{array}$ & $\begin{array}{l}77.6(8.6) \\
{[73.62-81.64]}\end{array}$ & $\begin{array}{l}78.2(8.7) \\
{[74.18-82.30]}\end{array}$ & $\begin{array}{l}79.4(11.0) \\
{[74.06-84.69]}\end{array}$ & $\begin{array}{l}74.3(6.9) \\
{[71.05-77.48]}\end{array}$ \\
\hline RMSSD & $\begin{array}{l}0.074(0.05) \\
{[0.05-0.10]}\end{array}$ & $\begin{array}{l}0.066(0.05) \\
{[0.04-0.09]}\end{array}$ & $\begin{array}{l}0.081(0.05) \\
{[0.06-0.10]}\end{array}$ & $\begin{array}{l}0.085(0.06) \\
{[0.06-0.11]}\end{array}$ & $\begin{array}{l}0.068(0.06) \\
{[0.04-0.09]}\end{array}$ \\
\hline SDANN & $\begin{array}{l}0.817(0.09) \\
{[0.77-0.86]}\end{array}$ & $\begin{array}{l}0.787(0.08) \\
{[0.75-0.82]}\end{array}$ & $\begin{array}{l}0.797(0.09) \\
{[0.75-0.84]}\end{array}$ & $\begin{array}{l}0.789(0.11) \\
{[0.74-0.84]}\end{array}$ & $\begin{array}{l}0.835(0.11) \\
{[0.78-0.89]}\end{array}$ \\
\hline VLF power & $\begin{array}{l}0.685(0.15) \\
{[0.61-0.76]}\end{array}$ & $\begin{array}{l}0.634(0.12) \\
{[0.58-0.69]}\end{array}$ & $\begin{array}{l}0.655(0.16) \\
{[0.58-0.73]}\end{array}$ & $\begin{array}{l}0.649(0.17) \\
{[0.57-0.73]}\end{array}$ & $\begin{array}{l}0.722(0.20) \\
{[0.63-0.82]}\end{array}$ \\
\hline LF power & $\begin{array}{l}0.0010(0.001) \\
{[0.00047-} \\
0.00184]\end{array}$ & $\begin{array}{l}0.0015(0.002) \\
{[0.00025-} \\
0.00157]\end{array}$ & $\begin{array}{l}0.0012(0.001) \\
{[-0.00064-} \\
0.00319]\end{array}$ & $\begin{array}{l}0.0013(0.001) \\
{[0.00069-} \\
0.00153]\end{array}$ & $\begin{array}{l}0.0011(0.001) \\
{[0.00070-} \\
0.00144]\end{array}$ \\
\hline HF power & $\begin{array}{l}0.0026(0.004) \\
{[0.00066-} \\
0.00446]\end{array}$ & $\begin{array}{l}0.0026(0.004) \\
{[0.00077-} \\
0.00443]\end{array}$ & $\begin{array}{l}0.0032(0.003) \\
{[0.00194-} \\
0.00452]\end{array}$ & $\begin{array}{l}0.0033(0.004) \\
{[0.00158-} \\
0.00497]\end{array}$ & $\begin{array}{l}0.0024(0.003) \\
{[0.00109-} \\
0.00361]\end{array}$ \\
\hline LF/HF ratio & $\begin{array}{l}1.549(1.32) \\
{[0.93-2.17]}\end{array}$ & $\begin{array}{l}1.711(1.47) \\
{[1.02-2.40]}\end{array}$ & $\begin{array}{l}1.298(1.14) \\
{[0.77-1.83]}\end{array}$ & $\begin{array}{l}1.150(0.73) \\
{[0.80-1.50]}\end{array}$ & $\begin{array}{l}1.504(1.31) \\
{[0.89-2.12]}\end{array}$ \\
\hline $\begin{array}{l}\text { Poincaré plot } \\
\text { parameters }\end{array}$ & & & & & \\
\hline SDI & $\begin{array}{l}0.120(0.06) \\
{[0.09-0.15]}\end{array}$ & $\begin{array}{l}0.132(0.07) \\
{[0.10-0.16]}\end{array}$ & $\begin{array}{l}0.163(0.05) \\
{[0.14-0.19]}\end{array}$ & $\begin{array}{l}0.152(0.06) \\
{[0.12-0.18]}\end{array}$ & $\begin{array}{l}0.127(0.06) \\
{[0.10-0.16]}\end{array}$ \\
\hline SD2 & $\begin{array}{l}0.079(0.06) \\
{[0.05-0.11]}\end{array}$ & $\begin{array}{l}0.083(0.06) \\
{[0.05-0.11]}\end{array}$ & $\begin{array}{l}0.099(0.05) \\
{[0.07-0.12]}\end{array}$ & $\begin{array}{l}0.097(0.06) \\
{[0.07-0.13]}\end{array}$ & $\begin{array}{l}0.082(0.06) \\
{[0.05-0.11]}\end{array}$ \\
\hline SD1/SD2 ratio & $\begin{array}{l}2.306(1.05) \\
{[1.81-2.80]}\end{array}$ & $\begin{array}{l}2.484(1.29) \\
{[1.88-3.09]}\end{array}$ & $\begin{array}{l}2.722(1.91) \\
{[1.83-3.62]}\end{array}$ & $\begin{array}{l}2.356(1.55) \\
{[1.61-3.10]}\end{array}$ & $\begin{array}{l}2.216(1.10) \\
{[1.70-2.73]}\end{array}$ \\
\hline
\end{tabular}


Figure 2. Average pattern of heart rate and linear heart rate variability indices which demonstrated significant changes before, during and after PNES episodes. The blue line represents the average HR/HRV characteristic, with $95 \%$ confidence intervals in grey. Each interval lasted approximately 5 minutes: Intervals 12 to -1 comprise the hour preceding PNES, the intervals il and i2 cover the PNES, and the hour following PNES consists of the intervals +1 to +12 . The line between interval i2 and +1 is dashed because not all patients had episodes consisting of exactly 2 intervals. ${ }^{*}=p<0.05, \mathrm{~ns}=$ Not significant. $H R=$ heart rate, $H F=$ high frequency power, SDANN = standard deviation of average NN intervals, VLF = very low frequency power.

\section{$H R$}

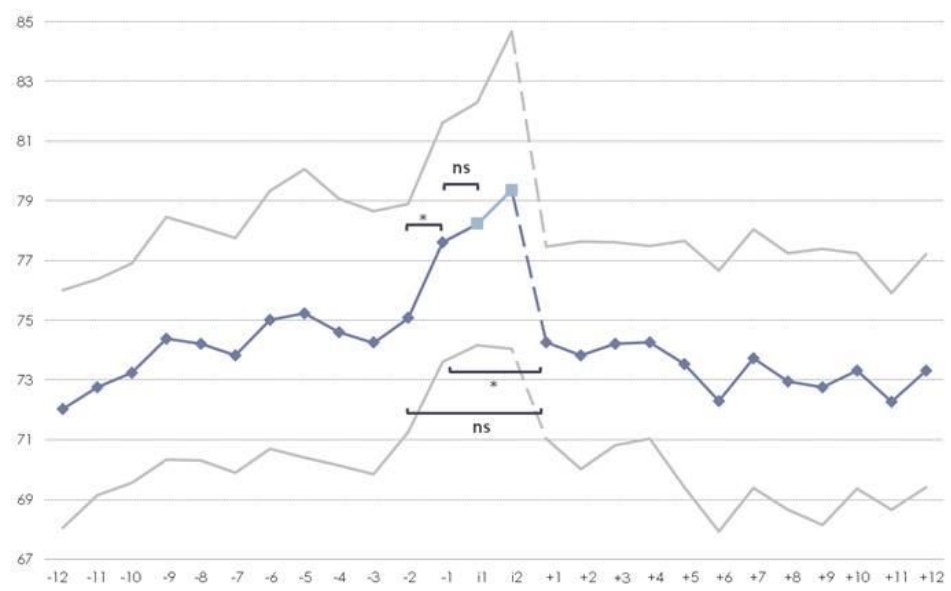

\section{SDANN}

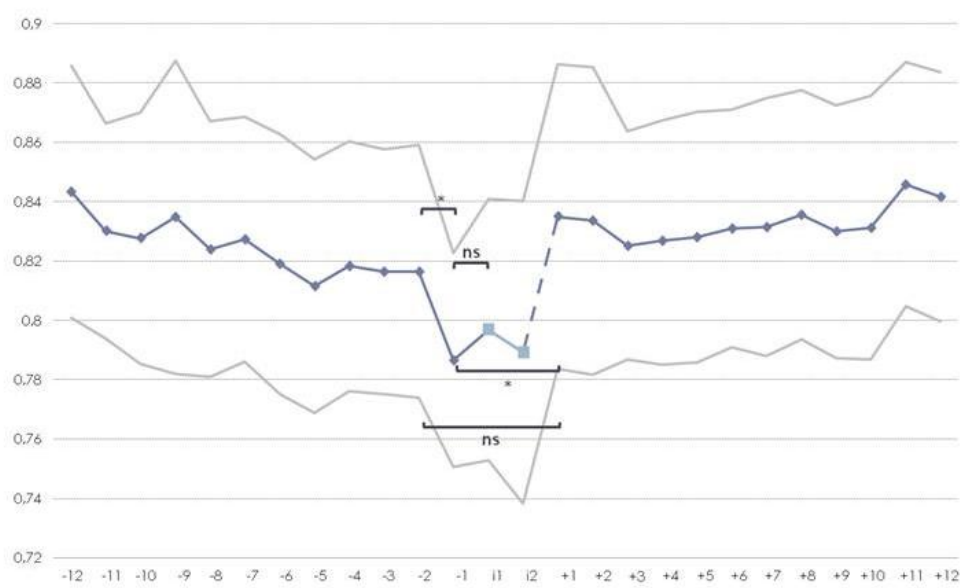




\section{HF}

0.006

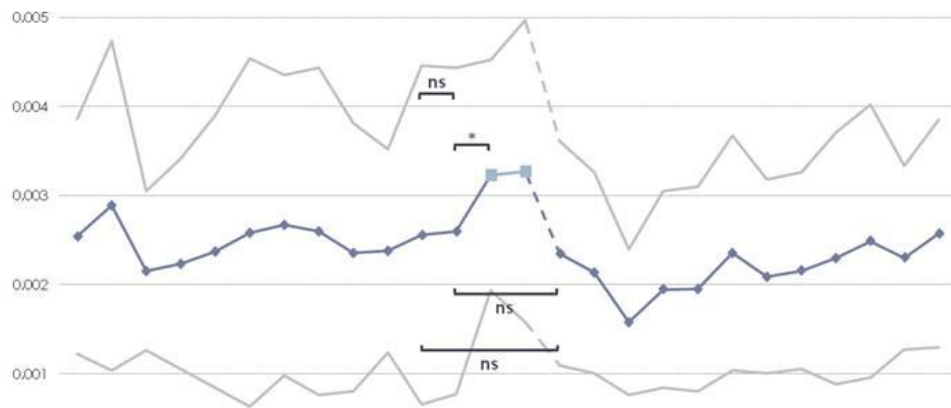

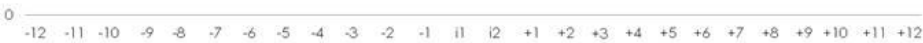

\section{VLF}

0.85

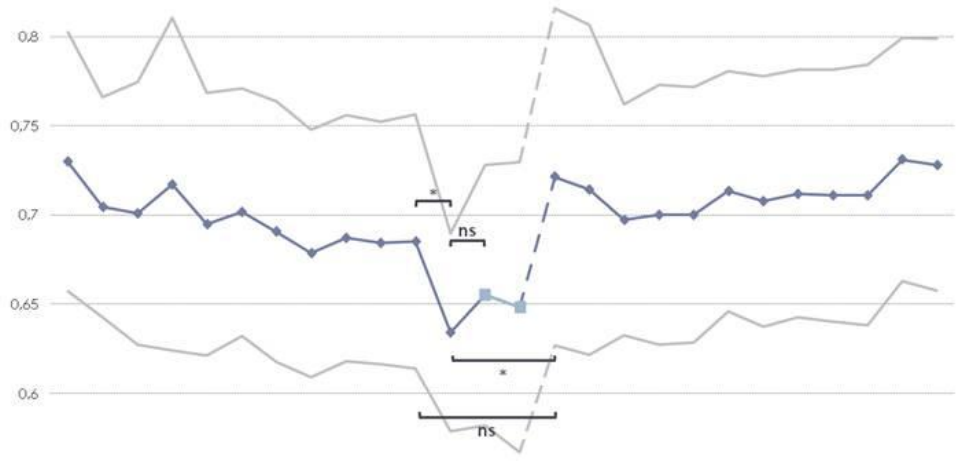

$\begin{array}{llllllllllllllllllllllllllll}0.55 & -12 & -11 & -10 & -9 & -8 & -7 & -6 & -5 & -4 & -3 & -2 & -1 & 11 & 12 & +1 & +2 & +3 & +4 & +5 & +6 & +7 & +8 & +9 & +10 & +11 & +12\end{array}$ 
Figure 3. Example Poincaré plots of the 5-minute intervals directly before and after a PNES episode. The preseizure interval is depicted in red, the post-seizure interval is depicted in blue.

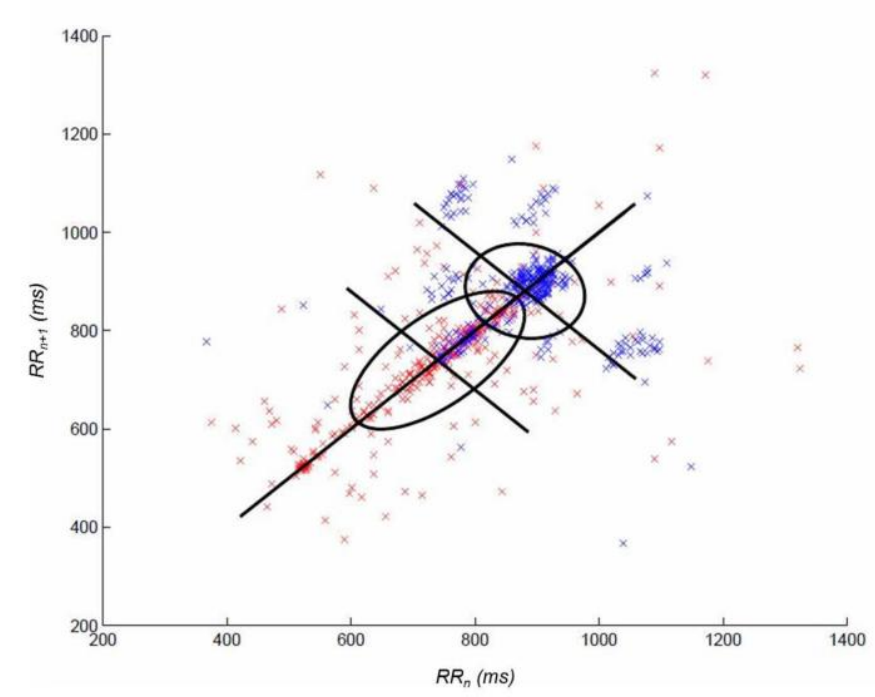

\subsection{Discussion}

The current study examined differences in autonomic functioning associated with the occurrence of PNES. Heart rate measures were recorded during video-EEG monitoring. Significant changes in HRV measures were indentified only shortly before a PNES occurred: In the five-minute interval before a PNES, an average increase in heart rate and decreases in SDANN and VLF power were observed. During PNES, there was a significant increase in HF power, SD1 and SD2. In the five minutes directly after PNES, SDANN and VLF power were significantly increased and the heart rate and SD1/SD2 ratio decreased significantly, compared to the interval preceding a PNES. No significant changes were identified between intervals longer away from the PNES.

\subsubsection{Clinical interpretation}

The increase in heart rate and decrease in SDANN in the interval before PNES suggest an increase in sympathetic functioning, and therewith an increase in 
arousal, shortly before a PNES episode. These findings are consistent with the hypothesis that PNES are caused by - and the somatic manifestation of - increased (emotional) discomfort (Bodde et al., 2009a; Stone and Carson, 2013). The discomfort can result from internal or external sources of stress, but could also be caused by "prodromal" feelings that an episode is coming which may cause uncomfortableness (Stone and Carson, 2013). Another explanation of the increased sympathetic functioning which precedes PNES episodes is the body's anticipation to movement, which could either be conscious or subconscious.

The significant increases in HF power and SDI during an episode suggest increased vagal influence, which implies PNES to occur in a state of relative relaxation. The significant decrease in HR and SDANN in the interval following a PNES, when compared with the values in the interval before the episode, suggest a decrease in sympathetic functioning by the episodes. Based on this apparent calming effect of PNES episodes, a plausible function of PNES may be to serve as a coping mechanism to deal with tension. These findings correspond well with patients reporting to feel alleviated after a PNES (Stone and Carson, 2013).

The significant increase in SD2 during the episode and the decrease in SD1/SD2 ratio following PNES, when compared with the interval before the episode, are more difficult to explain since SD2 reflects total variability (Brunetto et al., 2005). Similarly, the physiological nature of VLF power, which decreased in the interval before PNES and the increased after PNES, is still unclear (Malik et al., 1996).

Our findings are contradictory to the results of Ponnusamy et al. (2012), who found significant decreases of RMSSD and HF power during PNES episodes when compared to interictal intervals. An important factor that may explain this discrepancy may be the different study design (in the study of Ponnusamy et al., the interictal ECG samples differed in occurrence in time relative to the PNES episode).

\subsubsection{Implications for treatment}

Our findings of increased arousal before, and alleviation by, PNES episodes could have important implications for the psychological treatment of PNES. These findings suggest that PNES episodes are adopted as a coping style to decrease (emotional) arousal. In patients with PNES with similar HRV patterns, therapy should focus on showing the patients insight into their behavior, and on replacing invalidating 
coping styles with other means for stress reduction and relaxation techniques. However, if the increased sympathetic functioning is caused by an aroused feeling because the patient feels that an episode is coming, the implication for treatment is different, and therapy should focus on means to avoid the attack.

In future, after consistent replication of our findings in individual patients also, heart rate variability measurements themselves could be valuable for treatment: If the occurrence of PNES could eventually be predicted by HRV measures within individual patients, it would be possible to design an ambulatory device that monitors these physiological characteristics. Ambulatory monitoring during everyday life, in the subject's own environment (naturalistic settings), could be of additional value in the course of psychological treatment, providing information about individual (reactivity to) (socio-) emotional stressors (tracked by diary keeping). It would be particularly important for the examination of the situations which elicit PNES in the individual patient. This knowledge could eventually improve the psychological treatment of patients with PNES. However, therapists should consider the feelings of stress which might be elicited by the handling of a device and dairy keeping in some patients, which might adversely affect the treatment. Finding a relationship between HRV parameters and PNES could also offer options for treatment in the form of biofeedback, although sensitivity (avoidance of falsepositive warnings) and unobtrusiveness of the device are important concerns.

\subsubsection{Limitations}

This study had an exploratory character and therewith included a relatively small study population. The small study population may have led to type I errors (false negatives) due to lack of power, while the relatively large amount of comparisons may have resulted in type II errors (false positives). Also, only patients with major motor symptoms were studied, none of the patients experienced PNES episodes only characterized by unresponsiveness. Future research should include both patient types, although the duration of episodes of unresponsiveness could be difficult to determine. Furthermore, many patients were on (antiepileptic) medication, of which the effects on the autonomic outcome measures are not exactly known. However, Ponnusamy at al. (2012) reported no significant differences in the majority of the HRV measures between patients with PNES on antiepileptic medication and patients 
with PNES not on antiepileptic medication. Also, in view of conflicting reports of other studies of the influence of antiepileptic medication on heart rate variability (Tomson et al., 1998; Harnod et al., 2009), we do not expect our findings to be largely influenced by these medications.

\subsubsection{Conclusion}

Our study suggests PNES episodes to be preceded by increased sympathetic functioning, which is followed by an increase in parasympathetic functioning during and after PNES. Future research is needed to identify the exact cause of the increased arousal that precedes PNES episodes; do PNES serve as a coping mechanism in dealing with increased (emotional) arousal, or is the increased arousal caused by the prodromal feeling that the attack is coming? 


\section{Chapter 8}

AUTONOMIC NERVOUS SYSTEM FUNCTIONING ASSOCIATED WITH EPILEPTIC SEIZURES: ANALYSIS OF HEART RATE VARIABILITY

S.J.M. van der Kruijs, K.E.J. Vonck, L.M.G. Feijs, N.M.G. Bodde, R.H.C. Lazeron, E. Carrette, P.A.J.M. Boon, W.H. Backes, J.F.A. Jansen, A.P. Aldenkamp, P.J.M. Cluitmans. Submitted for publication.

\subsection{Abstract}

Little is known about the (peri-) ictal changes in autonomic nervous system activity of epileptic seizures. Such information may be useful for seizure prediction paradigms and differential diagnosis between epilepsy and psychogenic nonepileptic seizures (PNES). The current study investigated the peri-ictal time course of heart rate variability (HRV) measures, which reflect autonomic nervous system functioning.

HRV measures were extracted from electrocardiography data collected during 1-7 days of video-electroencephalography monitoring of 17 patients with epilepsy and 20 patients with PNES. Heart rate (HR) and HRV measures (standard deviation of average beat-to-beat intervals (SDANN), root mean square of successive differences (RMSSD), high frequency (HF) power, low frequency (LF) power and very low frequency (VLF) power) were averaged over consecutive five-minute intervals. Quantitative analyses of Poincaré plot parameters (SD1, SD2 and SD1/SD2 ratio) were also performed. In addition, differences with HRV parameters of patients with PNES, described in one of our previous studies, were explored.

In epilepsy, no significant pre-ictal changes in HR and HRV parameters were observed. During seizures, HR, SDANN, SD1 and SD1/SD2 ratio significantly increased while VLF power significantly decreased. In the five-minute interval immediately following seizures, HR, SDANN and SDI were back to pre-seizure levels, while VLF power remained significantly decreased and SD1/SD2 ratio remained significantly increased. Significant between-group differences were identified for several preictal and ictal HRV parameters, but not for post-ictal measurements. 
The ictal HR and HRV changes reflect increased sympathetic system activation during epileptic seizures. The HRV parameters of patients with epilepsy differed significantly from the peri-ictal HRV pattern of patients with PNES, which suggested increased sympathetic system activation and decreased vagal tone shortly before PNES and return to normal levels shortly after the episode. Implications for differential diagnosis and treatment are discussed.

\subsection{Introduction}

Epileptic seizures result from brief episodes of abnormal excessive and synchronous neuronal activity in the brain. Examination of heart rate variability (HRV) parameters, which reflect (co-)activation of the sympathetic and parasympathetic branches of the autonomic nervous system in epilepsy, has previously identified altered sympathetic and vagal tone during interictal and ictal states (Delamont et al., 1999; Leutmezer et al., 2003; Zaatreh et al., 2003; Jeppesen et al., 2010; Pradhan et al., 2011; Ponnusamy et al., 2012; Behbahani et al., 2013). Such findings may provide important insight in the prognosis of patients with epilepsy. For example, the ictal reduction of the vagal tone that has been repeatedly observed has been suggested to be one of the reasons for sudden unexpected death in epilepsy (SUDEP) (Tomson et al., 2008; Surges et al., 2009).

A more detailed analysis of how HRV parameters change in the immediate pre-ictal period may be useful for seizure prediction paradigms, which could be used in vagal nerve or deep brain stimulators or for the purpose of real time seizure detection in physiological monitoring devices (Ponnusamy et al., 2012). In a recent study, we investigated peri-ictal HRV patterns of psychogenic non-epileptic seizures (PNES) which are epilepsy-like episodes that lack epileptiform brain activity in the electroencephalogram (EEG), but instead originate from psychogenic factors (Bodde et al., 2009a; Reuber, 2009). We identified significantly increased heart rate and decreased SDANN in the pre-ictal interval, reflecting increased sympathetic system activation and decreased vagal tone, which returned to normal levels shortly after the episode (Van der Kruijs et al., 2014b). To examine whether similar changes could be identified in patients with genuine epilepsy, the current study examined the peri-ictal HRV pattern associated with epileptic seizures. In addition, differences between the peri-ictal patterns of HRV changes in epilepsy and PNES were explored. 


\subsection{Materials and methods}

\subsubsection{Study population}

The methods were comparable with the methods described in our paper about peri-ictal HRV patterns in patients with psychogenic non-epileptic seizures (Van der Kruijs et al., 2014b). The study population of the current study consisted of 17 patients with epilepsy (4M/13F), who were compared with the group of 20 patients with PNES $(2 \mathrm{M} / 18 \mathrm{~F})$ that was described in our previous study. All patients had been previously monitored with video-EEG for 1-7 consecutive days in the Reference Centre for Refractory Epilepsy of Ghent University Hospital in Belgium. The diagnoses of epilepsy and PNES were based on the analysis of at least two episodes captured on videoEEG by two epileptologists with extensive experience in this field $>10$ years experience). Patients with dual pathology (epilepsy and PNES), were also included in the PNES group when epileptic seizures were controlled and when the PNES were confirmed by video-EEG monitoring. Exclusion criteria were uncertainty about the diagnosis and comorbid psychiatric disorders (e.g. mood and anxiety disorders, schizophrenia and psychosis, and substance-related disorders). The investigation received ethical approval by the Medical Ethical Committee of Ghent University.

\subsubsection{Electrocardiogram recordings}

The ECG was recorded via precordial electrode positions V1-V4 throughout the video-EEG monitoring period (1-7 days) with the Micromed EEG system (Micromed S.p.A., Mogliano Veneto, Treviso, Italy). For the monitoring period, patients were in supine position in bed or on a chair during the day, and lying down in bed during the night. The start and end of epileptic seizures were defined by an epileptologist based on epileptiform brain activity on the EEG. The start and end of a PNES episode were defined by the associated motor symptoms (verified by the video recordings), which were often accompanied by unresponsiveness.

\subsubsection{Heart rate variability analysis}

HRV measures were derived according to the recommendations of the task force of the European Society of Cardiology and the North American Society of Pacing and Electrophysiology (Malik et al., 1996). ECG data were exported in European Data 
Format (EDF, (Kemp and Olivan, 2003)) from the Micromed reporting system. These EDF files were imported in Matlab (Mathworks Inc., Natick, MA, USA). Custom-built Matlab scripts were used to subsequently carry out R-peak detection, model-based validation and - if necessary - correction of the list of subsequent RR intervals (tachogram) and HRV parameter calculation.

Two time-domain measures of HRV were calculated: SDANN (standard deviation of the average beat-to-beat intervals) and RMSSD (square root of the mean squared difference of successive beat-to-beat intervals). SDANN in general reflects the overall cyclic nature of HRV (the more sinusoidal the tachogram is, the higher SDANN), and is considered to be a measure for overall variability. RMSSD is considered to be a measure for vagal control of heart rate but also includes respiratory sinus arrhythmia, i.e., the local, intra-thoracic effect in HR fluctuations caused by respiratory pressure change during breathing.

Frequency-domain measures of HRV were calculated, using Fast Fourier Transformation to derive the spectral distribution of HRV frequency. Indices included high-frequency (HF) power (0.15-0.40 Hz), low-frequency (LF) power (0.04-0.15 Hz), and very low frequency (VLF) power $(3-30 \mathrm{mHz}$ ). Efferent vagal activity is a major contributor to the HF component, as has been consistently demonstrated by clinical and experimental observations (Akselrod et al., 1981; Pomeranz et al., 1985; Malliani et al., 1991). Consequently, HF power can be seen as a reliable index of parasympathetic nervous system activity. The interpretation of the LF component is more controversial; some studies suggest LF power to be a marker of sympathethic modulation (Malliani et al., 1991; Kamath and Fallen, 1993; Rimoldi et al., 1990; Montano et al., 1994), while others conclude LF power to be a parameter that includes both sympathetic as vagal influences (Akselrod et al., 1981; Appel et al., 1989). As a result, it is unclear whether the ratio of the latter two indices (LF/HF), can be regarded as a measure of sympathovagal balance or of sympathetic modulations. The physiological correlates of very low frequency components (VLF) of HRV are still unknown (Malik et al., 1996).

Quantitative analyses of Poincaré plot parameters were also performed. The Poincaré plot is a plot of $R R(n)$ on the $x$-axis versus $R R(n+1)$ on the $y$-axis; it plots the duration of each RR interval against the duration of the next RR interval. The technique most commonly used to quantify a Poincaré plot is fitting an ellipse to the plot (Marciano et al., 1994; D'Addio et al., 1998; Huikuri et al., 1996; Tulppo et al., 
1996). We obtained the standard deviation of instantaneous inter-beat interval (IBI) variability, SD1 (which measures the width of the Poincaré cloud) (Tulppo et al., 1996; Kamen and Tonkin, 1995; Kamen et al., 1996, Kamen 1996), the standard deviation of continuous long-term IBI variability, SD2 (which measures the length of the Poincaré cloud) (Tulppo et al., 1996; Kamen and Tonkin, 1995; Kamen et al., 1996, Kamen 1996) as well as the SD1/SD2 ratio. SD1, as a measure of instantaneous changes in IBI, is assumed to reflect vagal efferent activity (Tulppo et al., 1996), whereas SD2 expresses the overall variability in heart rate (Brunetto et al., 2005).

\subsubsection{Statistical analysis}

The peri-ictal HRV patterns were previously analyzed for the PNES group (Van der Kruijs et al., 2014b). In the current study, we adopted the same approach to examine patterns of HRV measures circa 1 hour before and circa 1 hour after epileptic seizures, and additionally assessed differences in HR and HRV parameters between the two groups.

Twelve intervals (of approximately 5 minutes each) that preceded and followed the seizures were selected. Since it was not possible to select 25-26 intervals in total for all seizures (12 pre-ictal intervals, 1-2 ictal intervals, and 12 post-ictal intervals) due to the occurrence of another seizure in a short time window or the removal of intervals which were disturbed by artefacts, $n$ differed per interval. Therefore, conservative non-parametric tests were used. To prevent patients with a high number of seizures from dominating the average, the intervals were first averaged per patient before inclusion in the within-subject analysis, resulting in an $\mathrm{n}$ of 17 ( $n=20$ for the PNES group). After visual inspection of the plotted averages of the HRV parameters, related-samples Wilcoxon signed-rank tests were used to test for statistical differences between all selected intervals. To assess differences between patients with epilepsy and patients with PNES for HR and HRV parameters, independent-samples Mann-Whitney $U$ tests were carried out. P-values $<0.05$ were considered statistically significant. 


\subsection{Results}

\subsubsection{Demographic and clinical characteristics}

The study population included 17 patients with epilepsy (13 women, 4 men, age 37.7 \pm 17.4 , number of seizures during registration $4.7 \pm 3.0$ ), showing in total 80 seizures during the recording. This population was compared with a group of 20 patients with PNES (18 women, 2 men, age $35.7 \pm 10.4$, number of seizures during registration $5.9 \pm$ 5.7), who had a total number of 118 PNES episodes during video-EEG monitoring. Extensive information about demographical and clinical characteristics of the patients with PNES can be found in Van der Kruijs et al. (2014b). Demographic information and clinical characteristics of the patients with epilepsy are summarized in Table 1.

Table 1. Participant demographics and characteristics of the epilepsy group.

\begin{tabular}{|c|c|c|c|c|}
\hline ID & Age & Gender & $\begin{array}{l}\text { Nr. seizures } \\
\text { during } \\
\text { registration }\end{array}$ & Type of epilepsy \\
\hline 1 & 11 & $\mathrm{~F}$ & 2 & Simple partial seizures (right frontal lobe origin) \\
\hline 2 & 18 & $\mathrm{~F}$ & 3 & Complex partial seizures (left frontal or temporal origin) \\
\hline 3 & 16 & $\mathrm{~F}$ & 8 & Simple partial seizures (left frontal lobe origin) \\
\hline 4 & 66 & $\mathrm{~F}$ & 5 & Primary generalized epilepsy (absence seizures) \\
\hline 5 & 58 & $\mathrm{~F}$ & 8 & Complex partial seizures (right or left temporal lobe origin) \\
\hline 6 & 29 & $\mathrm{~F}$ & 4 & Complex partial seizures (left temporal lobe origin) \\
\hline 7 & 45 & $\mathrm{~F}$ & 2 & Complex partial seizures (temporal lobe origin) \\
\hline 8 & 60 & M & 2 & Complex partial seizures (left temporal lobe origin) \\
\hline 9 & 39 & $\mathrm{~F}$ & 3 & Complex partial seizures (right hemisphere origin) \\
\hline 10 & 50 & $\mathrm{~F}$ & 3 & Complex partial seizures \\
\hline 11 & 60 & $\mathrm{~F}$ & 2 & Primary generalized epilepsy, non-convulsive status epilepticus \\
\hline 12 & 48 & M & 3 & Frontal lobe epilepsy \\
\hline 13 & 34 & $\mathrm{~F}$ & 9 & Lennox-Gastaut Syndrome (tonic seizures) \\
\hline 14 & 19 & M & 3 & $\begin{array}{l}\text { Primary generalized epilepsy or left frontal lobe seizures (tonic } \\
\text { seizures with myoclonic jerks }+/ \text { - secondary generalization) }\end{array}$ \\
\hline 15 & 32 & M & 12 & Complex partial seizures (right hemisphere origin) \\
\hline 16 & 35 & $\mathrm{~F}$ & 6 & Complex partial seizures (left hemisphere origin) \\
\hline 17 & 21 & $\mathrm{~F}$ & 5 & Lennox-Gastaut syndrome (tonic and atonic seizures) \\
\hline
\end{tabular}




\subsubsection{Heart rate and heart rate variability parameters}

The average heart rate and heart rate variability measures are summarized in Table 2 and Figure 1. Non-parametric related-samples testing demonstrated no significant changes in HR and HRV parameters shortly before epileptic seizures. During seizures, $\operatorname{HR}(p=0.003)$ and SDANN ( $p=0.005)$ significantly increased while VLF power significantly decreased ( $p=0.002$ ). In the five-minute interval immediately following seizures, HR and SDANN were back to pre-seizure levels, while VLF power remained significantly decreased compared to the pre-seizure interval $(p=0.009)$.

In the 5-minute interval preceding PNES, there was a significant increase in HR $(p=0.037)$ and a significant decrease in SDANN $(p=0.028)$ and VLF power $(p=$ 0.026). During PNES, there was a significant increase in HF power ( $p<0.001)$. In the interval following PNES, SDANN $(p=0.001)$ and VLF power $(p=0.001)$ were increased and HR ( $p=0.037)$ was decreased, compared to the pre-seizure interval.

\subsubsection{Poincaré plot parameters}

Non-parametric related-samples tests indicated no significant changes in Poincaré plot parameters shortly before epileptic seizures. During seizures, SDI ( $p=0.005)$ and SD1/SD2 ratio $(P=0.01)$ significantly increased. In the five-minute interval immediately following seizures, SD1 decreased to pre-seizure levels, while SD1/SD2 ratio remained significantly increased compared to the pre-seizure interval $(p=$ $0.019)$.

In the first interval of PNES episodes, significant increases in SD1 ( $p=0.010)$ and SD2 ( $p=0.019$ ) were observed. In the interval following PNES, the SDI/SD2 ratio significantly decreased when compared to the pre-seizure interval $(p=0.044)$.

\subsubsection{Comparison between epileptic seizures and PNES episodes}

Non-parametric independent-samples tests demonstrated significantly higher preictal SD1/SD2 ratios in patients with epilepsy compared to patients with PNES. Ictal RMSSD, HF power, LF power and SD2 were significantly higher in patients with PNES compared to patients with epilepsy. SDANN, LF/HF ratio and SD1/SD2 ratio were significantly higher in patients with epilepsy. No significant between-group differences were identified for the post-ictal HRV parameters. 
Table 2. Descriptive statistics of heart rate and heart rate variability parameters. Results are reported as Mean (SD). Abbreviations: $H R=$ heart rate, $R M S S D=$ root mean square of successive differences, SDANN = standard deviation of average beat-to-beat intervals, VLF = very low frequency, $L F=$ low frequency, $H F=$ high frequency, $S D=$ standard deviation. ${ }^{*}=$ Significant between-group differences for $p<0.05$. ${ }^{* *}=$ Significant between-group differences for $p<0.01$. Within-group differences are described in the text.

\begin{tabular}{|c|c|c|c|c|c|c|}
\hline & & Interval -2 & Interval -1 & Interval il & Interval i2 & Interval + 1 \\
\hline \multicolumn{7}{|c|}{ HR } \\
\hline - & Epilepsy & $75.0(12.1)$ & $75.1(12.1)$ & $79.8(14.6)$ & $79.2(11.0)$ & $78.3(9.9)$ \\
\hline - & PNES & $75.1(8.2)$ & $77.6(8.6)$ & $78.2(8.7)$ & $79.4(11.0)$ & $74.3(6.9)$ \\
\hline \multicolumn{7}{|c|}{ RMSSD } \\
\hline - & Epilepsy & $0.055(0.07)$ & $0.057(0.07)$ & $0.059(0.08) *$ & $0.033(0.02)^{* *}$ & $0.054(0.08)$ \\
\hline - & PNES & $0.074(0.05)$ & $0.066(0.05)$ & $0.081(0.05)$ & $0.085(0.06)$ & $0.068(0.06)$ \\
\hline \multicolumn{7}{|c|}{ SDANN } \\
\hline - & Epilepsy & $0.855(0.62)$ & $0.941(0.60)$ & $1.189(0.60) *$ & $0.921(0.32)$ & $0.928(0.63)$ \\
\hline - & PNES & $0.817(0.09)$ & $0.787(0.08)$ & 0.797 (0.09) & $0.789(0.11)$ & $0.835(0.11)$ \\
\hline \multicolumn{7}{|c|}{ VLF power } \\
\hline - & Epilepsy & $0.706(0.22)$ & $0.709(0.21)$ & $0.638(0.20)$ & $0.618(0.16)$ & $0.631(0.15)$ \\
\hline- & PNES & $0.685(0.15)$ & $0.634(0.12)$ & $0.655(0.16)$ & $0.649(0.17)$ & $0.722(0.20)$ \\
\hline \multicolumn{7}{|c|}{ LF power } \\
\hline - & Epilepsy & $0.0010(0.002)$ & $0.0011(0.001)$ & $0.0013(0.002)$ & $0.0006(0.000)$ & 0.0011 (0.002) \\
\hline- & PNES & $0.0010(0.001)$ & $0.0015(0.002)$ & $0.0012(0.001)$ & $0.0013(0.001)^{*}$ & $0.0011(0.001)$ \\
\hline \multicolumn{7}{|c|}{ HF power } \\
\hline - & Epilepsy & $0.0019(0.005)$ & $0.0023(0.005)$ & $0.0022(0.005)^{*}$ & $0.001(0.001)^{* *}$ & $0.0019(0.005)$ \\
\hline - & PNES & $0.0026(0.004)$ & $0.0026(0.004)$ & $0.0032(0.003)$ & $0.003(0.004)$ & $0.0024(0.003)$ \\
\hline \multicolumn{7}{|c|}{ LF/HF ratio } \\
\hline - & Epilepsy & $1.820(1.12)$ & $1.927(1.42)$ & $1.894(1.13)$ & $2.408(2.24) *$ & $2.176(1.34)$ \\
\hline- & PNES & $1.549(1.32)$ & $1.711(1.47)$ & $1.298(1.14)$ & $1.150(0.73)$ & $1.504(1.31)$ \\
\hline \multicolumn{7}{|c|}{$\begin{array}{l}\text { Poincaré plot } \\
\text { parameters }\end{array}$} \\
\hline \multicolumn{7}{|c|}{ SDl } \\
\hline - & Epilepsy & $0.104(0.06)$ & $0.115(0.06)$ & $0.150(0.06)$ & $0.121(0.04)$ & $0.114(0.06)$ \\
\hline- & PNES & $0.120(0.06)$ & $0.132(0.07)$ & $0.163(0.05)$ & $0.152(0.06)$ & $0.127(0.06)$ \\
\hline \multicolumn{7}{|c|}{ SD2 } \\
\hline - & Epilepsy & $0.056(0.06) *$ & $0.061(0.07)$ & $0.066(0.07) *$ & $0.042(0.03)^{* *}$ & $0.058(0.07)$ \\
\hline - & PNES & $0.079(0.06)$ & $0.083(0.06)$ & $0.099(0.05)$ & $0.097(0.06)$ & $0.082(0.06)$ \\
\hline \multicolumn{7}{|c|}{ SD1/SD2 ratio } \\
\hline - & Epilepsy & $2.740(1.04)$ & $2.787(1.30)^{*}$ & $3.998(2.23) *$ & $3.864(1.69)^{*}$ & $3.219(1.57)$ \\
\hline - & PNES & $2.306(1.05)$ & 2.484 (1.29) & $2.722(1.91)$ & $2.356(1.55)$ & $2.216(1.10)$ \\
\hline
\end{tabular}


Figure 1. Average pattern of heart rate and linear heart rate variability indices which demonstrated significant peri-ictal changes in the epilepsy group. The blue line represents the average HR/HRV characteristic, with $95 \%$ confidence intervals in grey. Each interval lasted approximately 5 minutes: Intervals 12 to -1 comprise the hour preceding the seizure, the intervals il and i2 cover the seizure, and the hour following the seizure consists of the intervals +1 to +12 . The line between interval i2 and +1 is dashed because not all patients had episodes consisting of exactly 2 intervals. ${ }^{*}=p<0.05$, ns $=$ Not significant. HR $=$ heart rate, SDANN = standard deviation of average NN intervals, VLF = very low frequency.

\section{HR}

92

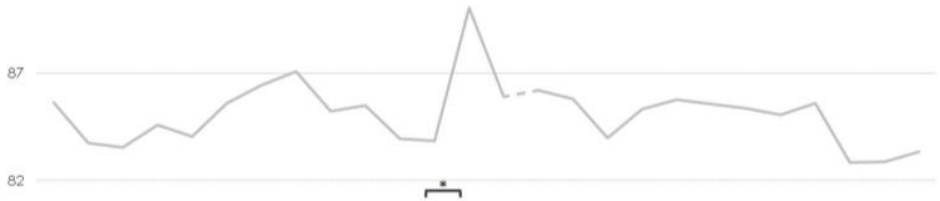

$8 2 \longdiv { \circ }$

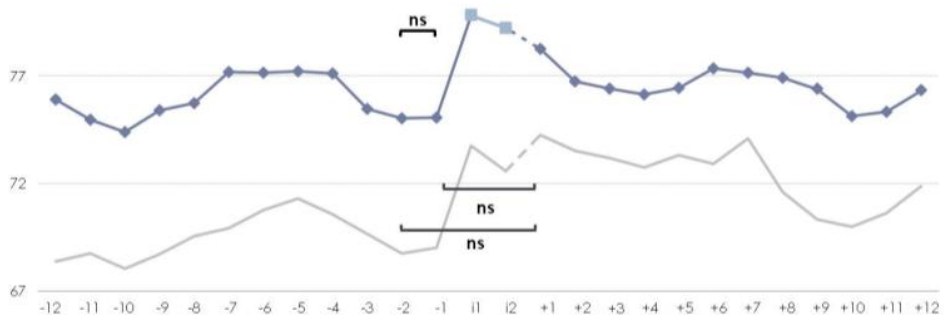




\section{SDANN}

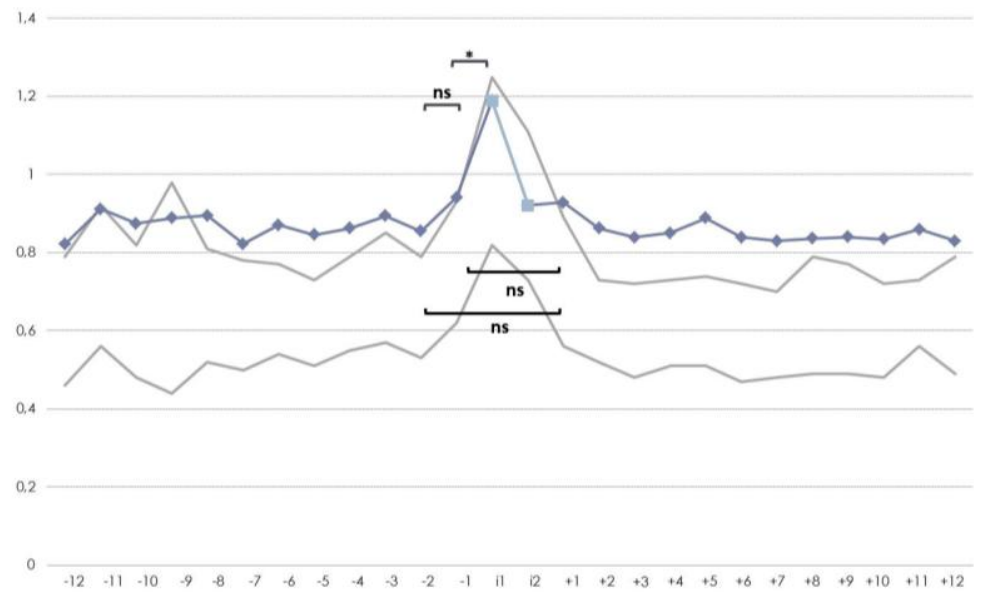

\section{VLF power}

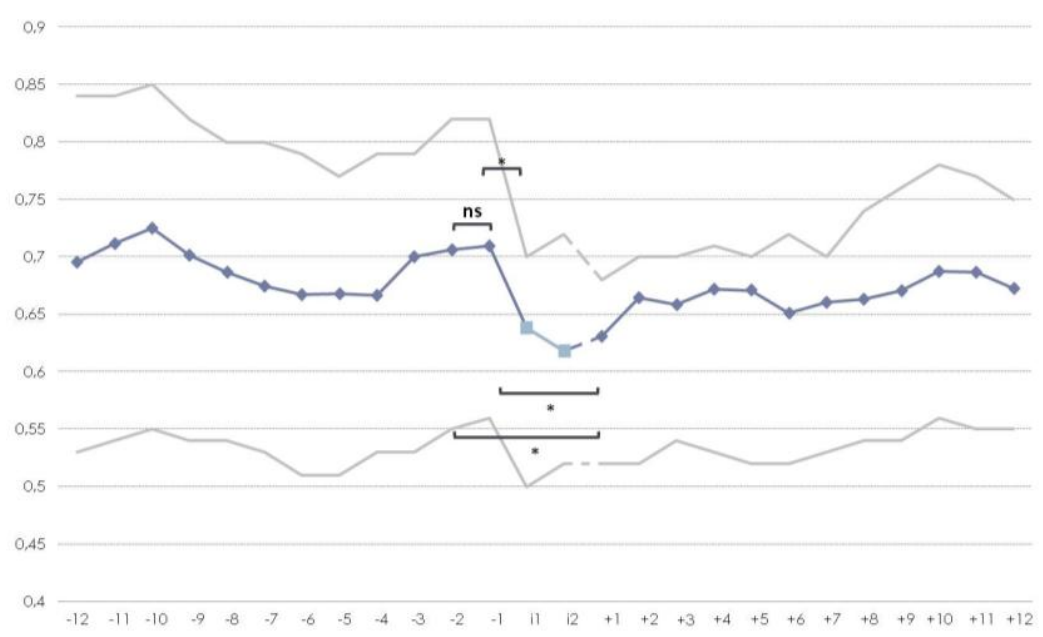




\subsection{Discussion}

The current study examined differences in autonomic functioning associated with the occurrence of epileptic seizures. Heart rate measures were determined from video-EEG monitoring recordings. Significant ictal changes in HRV measures were identified: an average increase in heart rate, SDANN, SD1 and SDI/SD2 ratio and a decrease in VLF power were observed. In the five minutes directly after the seizure, heart rate, SDANN and SDI returned to pre-seizure levels, while VLF power remained significantly decreased and SD1/SD2 ratio remained significantly increased compared to the interval preceding the seizure. No significant changes were identified in the pre-ictal interval or in intervals distant from the seizure.

Comparison with previously identified peri-ictal HRV patterns of patients with PNES resulted in significant between-group differences in pre-ictal SD2 and SD1/SD2 ratio and ictal RMSSD, SDANN, LF power, HF power, LF/HF ratio, SD2 and SDI/SD2 ratio. No significant differences were identified in post-ictal HRV parameters.

\subsubsection{Clinical interpretation}

The ictal increase in heart rate suggests an increase in sympathetic functioning and reduced vagal tone during epileptic seizures, which is consistent with previous findings reported in literature (Leutmezer et al., 2003; Ponnusamy et al., 2012). In contrast, the Poincaré plot parameter SD1 increased, which is assumed to reflect elevated vagal tone. The increase in SDANN and decrease in VLF power are more difficult to interpret, since the exact physiological correlates are still unknown. However, it has been shown that SDANN is heavily influenced by physical activity (Roach et al., 1998; Roach et al., 2004; Raj et al., 2004), which may explain the ictal changes.

It has been suggested that the ictal reduction of the vagal tone may be one of the reasons for sudden unexpected death in epilepsy (SUDEP), although very few SUDEP cases have been reported during video-EEG (and ECG) monitoring and the exact mechanism leading to the seizure-related cardiac arrest remains unclear (Tomson et al., 2008). Specific factors may predispose patients with epilepsy to parasympathetic dysfunction and form possible reasons for extra supervision, such as use of carbamazepine (Persson et al., 2003). 


\subsubsection{Implications for seizure prediction}

We did not identify substantial pre-ictal changes in heart rate and HRV parameters. This may be due to the fact that we examined averages over 5-minute intervals; we did not assess the dynamics of the change from the pre-ictal to the ictal HRV profile on ms-sec level. Our study can therefore not be compared with the findings of Jeppesen et al. (2010), who identified specifically high HF power 10 seconds preceding seizure onset in three patients with temporal lobe epilepsy. Possibly, preictal changes in HR(V) parameters only emerge seconds before the seizure and are therefore missed by our research design.

In contrast, findings of Behbahani et al., (2013) do suggest that the 5-minute interval preceding a seizure can be considered as prediction time for designing an algorithm of early detection of seizure onset based on HRV. They observed increased heart rate, LF/HF ratio and SD1/SD2 ratio 30 minutes before the seizure, and an even stronger increase 5 minutes before the seizure, when compared to 240 minutes before the seizure. As a consequence, we must not exclude the potential of HRV parameters as measured on a 5-minute time-scale as seizure predictors; possibly other factors such as small $n$ or heterogeneity of the study population have negatively influenced our ability to identify significant pre-ictal HRV changes. Future investigation of HRV changes measured in seconds or milliseconds and in larger patient populations would be particularly interesting for seizure detection uses.

\subsubsection{Implications for differential diagnosis}

Differential diagnosis between epilepsy and psychogenic non-epileptic seizures has been proven to be complicated; the period between the onset of PNES and the eventual diagnosis is often more than 6 years (Alsaadi and Marquez, 2005). The initial misdiagnosis as epilepsy has serious consequences for patients with PNES, such as exposure to unnecessary antiepileptic medication, and also has a substantial societal burden, as it causes the patients to consume a disproportionate amount of scarce medical resources (Kirmayer and Robbins, 1991) and erroneous treatments for intractable epilepsy are expensive (Martin et al., 1998).

For these reasons, it is important to identify factors that can accurately differentiate between PNES and epilepsy. Ponnusamy et al. (2012) were the first to compare the autonomic nervous system functioning of patients with epilepsy and 
patients with PNES. They identified significantly lower heart rate and higher RMSSD, LF power and HF power during PNES episodes compared with epileptic seizures, and demonstrated that the altered ictal HRV parameters could be used to differentiate epileptic seizures from PNES. Their findings are similar to the between-group differences that were identified in the current study, although their study design was not suited to draw conclusions about peri-ictal changes in HRV parameters. The results of the current study suggest that, in addition to ictal between-group differences, pre-ictal differences in HRV parameters may also be possible factors to distinguish epileptic seizures from PNES.

\subsubsection{Limitations}

We have carried out a relatively high number of statistical comparisons on a relatively modest dataset. The small study population may have led to type I errors (false negatives) due to lack of power, while the relatively large amount of comparisons may have resulted in type II errors (false positives). Also, the small $\mathrm{n}$ may have led several of the HRV averages to fall outside the $95 \%$ confidence interval, although the confidence intervals show the same trends as shown by the averages. Furthermore, the study population of patients with epilepsy was very heterogeneous, since multiple seizure types were included, each of which may have a distinctive influence on heart rate and heart rate variability. However, in view of the exploratory nature of this first study of the peri-ictal pattern of HRV parameters we thought it was appropriate to report our findings in this form.

\subsubsection{Conclusion}

Accepting the limitations, our data show that epileptic seizures are associated with increased heart rate, indicating an increased sympathetic tone and reduced vagal tone. HRV parameter changes are more difficult to interpret and need further investigation. The between-group differences that were identified between epileptic seizures and PNES even suggest that, after replication of our findings by future research, it may even be possible to identify peri-ictal $H R(V)$ signatures with sufficient specificity to aid in the differential diagnosis between epilepsy and PNES. 



\section{Chapter 9}

\section{DISCUSSION}

\subsection{Rationale}

The goal of this thesis was to investigate physiological characteristics of psychogenic non-epileptic seizures, in order to elucidate some of the psychogenic mechanisms of PNES. A specific focus was on the process of dissociation, since PNES are believed to often occur during dissociative episodes and an increased dissociation tendency has been frequently reported in patients with PNES. Therefore, the role of dissociation was extensively examined in a population of patients with PNES and in specific subgroups (Chapter 4).

In Chapter 2 and 3, previous literature was reviewed, and evidence was found for abnormalities in brain structure, brain function, and neuroendocrine functioning in patients with dissociative conditions such as PNES. However, only few physiological parameters have been explored in patients with PNES. For example, within the area of brain imaging, previous studies focused only on macrostructural MRI abnormalities (Devinsky et al., 2001; Reuber et al., 2002), which may not have sufficient sensitivity to detect abnormalities and provide minimal insight the processing of information and emotion. We considered functional imaging to be essential to gain insight in underlying brain mechanisms of PNES and dissociation. In other dissociative conditions, functional MRI analyses, specifically estimates of functional connectivity, have previously provided valuable insights in characteristics of brain networks associated with such conditions (Cojan et al., 2009; Voon et al., 2010b; De Lange et al., 2010; Voon et al., 2011). We investigated the potential of this technique in an exploratory study with patients with PNES (Chapter 5) and broadened our study population and analyses after positive findings (Chapter 6 ).

Literature on heart rate and heart rate variability parameters derived from electrocardiography (ECG) data of patients with PNES was limited to three investigations. Two studies indicated patients with PNES to have a lower resting vagal tone than healthy volunteers, which suggests the patients to be in a 
continuous state of hypervigilance (Bakvis et al., 2009; Ponnusamy et al., 2011). In addition, indications for an increase in vagal tone during PNES episodes have been identified (Ponnusamy et al., 2012), which suggest PNES episodes to have a calming effect rather than being a stress response. These latter findings correspond well with the observation of increased parasympathetic activation after hypnotic induction (Diamond et al., 2008; Aubert et al., 2009; Vandevusse et al., 2010). However, explanations about the pattern of arousal before, during and after PNES episodes cannot be derived from the comparison of an ECG sample during PNES with a sample during rest which is chosen irrespective of occurrence in time relative to the PNES episode (as in the study of Ponnusamy et al. (2012)). We considered this information to be crucial for identifying the emotional function of PNES, and have therefore examined longer ECG samples that captured PNES episodes (Chapter 7). To examine the potential aid of ECG-derived parameters in the differential diagnosis between PNES and epilepsy, we also investigated the peri-ictal patterns of heart rate (variability) in a population of patients with genuine epileptic seizures (Chapter $8)$.

\subsection{The role of dissociation in PNES}

Describing a general personality profile of a population of patients with PNES appeared to conceal specific subgroups (Chapter 4). A remarkable finding was the absence of increased dissociation scores in the average profile. However, one of the subgroups that was defined concerned a 'psychotrauma subgroup' with dissociative disorders, in which patients showed a high level of somatoform dissociation, complaints in daily life and cognitive coping problems. These findings indicate similarity with dissociative disorder (as defined in ICD-10) and with a subgroup of post-traumatic stress disorder. Based on the results it is assumed that $1 / 4$ to $1 / 3$ of the total population of patients with PNES fits within this profile.

Other subgroups represented patients with a strong tendency to react with (psycho-) somatic complaints on psychological distress and patients with a high vulnerability on personality factors such as impulsivity, self-blame and rigidity. Based on these findings, not all patients with PNES demonstrate an increased dissociation tendency; although a considerable subgroup could be identified that showed increased dissociation scores. 


\subsection{Functional MRI}

We explored the possibilities of functional MRI activation mapping and connectivity analyses in a pilot study (Chapter 5). Patients with PNES demonstrated significantly lower cognitive performance, higher dissociation tendency and increased functional connectivity between brain areas involved in emotion, executive functions and motor planning compared to healthy controls. Since dissociation scores were significantly correlated with the strength of these functional connections, we suggested a dissociation mechanism to be responsible for an increased tendency in patients with PNES to translate emotions into motor manifestations.

In a second study, involving a larger patient group (Chapter 6), the data-driven approach of independent component analysis (ICA) was applied to investigate alterations in whole-brain resting-state networks. Significant group differences were revealed in resting-state networks associated with executive control, sensorimotor functions, fronto-parietal activation and the default mode, which were also correlated with dissociation scores. These findings made us assume that dissociation is perturbing multiple cognitive functions and brain networks besides emotion and motor control.

\subsection{Electrocardiography}

To gain insight in the pattern of heart rate variability around PNES episodes, we analyzed the ECG data of 20 patients which were collected during videoelectroencephalography monitoring (Chapter 7). In the five-minute interval before a PNES episode, we identified a significant increase in heart rate, while SDANN and very low frequency power significantly decreased. In the five-minute interval after a PNES, we observed opposite effects. These findings indicate an increase in sympathetic functioning to precede PNES episodes, and an increase in parasympathetic functioning during and after PNES. Future research is needed to identify the exact nature of the increased arousal shortly before the episode; it may indicate an increased feeling of discomfort, which is relieved by the passing of the PNES. However, the increased sympathetic functioning may also result from the body's anticipation to movement. 
To explore the possibilities of heart rate variability parameters in the differential diagnosis between PNES and epilepsy, we also analyzed peri-ictal ECG data of 17 patients with genuine epileptic seizures (Chapter 8). Patients with epilepsy did not demonstrate significant pre-ictal HRV changes, and the significant differences between epileptic seizures and PNES that were identified suggested that pre-ictal and ictal differences in HRV parameters may in future indeed be possible factors to distinguish epileptic seizures from PNES.

\subsection{Clinical interpretation}

The results presented in this thesis suggest that patients with PNES use alternative routes of information and emotion processing in the brain, which appear to be related to the process of dissociation. In addition, ECG analyses indicated PNES to have a function in alleviating arousal. These findings raise questions which are important with regard to clinical interpretation. The aim of this paragraph is to provide possible answers to some of these questions, while reflecting on the previous chapters of this thesis and literature.

Do the findings presented in this thesis indicate that psychogenic non-epileptic seizures are not purely psychogenic, but also have a physiological origin (i.e. should be renamed as psychophysiological non-epileptic seizures)?

Although the research in this thesis demonstrates psychogenic non-epileptic seizures to be accompanied by physiological changes, it is not possible to refer to these physiological abnormalities as cause of the episodes, since the observed physiological changes may also well be a consequence of the psychological processes that lead to the occurrence of a PNES. The changes in heart rate variability that precede and follow PNES indicate the episodes to have a function in relieving arousal, but the exact nature of the arousal remains unclear. The physiological arousal may be caused by emotional distress from external or internal factors, but may also result from the feeling that a PNES is coming, or from the body's anticipation to movement. The same question holds for the observations of altered brain network connectivity, which elucidate the dissociative mechanism 
adopted by patients with PNES, but could either be the cause or consequence of dissociation and psychogenic non-epileptic seizures.

However, since all research in this thesis suggests physiological changes to cooccur with PNES, changing the terminology to psychophysiological non-epileptic seizures might not be inadequate, as psychophysiological phenomena can be defined as physiological correlates of psychological processes. Nonetheless, a classification based on psychopathology would possibly be more relevant for tailoring treatment of patients with PNES to the main underlying etiological problem, since describing all patients as having psychogenic or psychophysiological nonepileptic seizures seems to conceal specific subgroups. For example, based on the research presented in this thesis, it could be advised to define a subgroup of patients having dissociative non-epileptic seizures. Other subgroups, e.g. defined on somatization tendency or personality problems, probably benefit from different treatment strategies than patients with the dissociative type of PNES. In fact, similar developments are needed as were accomplished with regard to the diagnostic classification of epilepsy: Beside the general diagnosis (epilepsy), subgroups have been determined based on pathology (e.g. frontal-lobe, temporal-lobe or generalized epilepsy), and treatment is tailored consequently.

In conclusion, the physiological correlates of psychogenic non-epileptic seizures are important for better understanding of - at least - one of the pathological mechanisms, and as such can be valuable in defining subgroups, but do not necessarily need to be implemented in terminology.

Can physiological measures extracted from MRI and/or ECG aid the differential diagnosis between PNES and epilepsy?

The primary aim of the research described in this thesis was to use physiological signals as measured by MRI and ECG to gain insight in pathological mechanisms underlying PNES. The purpose of the MRI investigations was to identify deviations from normal brain functioning, which is why the control group consisted of healthy participants without epilepsy. Therefore, no conclusions about the potential use of functional (connectivity) MRI to aid differential diagnosis can be drawn based on our MRI findings. Also, since we were the first to use fMRI in patients with PNES, no indications can be deduced from previous literature. 
We did identify one previous study that has examined the potential use of ECG data for differential diagnosis: Ponnusamy et al. (2012) focused on heart rate variability parameters to distinguish patients with PNES from patients with complex partial seizures, and found a larger increase in heart rate and a larger decrease in heart rate variability during epileptic seizures than during PNES. Their findings suggest ECG and heart rate variability analyses to potentially be useful in the process of differential diagnosis, although discrimination is still difficult since both seizure types expressed increased sympathetic nervous system activation and reduced vagal tone.

The aim of our ECG investigation in patients with PNES was to identify withinsubject changes in peri-ictal autonomic functioning and therefore needed no control group. Similarly, the primary aim of the ECG study in patients with epilepsy was to define the peri-ictal pattern of HRV changes, but preliminary conclusions on possibilities for differential diagnosis were also discussed. Our studies demonstrated a pre-ictal increase in sympathetic activity and reduced vagal tone in patients with PNES, whereas patients with epilepsy demonstrated no significant pre-ictal changes in heart rate and HRV parameters on the time scale measured. Between-group analyses revealed significant differences in pre-ictal and ictal HRV parameters, whereas no significant post-ictal differences were identified. Our findings were similar to the between-group differences in ictal HRV parameters that were previously described by Ponnusamy et al. (2012). Replication of our findings and those of Ponnusamy et al. would be a first step in using ECG-derived parameters as a tool in differential diagnosis. Nevertheless, the aforementioned studies are all based on group averages; differential diagnosis with ECG is not feasible until significant changes in autonomic functioning can be demonstrated in individual patients.

How to interpret the observation that patients have PNES without increased dissociation tendency?

The MRI research in this thesis positioned increased dissociation tendency as a key feature of patients with PNES. Indeed, the average scores on dissociation scales were significantly higher in the PNES group compared to the control group. There were however patients with PNES whose dissociation tendency was within normal range, which suggests other etiological factors to be responsible for PNES 
development. The research on subgroups indicates that 1/4 to 1/3 of the total population of patients with PNES shows increased dissociation tendencies, possibly as a result of traumatic experiences. Other subgroups, which did not show increased dissociation scores, may have developed PNES due to a strong somatization tendency and possible personality disorders.

However, it is important to mention that normal dissociation scores do not automatically imply that patients do not have dissociative psychogenic nonepileptic seizures. It is very likely that even patients without increased dissociation tendency experience dissociative PNES episodes, according to the symptoms of depersonalization and derealization that accompany the PNES episodes also in these patients.

Can persons with high dissociation tendencies function without pathological symptoms?

A high dissociation tendency does not necessarily have to lead to invalidating forms of dissociation such as are observed in patients with PNES, the dissociative type of post-traumatic stress disorder, and dissociative identity disorder. In the absence of traumatic events or extreme stress, persons with a high dissociation tendency may not experience any negative effects on their daily functioning. In fact, persons with a high dissociation tendency are observed to have increased creative imagination (Pérez-Fabello and Campos, 2011), suggesting some beneficial effects of dissociation in daily life as well.

Can PNES be fully explained as a dissociative mechanism? Or can it also be considered as a symptom of somatization, conversion, or an alternative phenomenon?

PNES are considered to have a dissociative nature because the key features of many PNES are depersonalization and derealization. Moreover, patients with PNES often demonstrate an increased dissociation tendency (Alper et al., 1997; Bowman and Coons, 2000; Prueter et al., 2002). The results of our MRI studies also clearly indicate a higher than average dissociation tendency in patients with PNES, and a 
relationship between the functional brain abnormalities in PNES and dissociation tendency.

Somatization and conversion are two other phenomena frequently observed in patients with PNES. Somatization can be seen as the tendency to express emotional distress in the form of physical symptoms and to seek medical help for them (Lipowski, 1988). Conversion is the observation of the occurrence of neurological symptoms in response to stressful situations. The difference with somatization is that conversion symptoms are almost always preceded by a traumatic event, while somatization is a more chronic condition (Stone et al., 2005).

Patients with PNES often demonstrate other forms of somatization (Devinsky, 1998; Ford, 1993) and have been differentiated from patients with epilepsy using somatization scales (Kuyk et al., 1999). However, not all patients with PNES demonstrate a somatization tendency. Two of the subgroups described in Chapter 4, the 'high vulnerability somatization subgroup' and 'high vulnerability somatization subgroup with a low cognitive level', represent two subgroups of patients with PNES who show a strong tendency to react with somatic complaints on psychological distress, but which differ on cognitive level. These subgroups may represent about $35 \%$ of the population of patients with PNES.

Reasons for considering PNES as conversion symptom are the reports of traumatic experiences by patients with PNES and the occurrence of PNES in patients with post-traumatic stress syndrome (Fiszman et al., 2004). The 'psychotrauma subgroup', which also shows increased dissociation tendency (Chapter 4), can be considered to have PNES as a symptom of conversion and dissociation.

It appears that characteristics of somatization, conversion and dissociation are evident in particular subgroups of patients with PNES, but not all patients can be ordered under all three headings. There are additional explanations for the occurrence of PNES, as described in Chapter 4. The varying explanations for the occurrence of PNES, all in need of a specific treatment approach, plead for the definition of subgroups based on etiology, as previously discussed. 
What advice, based on the research presented in this thesis, can be given for the diagnosis and treatment of PNES?

The diagnostic process of PNES should consist of two stages, the first being the exclusion of epilepsy or other organic factors. The more specialists are alert on factors that might indicate a psychogenic origin of symptoms, the earlier patients may be referred to an epilepsy centre for video-EEG for differential diagnosis, which would result in a reduction of the average delay of the correct diagnosis of PNES. Based on the research in this thesis, trauma history, dissociation tendency, and somatization tendency may be proposed as factors neurologists may be attentive to. The diagnosis of "no epilepsy", which is frequently established in a tertiary referral centre, must be followed by careful explaining the PNES diagnosis to the patient and his/her family, in which the neurologist or epileptologist has an important role (Bodde et al., 2009b). For a small group of patients this is sufficient to reduce seizure frequency or even to become seizure free (Bodde et al., 2007).

In the second diagnostic stage, a positive diagnosis is established in which underlying psychological and social factors are evaluated. The resulting psychological profile, which commonly includes multiple underlying factors, can be used to determine treatment indications. For example, treatment of the 'psychotrauma subgroup' should focus on trauma processing, but also on additional factors such as the replacement of dissociation as a coping style.

The initial phase of treatment often focuses on stress reduction in daily life and extension of coping strategies, which is verified by the results of our ECG analyses: The increased sympathetic system activation we observed shortly before PNES episodes may indicate increased arousal and PNES serving as a deficient coping strategy. This is in line with findings of Testa et al. (2012), who report patients with PNES to have elevated levels of perceived stress and fewer action strategies to reduce the impact of a stressor.

\subsection{Future perspectives}

The research presented in this thesis suggests subgroup analysis of patients with PNES to be important. Therefore, objective and international criteria are needed to distinguish these subgroups in order to facilitate comparison of subgroup research. 
Ideally, randomized clinical trials are designed to identify the most suitable treatment of the specific subgroups in the PNES population.

Also, the effects of dissociation and PNES on brain networks could not be disentangled based on the results of our MRI studies. Future studies could therefore compare the functional connectivity patterns of patients with PNES and high dissociation tendency with those of PNES subgroups with low dissociation tendency (e.g. patients who have PNES as a result of increased somatization tendency or other personality factors) or healthy controls with high dissociation tendency.

Finally, the role of stress as a triggering factor of PNES episodes needs further research. Our ECG findings suggest PNES to be preceded by increased arousal, but it is unclear whether the increased sympathetic system activity results from external or internal stressors, from "prodromal" feelings that a PNES is coming, or from the body's anticipation to movement. Future investigation is needed to replicate our findings and to identify the exact nature of the increased arousal that precedes PNES. 


\section{Summary}

The goal of this thesis was to investigate physiological characteristics of patients with psychogenic non-epileptic seizures (PNES) in order to explore possible pathological mechanisms. A specific focus was on the process of dissociation, since PNES often involve dissociative phenomena and an increased dissociation tendency has been previously reported in patients with PNES. This thesis investigated the exact role of dissociation in (subgroups of) patients with PNES, and examined physiological characteristics derived from magnetic resonance imaging and electrocardiography data in order to clarify the underlying processes that lead to the occurrence of PNES.

Chapter 2 reviewed the literature on physiological characteristics of patients with PNES. All studies that were identified had an exploratory character. However, the results suggest that neurophysiological characteristics such as brain activity, cardiovascular parameters and neuroendocrine functioning may be abnormal in patients with PNES, and warranted future research.

In Chapter 3, literature on neurophysiological correlates of the wider concept of functional neurological syndromes and symptoms (FNSS) and related dissociative characteristics was reviewed in order to explore potential underlying mechanisms of PNES. HRV, EEG and (functional) MRI emerged as sensitive methods to detect physiological changes related to hypnosis, dissociation and dissociative disorders such as FNSS, and can possibly provide more information about their etiology. It was suggested that the use of such measures in future research could provide more insight in underlying mechanisms and could eventually provide guidelines for appropriate treatment of dissociative conditions.

The study described in Chapter 4 aimed to define a general psychological profile of patients with PNES and to specify possible subgroups. Describing a general profile appeared to conceal specific subgroups with subsequent treatment implications. Four important subgroups were identified; a subgroup of patients with trauma history 
and increased dissociation scores, two subgroups of patients with increased somatization tendency (which were differentiated based on the presence or absence of disturbed level of cognitive functioning), and a subgroup of patients whose vulnerability resulted from other personality factors.

Chapter 5 describes the findings of a study in which seed-based functional connectivity analyses of MRI data were used to identify differences in resting-state brain networks between patients with PNES and healthy controls. Patients demonstrated stronger functional connectivity values between areas involved in emotion (insula), executive control (inferior frontal gyrus and parietal cortex) and movement (precentral sulcus) which were significantly associated with dissociation scores. We suggested that the abnormally strong functional connectivity in patients with PNES provides a possible neurophysiological correlate for the underlying psychoform and somatoform dissociation mechanism where emotion can influence executive control, resulting in a motor reaction (e.g., seizure-like episodes).

In the study described in Chapter 6, resting-state brain networks of patients with PNES were assessed in a larger study population, and using the data-driven approach of independent component analyses. Patients displayed increased contribution of the orbitofrontal, insular and subcallosal cortex in the resting-state fronto-parietal network; the cingulate and insular cortex in the resting-state network associated with executive control; the cingulate gyrus, superior parietal lobe, preand postcentral gyri and supplemental motor cortex in the resting-state network associated with sensorimotor functioning; and the precuneus and (para-) cingulate gyri in the default-mode network. The connectivity strengths within these regions of interest significantly correlated with dissociation scores. In the discussion, we proposed possible pathways by which the alterations identified in the resting-state networks could contribute to the process of dissociation in patients with PNES.

Chapter 7 describes the results of heart rate variability (HRV) analyses in patients with PNES. In the five-minute interval before PNES, we observed significantly increased activity of the sympathetic branch of the autonomic nervous system, and significantly increased parasympathetic functioning after PNES. Future investigation is needed to identify the exact nature of the increased arousal that precedes PNES, 
since it is unclear whether the increased sympathetic system activity results from external or internal stressors, from "prodromal" feelings that a PNES is coming, or from the body's anticipation to movement.

In Chapter 8, peri-ictal heart rate variability parameters of patients with epilepsy were examined and the potential aid of these parameters to predict seizures and differentiate between epilepsy and PNES is discussed. Since no significant pre-ictal changes in heart rate and HRV parameters were observed, the prediction of seizures appears not possible based on the used parameters and approach. It also suggests the pre-ictal changes we observed in patients with PNES (Chapter 7) to be specific for this population and potentially useful for differential diagnosis in future.

In Chapter 9, the clinical implications of the findings presented in this thesis were discussed, as well as possibilities for future research. 



\section{Samenvatting}

Het onderzoek in dit proefschrift richt zich op fysiologische kenmerken van patiënten met psychogene niet-epileptische aanvallen (PNEA) met als doel mogelijke pathologische mechanismen te verkennen. Specifieke aandacht werd gericht op het proces van dissociatie, omdat PNEA vaak gepaard gaan met dissociatieve kenmerken, en omdat vit eerder onderzoek is gebleken dat patiënten met PNEA vaak een verhoogde neiging tot dissociatie hebben. De precieze rol van dissociatie in (subgroepen van) patiënten met PNEA werd onderzocht, en magnetic resonance imaging (MRI) en electrocardiografie (ECG) technieken werden ingezet om meer duidelijkheid te verschaffen over de onderliggende processen die leiden tot het optreden van de aanvallen.

Hoofdstuk 2 betreft een review van de reeds bestaande literatuur over fysiologische kenmerken van patiënten met PNEA. Alle onderzoeken die eerder zijn vitgevoerd hadden een verkennend karakter. De resultaten wezen er echter op dat neurofysiologische karakteristieken zoals hersenactiviteit, cardiovasculaire parameters en neuroendocrien functioneren mogelijk afwijkend zijn in patiënten met PNEA en gaven aanleiding tot nader onderzoek.

In Hoofdstuk 3 wordt literatuur over neurofysiologische correlaten van functionele neurologische syndromen en symptomen (FNSS) en gerelateerde dissocatieve kenmerken besproken om zo mogelijke onderliggende mechanismen van PNEA te onderzoeken. MRI, EEG en ECG technieken bleken sensitief genoeg om fysiologische veranderingen te detecteren die gepaard gaan met hypnose, dissociatie en dissociatieve aandoeningen zoals FNSS, en kunnen mogelijk meer informatie verschaffen over de etiologie. We concludeerden dat het gebruik van zulke technieken in toekomstig onderzoek mogelijk meer inzicht in de onderliggende mechanismen van dissociatieve aandoeningen kan bieden, en wellicht ook richtlijnen voor gepaste behandeling oplevert. 
Het onderzoek dat wordt omschreven in Hoofdstuk 4 had als doel om een algemeen psychologisch profiel van patiënten met PNEA te definiëren en om mogelijke subgroepen te onderscheiden. Factoranalyse toonde vier subgroepen; een subgroep van patiënten met psychotrauma en toegenomen dissociatietendens, twee subgroepen van patiënten met toegenomen somatisatietendens (bij een daarvan was ook het cognitief functioneren van de patiënten aangedaan), en een subgroep van patiënten die werden gekenmerkt door persoonlijkheidsproblemen.

Hoofdstuk 5 beschrijft de bevindingen van een MRI onderzoek waarin de functionele hersenconnectiviteit werd geanalyseerd om de hersennetwerken in rust (zgn. resting-state netwerken) van patiënten met PNEA en gezonde controles te vergelijken. Patiënten met PNEA vertoonden sterkere functionele connecties tussen hersengebieden die betrokken zijn bij emotie (insula), executief functioneren (inferieur frontale gyrus en pariëtale cortex) en beweging (precentrale sulcus) die significant correleerden met dissociatiescores. We concludeerden dat de abnormaal sterke functionele connectiviteit bij patiënten met PNEA een mogelijk neurofysiologisch correlaat is van het onderliggende psychoforme en somatoforme dissociatiemechanisme, waardoor emotie mogelijk executieve controle kan beïnvloeden, resulterend in een motorische reactie (zijnde een aanval).

In het onderzoek dat wordt omschreven in Hoofdstuk 6 werden de resting-state hersennetwerken van een grotere studiepopulatie onderzocht middels analyse van onafhankelijke componenten (independent component analyses; ICA). Patiënten met PNEA vertoonden een sterkere bijdrage van de orbitofrontale cortex, insula en gyrus cinguli in het frontaal-pariëtale netwerk; de gyrus cinguli en insula in het netwerk dat geassocieerd wordt met executieve controle; de gyrus cinguli, superior pariëtaalkwab, pre- en postcentrale gyri en supplementaire motorische cortex in het netwerk dat geassocieerd wordt met sensorisch-motorisch functioneren; en de precuneus en gyrus cinguli in het zgn. default mode netwerk.

Hoofdstuk 7 beschrijft de resultaten van onderzoek naar de hartslagvariabiliteit (heart rate variability; HRV) van patiënten met PNEA dat werd vitgevoerd om meer inzicht te krijgen in het functioneren van het autonome zenuwstelsel rondom een 
aanval. In het 5-minuten interval voorafgaand aan een PNEA werd een significante toename van het sympathisch functioneren waargenomen, en na een PNEA werd een significante toename in parasympathisch functioneren gezien. Verder onderzoek is nodig om de oorzaak van de toename in sympathisch functioneren voorafgaand aan een aanval te achterhalen, aangezien het onduidelijk is of deze wordt veroorzaakt door externe of interne stressoren, door "prodromale" gevoelens dat een PNEA nadert, of doordat het lichaam zich anticipeert op beweging.

In Hoofdstuk 8 werden de peri-ictale HRV parameters van epileptische aanvallen onderzocht, en werd gekeken naar de potentiële bruikbaarheid van deze maten om aanvallen te voorspellen en te differentiëren tussen epilepsie en PNEA. Aangezien er geen significante pre-ictale veranderingen in hartslag en HRV parameters werden waargenomen, lijkt het voorspellen van aanvallen niet mogelijk met de gebruikte parameters en analysemethoden. Ook kan worden geconcludeerd dat de pre-ictale veranderingen die we bij patiënten met PNEA identificeerden (Hoofdstuk 7) specifiek zijn voor deze patiëntenpopulatie en wellicht in de toekomst kunnen worden ingezet voor differentiaaldiagnostiek.

In Hoofdstuk 9 werden de klinische implicaties van de bevindingen in dit proefschrift en mogelijkheden voor toekomstig onderzoek besproken. 

Abubakr A, Kablinger A, Caldito G. Psychogenic seizures: clinical features and psychological analysis. Epilepsy Behav 2003;4:241-245.

Akselrod S, Gordon D, Ubel FA, et al. Power spectrum analysis of heart rate fluctuation: a quantitative probe of beat to beat cardiovascular control. Science 1981;213:220-22.

Aldenkamp AP, Alpherts WC. The effect of the new antiepileptic drug rufinamide on cognitive functions. Epilepsia 2006;47:1 153-9.

Aldenkamp AP, Mulder OG. Behavioural mechanisms involved in pseudoepileptic seizures: a comparison between patients with epileptic seizures and patients with pseudo-epileptic seizures. Seizure 1997;6:275-82.

Ali F, Rickards $\mathrm{H}$, Bagary $M$, et al. Ictal consciousness in epilepsy and nonepileptic attack disorder. Epilepsy Behav 2010;19:522-5.

Ali S, Jabeen S, Arain A, et al. How to use your clinical judgment to screen for and diagnose psychogenic nonepileptic seizures without videoelectroencephalogram. Innov Clin Neurosci 2011;8:36-42.

Alper K. Nonepileptic seizures. Neurol Clin 1994;12:153-73.

Alper K, Devinsky O, Perrine $K$, et al. Dissociation in epilepsy and conversion nonepileptic seizures. Epilepsia 1997;38:991-7.

Alsaadi TM, Marquez AV. Psychogenic nonepileptic seizures. Am Fam Physician 2005;2:849-56.

Alsaadi TM, Thieman C, Shatzel A, et al. Video-EEG telemetry can be a crucial tool for neurologists experienced in epilepsy when diagnosing seizure disorders. Seizure 2004;13:32-4.

Appel ML, Berger RD, Saul JP, et al. Beat to beat variability in cardiovascular variables: noise or music? J Am Coll Cardiol 1989;14:1 139-48.

Arnold LM, Privitera MD. Psychopathology and trauma in epileptic and psychogenic seizure patients. Psychosomatics 1996;37:438-43.

Atmaca $M$, Aydin A, Tezcan E, et al. Volumetric investigation of brain regions in patients with conversion disorder. Prog Neuropsychopharmacol Biol Psychiatry 2006;30:708-13. 
Aubert AE, Verheyden B, Beckers $F$, et al. Cardiac autonomic regulation under hypnosis assessed by heart rate variability: spectral analysis and fractal complexity. Neuropsychobiology 2009;60:104-12.

Baghdadi G, Nasrabadi AM. EEG phase synchronization during hypnosis induction. J Med Eng Technol 2012;36:222-9.

Bagshaw AP, Cavanna AE. Resting state networks in paroxysmal disorders of consciousness. Epilepsy Behav 2013;26:290-4.

Baillès $E$, Pintor $L$, Torres $X$, et al. Psychiatric disease in patients with psychogenic nonepileptic seizures referred from an epilepsy unit in a general hospital. Actas Esp Psiquiatr 2004;32:76-81.

Bakvis P, Roelofs K, Kuyk J, et al. Trauma, stress, and preconscious threat processing in patients with psychogenic nonepileptic seizures. Epilepsia 2009:50:1001-11.

Bakvis P, Spinhoven P, Giltay EJ, et al. Basal hypercortisolism and trauma in patients with psychogenic nonepileptic seizures. Epilepsia 2010;51:752-59.

Bakvis P, Spinhoven P, Zitman FG, et al. Automatic avoidance tendencies in patients with psychogenic non-epileptic seizures. Seizure 2011 ;20:628-34.

Bammer R. Basic principles of diffusion-weighted imaging. Eur J Radiol 2003;45:16984.

Barry JJ, Sanborn K. Etiology, diagnosis and treatment of nonepileptic seizures. Curr Neurol Neurosci Rep 2001;1:381-9.

Baslet G. Psychogenic non-epileptic seizures: A model of their pathogenic mechanism. Seizure 2011;20:1-13.

Baslet G, Roiko A, Prensky E. Heterogeneity in psychogenic nonepileptic seizures: understanding the role of psychiatric and neurologic factors. Epilepsy Behav 2010;17:236-41.

Bassett, DS, Bullmore ET. Human brain networks in health and disease. Curr Opin Neurol 2009;22:340.

Bautista RD. Expanding the theory of symptom modelling in patients with psychogenic nonepileptic seizures. Epilepsy Behav 2008;13:407-9.

Beckmann CF, Deluca M, Devlin JT, et al. Investigations into resting-state connectivity using independent component analysis. Phil Trans R Soc B 2005;360:1001-13. 
Behbahani S, Dabanloo NJ, Nasrabadi AM, et al. Pre-ictal heart rate variability assessment of epileptic seizures by means of linear and non-linear analyses. Anadolu Kardiyol Derg 2013;13:797-803.

Bell V, Oakley DA, Halligan PW, et al. Dissociation in hysteria and hypnosis: evidence from cognitive neuroscience. J Neurol Neurosurg Psychiatry 201 1;82:332-9.

Benbadis SR, Allen HW, Hauser WA. An estimate of the prevalence of psychogenic non-epileptic seizures. Seizure 2000;9:280-1.

Berger S, Kliem A, Yeragani V, et al. Cardio-respiratory coupling in untreated patients with major depression. J Affect Disord 2012;139:166-71.

Bernstein EM, Putnam FW. Development, reliability, and validity of a dissociation scale. J Nerv Ment Dis 1986;174:727-35.

Bodde NM, Bartelet DC, Ploegmakers M, et al. MMPI-II personality profiles of patients with psychogenic nonepileptic seizures. Epilepsy Behav 201 1;20:674-80.

Bodde NM, Brooks JL, Baker GA, et al. Psychogenic non-epileptic seizures-Diagnostic issues: A critical review. Clin Neurol Neurosurg 2009a;1 11:1-9.

Bodde NM, Brooks JL, Baker GA, et al. Psychogenic non-epileptic seizures--definition, etiology, treatment and prognostic issues: a critical review. Seizure 2009b;18:543-53.

Bodde NM, Janssen AM, Theuns C, et al. Factors involved in the long-term prognosis of psychogenic nonepileptic seizures. J Psychosom Res 2007;6:545-51.

Bodde NM, Lazeron RH, Wirken JM, et al. Patients with psychogenic non-epileptic seizures referred to a tertiary epilepsy centre: patient characteristics in relation to diagnostic delay. Clin Neurol Neurosurg 2012;1 14:217-22.

Bosch NM, Riese H, Dietrich A, et al. Preadolescents' somatic and cognitive-affective depressive symptoms are differentially related to cardiac autonomic function and cortisol: the TRAILS study. Psychosom Med 2009;71:944-50.

Bovin MJ, Marx BP. The importance of the peritraumatic experience in defining traumatic stress. Psychol Bull $2011 ; 137: 47-67$.

Bowers KS. Imagination and dissociation in hypnotic responding. Int J Clin Exp Hypn 1992;40:253-75.

Bowman ES, Coons PM. The differential diagnosis of epilepsy, pseudoseizures, dissociative identity disorder, and dissociative disorder not otherwise specified. Bull Menninger Clin 2000;64:164-80. 
Bowman ES, Markand ON. Psychodynamics and psychiatric diagnoses of pseudoseizure subjects. Am J Psychiatry 1996;153:57-63.

Bracke D, Van Leeuwen K, Verhofstadt-Denève L. Comorbiditeit van zelfverwondend gedrag en dissociatieve symptomen bij vrouwelijke psychiatrische patienten. Tijdschr Psychiatr 2001;43:673-82.

Brand M, Eggers C, Reinhold N, et al. Functional brain imaging in 14 patients with dissociative amnesia reveals right inferolateral prefrontal hypometabolism. Psychiatry Res 2009;174:32-9.

Bremner JD, Southwick S, Brett E, et al. Dissociation and posttraumatic stress disorder in Vietnam combat veterans. Am J Psychiatry 1992;149:328-32.

Breslau N, Kessler RC, Chilcoat HD, et al. Trauma and posttraumatic stress disorder in the community: the 1996 Detroit Area Survey of Trauma. Arch Gen Psychiatry 1998;55:626-32.

Briere J, Scott C, Weathers F. Peritraumatic and persistent dissociation in the presumed etiology of PTSD. Am J Psychiatry 2005;162:2295-2301.

Brosschot JF, Van Dijk E, Thayer JF. Daily worry is related to low heart rate variability during waking and the subsequent nocturnal sleep period. Int J Psychophysiol 2007;63:39-47.

Brown MC, Levin BE, Ramsay $E$, et al. Characteristics of patients with nonepileptic seizures. J Epilepsy 1991;4:225-9.

Brown RJ, Cardena E, Nijenhuis E, et al. Should conversion disorder be reclassified as a dissociative disorder in DSM V? Psychosomatics 2007:48:369-78.

Brunetto AF, Silva BM, Roseguini BT, et al. Limiar ventilatório e variabilidade da frequência cardíaca em adolescentes. Rev Bras Med Esporte 2005;1 1:22-7.

Buckner RL, Vincent JL. Unrest at rest: default activity and spontaneous network correlations. Neurolmage 2007;37:1091-6.

Bullmore E, Sporns O. Complex brain networks: graph theoretical analysis of structural and functional systems. Nat Rev Neurosci 2009;10:186-98.

Burgmer $M$, Kugel $\mathrm{H}$, Pfleiderer $B$, et al. The mirror neuron system under hypnosis Brain substrates of voluntary and involuntary motor activation in hypnotic paralysis. Cortex 2013;49:437-45.

Butler LD, Duran RE, Jasiukaitis $P$, et al. Hypnotizability and traumatic experience: a diathesis-stress model of dissociative symptomatology. Am J Psychiatry $1996 ; 153: 42-63$. 
Calhoun VD, Liu J, Adali T. A review of group ICA for fMRI data and ICA for joint inference of imaging, genetic, and ERP data. Neurolmage 2009;45:S163-72.

Cancelliere AEB, Kertesz A. Lesion localization in acquired deficits of emotional expression and comprehension. Brain Cog 1990;13:133-147.

Cardeña E, Jönsson $P$, Terhune DB, et al. The neurophenomenology of neutral hypnosis. Cortex 2013;49:375-85.

Carlson EB. Trauma assessments: a clinician's guide. Guilford, USA, 1997.

Castillo RJ. Depersonalization and meditation. Psychiatry 1990;53:158-68.

Cavanagh JF, Figueroa CM, Cohen MX, et al. Frontal theta reflects uncertainty and unexpectedness during exploration and exploitation. Cereb cortex 2012;22:2575-86.

Cavanna AE. The precuneus and consciousness. CNS Spectr 2007;12:545-52.

Cavanna AE, Trimble MR. The precuneus: a review of its functional anatomy and behavioural correlates. Brain 2006;129:564-83.

Cerezuela GP, Tejero P, Chóliz M, et al. Wertheim's hypothesis on 'highway hypnosis': empirical evidence from a study on motorway and conventional road driving. Accid Anal Prev 2004;36:1045-54.

Chang JS, Yoo CS, Yi SH, et al. Differential pattern of heart rate variability in patients with schizophrenia. Prog Neuropsychopharmacol Biol Psychiatry 2009;33:991-5.

Chen $\mathrm{CH}$, Suckling J, Ooi $\mathrm{C}$, et al. A longitudinal fMRI study of the manic and euthymic states of bipolar disorder. Bipolar Disord. 2010;12:344-7.

Chu JA, Dill DL. Dissociative symptoms in relation to childhood physical and sexual abuse. Am J Psychiatry 1990;147:887-92.

Cianci V, Ferlazzo E, Condino F, et al. Rating scale for psychogenic nonepileptic seizures: scale development and clinimetric testing. Epilepsy Behav 2011;21:12831.

Cloninger CR. A systematic method for clinical description and classification of personality variants A proposal. Arch Gen Psychiatry 1987;44:573-88.

Cloninger CR, Przybeck TR, Svrakic DM, et al. The temperament and character inventory (TCl): a guide to its development and use. St. Louis, MS: Center for Psychobiology of Personality Washington University; 1994.

Cloninger CR, Svrakic DM, Przybeck TR. A psychobiological model of temperament and character. Arch Gen Psychiatry 1993;50:975-90. 
Cojan Y, Waber L, Schwartz S, et al. The brain under self-control: modulation of inhibitory and monitoring cortical networks during hypnotic paralysis. Neuron 2009;62:862-75.

Corrigan JD, Hinkeldey MS. Relationships between parts A and B of the Trail Making Test. J Clin Psychol 1987;43:402-9.

Court JH, Raven J. Manual for Raven's progressive matrices and vocabulary scales. Section 7: research and references: summaries of normative, reliability, and validity studies and references to all sections. Harcourt Assessment, USA, 1995.

Cragar DE, Berry DT, Fakhoury TA, et al. A review of diagnostic techniques in the differential diagnosis of epileptic and nonepileptic seizures. Neuropsychol Rev 2002;12:31-64.

Cragar DE, Berry DTR, Schmitt FA, et al. Cluster analysis of normal personality traits in patients with psychogenic nonepileptic seizures. Epilepsy Behav 2005;6:593-600.

Craig AD. How do you feel--now? The anterior insula and human awareness. Nat Rev Neurosci 2009;10:59-70.

D'Addio G, Acanfora D, Pinna GD, et al. Reproducibility of short- and long-term poincare plot parameters compared with frequency-domain HRV indexes in congestive heart failure. Comp cardiol 1998;381-4.

Daniels JK, Coupland NJ, Hegadoren KM, et al. Neural and behavioral correlates of peritraumatic dissociation in an acutely traumatized sample. J Clin Psychiatry 2012;73:420-6.

De Carvalho MR, Dias GP, Cosci F, et al. Current findings of fMRI in panic disorder: contributions for the fear neurocircuitry and CBT effects. Expert Rev Neurother 2010;10:291-303.

Dedovic K, Engert V, Duchesne A, et al. Cortisol awakening response and hippocampal volume: Vulnerability for major depressive disorder? Biol Psychiatry 2010;68:847-53.

Deeley $Q$, Oakley DA, Toone B, et al. Modulating the default mode network using hypnosis. Int J Clin Exp Hypn 2012;60:206-28.

Dekkers W, Van Domburg P. The role of doctor and patient in the construction of the pseudoepileptic attack disorder. Medical Health Care Phil. 2000;3:29-38.

Delamont RS, Julu PO, Jamal GA. Changes in a measure of cardiac vagal activity before and after epileptic seizures. Epilepsy Res 1999;35:87-94. 
De Lange FP, Toni I, Roelofs K. Altered connectivity between prefrontal and sensorimotor cortex in conversion paralysis. Neuropsychologia 2010;48:1782-8.

Dell PF. Dissociative phenomenology of dissociative identity disorder. J Nerv Ment Dis 2002;190:10-15.

Dell PF. Involuntariness in hypnotic responding and dissociative symptoms. J Trauma Dissociation 2010;11:1-18.

Demertzi A, Soddu A, Faymonville ME, et al. Hypnotic modulation of resting state fMRI default mode and extrinsic network connectivity. Prog Brain Res 2011;193:309-22.

Demertzi A, Vanhaudenhuyse A, Brédart S, et al. Looking for the self in pathological unconsciousness. Front Hum Neurosci 2013;7:538.

De Pascalis V. Psychophysiological correlates of hypnosis and hypnotic susceptibility. Int J Clin Exp Hypn 1999;47:1 17-43.

Devinsky $O$. Nonepileptic psychogenic seizures: quagmires of pathophysiology, diagnosis, and treatment. Epilepsia 1998;39:458-62.

Devinsky O, Gazzola D, Lafrance WC, Jr. Differentiating between nonepileptic and epileptic seizures. Nat Rev Neurol 201 1;7:210-20.

Devinsky O, Mesad S, Alper K. Nondominant hemisphere lesions and conversion nonepileptic seizures. J Neuropsychiatry Clin Neurosci 2001;13:367-73.

Devinsky O, Morrell MJ, Vogt BA. Contributions of anterior cingulate cortex to behaviour. Brain 1995;1 18:279-306.

Diamond SG, Davis OC, Howe RD. Heart-rate variability as a quantitative measure of hypnotic depth. Int J Clin Exp Hypn 2008;56:1-18.

Dickstein DP, Gorrostieta C, Ombao H, et al. Fronto-temporal spontaneous restingstate functional connectivity in pediatric bipolar disorder. Biol Psychiatry 2010;68:836-846.

Dienes Z, Brown E, Hutton S, et al. Hypnotic suggestibility, cognitive inhibition, and dissociation. Conscious Cogn 2009;18:837-847.

Ding J, An D, Liao W, et al. Altered functional and structural connectivity networks in psychogenic non-epileptic seizures. Disrupted topological properties of brain network in psychogenic non-epilepsy seizures. PLoS One 2013;8:e63850.

Diveky T, Prasko J, Latalova K, et al. Heart rate variability spectral analysis in patients with panic disorder compared with healthy controls. Neuro Endocrinol Lett 2012;33:156-66. 
Drake ME. Conversion hysteria and dominant hemisphere lesions. Psychosom J Consult Liaison Psychiatr 1993;34:524-30.

Drane DL, Williamson DJ, Stroup ES, et al. Cognitive impairment is not equal in patients with epileptic and nonepileptic seizures. Epilepsia 2006;47:1879-86.

Duijsens IJ, Spinhoven P. VTCl Handleiding. Handleiding van de Nederlandse Verkorte Temperament en Karakter Vragenlijst. Datec, The Netherlands, 2001.

Duijsens IJ, Spinhoven P, Goekoop JG, et al. The Dutch temperament and character inventory (TCl): dimensional structure, reliability and validity in a normal and psychiatric outpatient sample. Pers Individ Differ 2000;28:487-99.

Duijsens IJ, Spinhoven P, Verschuur $M$, et al. De ontwikkeling van de Nederlandse verkorte temperament en karakter vragenlijst (TCl-105). Ned Tijdschr Psychol 1999;54:276-83.

Dumas RA. EEG alpha-hypnotizability correlations: a review. Int J Psychophysiol $1977 ; 14: 431-8$.

Duncan R, Oto M. Predictors of antecedent factors in psychogenic nonepileptic attacks: multivariate analysis. Neurology 2008;71:1000-5.

Eddy CM, Cavanna AE. Video-electroencephalography investigation of ictal alterations of consciousness in epilepsy and nonepileptic attack disorder: Practical considerations. Epilepsy Behav 2014;30:24-7.

Egner T, Jamieson G, Gruzelier J. Hypnosis decouples cognitive control from conflict monitoring processes of the frontal lobe. Neurolmage 2005;27:969-78.

El-Hage W, Darves-Bornoz JM, Allilaire JF, et al. Posttraumatic somatoform dissociation in French psychiatric outpatients. J Trauma Dissociation 2002;3:5973.

Elzinga BM, Ardon AM, Heijnis MK, et al. Neural correlates of enhanced workingmemory performance in dissociative disorder: a functional MRI study. Psychol Med 2007;37:235-45.

Erdelyi MH. Subliminal perception and its cognates: theory, indeterminacy, and time. Conscious Cogn 2004;13:73-91.

Ettinger $A B$, Devinsky $O$, Weisbrot $D M$, et al. A comprehensive profile of clinical, psychiatric, and psychosocial characteristics of patients with psychogenic nonepileptic seizures. Epilepsia 1999;40:1292-8. 
Eurelings-Bontekoe EH, Duijsens IJ, Snellen WM, et al. DSM-III-R and ICD-10 personality disorders and personality dimensions as assessed by the Dutch short form of the MMPI: preliminary results. Pers Individ Differ 1995;18:231-9.

Evers A, Zaal JN, Evers AK. Ontwikkelingen in het testgebruik van Nederlands psychologen. De Psycholoog 2002;37:54-61.

Fargo JD, Schefft BK, Szaflarski JP, et al. Accuracy of self-reported neuropsychological functioning in individuals with epileptic of psychogenic nonepileptic seizures. Epilepsy Behav 2004;5:143-50.

Felmingham K, Kemp AH, Williams L, et al. Dissociative responses to conscious and non-conscious fear impact underlying brain function in posttraumatic stress disorder. Psychol Med 2008;38:1771-80.

Filippini N, Maclntosh BJ, Hough MG. Distinct patterns of brain activity in young carriers of the APOE-epsilon4 allele. Proc Natl Acad Sci USA 2009;106:7209-14.

Fiszman A, Alves-Leon SV, Nunes RG, et al. Traumatic events and posttraumatic stress disorder in patients with psychogenic nonepileptic seizures: a critical review. Epilepsy Behav 2004;5:818-25.

Fleisher W, Staley D, Krawetz P, et al. Comparative study of trauma-related phenomena in subjects with pseudoseizures and subjects with epilepsy. Am J Psychiatry 2002;159:660-3.

Fogassi L, Ferrari PF, Gesierich B, et al. Parietal Lobe: From action organization to intention understanding. Science 2005;308:662-7.

Ford C. Somatization and non-epileptic seizures. In: Gates JR, Rowan AJ (Eds.). Nonepileptic seizures, 1st ed. Butterworth-Heinemann, USA, 1993;153-64.

Frances PL, Baker GA, Appletoon PL. Stress and avoidance in pseudoseizures: testing the assumptions. Epilepsy Res 1999;34:241-9.

Franzen MD, Paul D, Iverson GL. Reliability of alternate forms of the Trail Making Test. Clin Neuropsychol 1996;10:125-9.

Fusar-Poli P, Broome MR. Conceptual issues in psychiatric neuroimaging. Curr Opin Psychiatry 2006;19:608-612.

Galimberti CA, Ratti MT, Murelli R, et al. Patients with psychogenic nonepileptic seizures, alone or epilepsy-associated, share a psychological profile distinct from that of epilepsy patients. J Neurol 2003;250:338-46.

Garnefski N, Kraaij V, Spinhoven P. Manual for the use of the Cognitive Emotion Regulation Questionnaire. Datec, The Netherlands; 2006. 
Garnefski N, Legerstee J, Kraaij V, et al. Cognitive self-regulation strategies and emotional problems: differences between adolescents and adults. J Adolesc 2002;25:603-11.

Gaudino EA, Geisler MW, Squires NK. Construct validity in the Trail Making Test: what makes Part B harder? J Clin Exp Neuropsychol 1995;17:529-35.

Gershuny BS, Thayer JF. Relations among psychological trauma, dissociative phenomena, and trauma-related distress: A review and integration. Clin Psychol Rev 1999;19:631-7.

Giesbrecht T, Geraerts E, Merckelbach H. Dissociation, memory commission errors, and heightened autonomic reactivity. Psychiatry Res 2007;150:277-85.

Goldstein LH, Drew C, Mellers J, et al. Dissociation, hypnotisability, coping styles and health locus of control: characteristics of pseudoseizure patients. Seizure 2000;9:314-22.

Goldstein LH, Mellers JD. Ictal symptoms of anxiety, avoidance behaviour, and dissociation in patients with dissociative seizures. J Neurol Neurosurg Psychiatry 2006;77:616-21.

Gudjonsson GH. Suggestibility, intelligence, memory recall and personality: an experimental study. Br J Psychiatry 1983;142:35-7.

Gusnard DA, Akbudak E, Shulman GL, et al. Medial prefrontal cortex and selfreferential mental activity: Relation to a default mode of brain function. Proc Natl Acad Sci USA 2001;98:4259-64.

Guz H, Doganay Z, Ozkan A, et al. Conversion and somatization disorders: Dissociative symptoms and other characteristics. J Psychosom Res 2004;56:287291.

Hall-Patch LH, Brown R, House A, et al. Acceptability and effectiveness of a strategy for the communication of the diagnosis of psychogenic nonepileptic seizures. Epilepsia 2010;51:70-8.

Harden CL, Jovine L, Burgut FT, et al. A comparison of personality disorder characteristics of patients with nonepileptic psychogenic pseudoseizures with those of patients with epilepsy. Epilepsy Behav 2009;14:481-3.

Harnod T, Yang CC, Hsin YL, et al. Heart rate variability in patients with frontal lobe epilepsy. Seizure 2009;18:21-5. 
Hasenkamp W, James GA, Boshoven W, et al. Altered engagement of attention and default networks during target detection in schizophrenia. Schizophr Res $2011 ; 125: 169-73$.

Havermans R, Nicolson NA, Berkhof J, et al. Patterns of salivary cortisol secretion and responses to daily events in patients with remitted bipolar disorder. Psychoneuroendocrinology 2011 ;36:258-65.

Henje Blom E, Olsson EM, Serlachius E, et al. Heart rate variability in adolescent females with anxiety disorders and major depressive disorder. Acta Paediatrica 2010;4:604-11.

Herman JP, Cullinan WE. Neurocircuitry of stress: central control of the hypothalamopituitary-adrenocortical axis. Trends Neurosci 1997;20:78-84.

Hermann BP. Neuropsychological assessment in the diagnosis of non-epileptic seizures. In: Rowan AJ, Gates JR (Eds.). Non-epileptic seizures, 1st ed. Butterworth-Heinemann, USA, 1993;221-32.

Hill SW, Gale SD. Neuropsychological characteristics of nonepileptic seizure semiological subgroups. Epilepsy Behav 2011;22:255-60.

Hingray C, Maillard L, Hubsch C, et al. Psychogenic nonepileptic seizures: characterization of two distinct patient profiles on the basis of trauma history. Epilepsy Behav 2011 ;22:532-6.

Hopper JW, Frewen PA, van der Kolk BA, et al. Neural correlates of reexperiencing, avoidance, and dissociation in PTSD: symptom dimensions and emotion dysregulation in responses to script-driven trauma imagery. J Trauma Stress 2007;20:713-25.

Horton JE, Crawford HJ, Harrington G, et al. Increased anterior corpus callosum size associated positively with hypnotizability and the ability to control pain. Brain 2004; 127:1741-7.

Huikuri HV, Seppanen T, Koistinen M, et al. Abnormalities in beat-to-beat dynamics of heart rate before spontaneous onset of life-threatening ventricular tachyarrhythmias in patients with prior myocardial infarction. Circulation 1996;93:1836-44.

Ito $M$, Adachi $N$, Okazaki $M$, et al. Evaluation of dissociative experiences and the clinical utility of the Dissociative Experience Scale in patients with coexisting epilepsy and psychogenic nonepileptic seizures. Epilepsy Behav 2009;16:491-4. 
Jansen JF, Vlooswijk MC, De Baets MH, et al. Cognitive fMRI and soluble telencephalin assessment in patients with localization-related epilepsy. Acta Neurol Scand 2008;1 18:232-9.

Jeppesen J, Beniczky S, Fuglsang-Frederiksen A, et al. Detection of epileptic-seizures by means of power spectrum analysis of heart rate variability: a pilot study. Technol Health Care 2010;18:417-26.

Kamath MV, Fallen EL. Power spectral analysis of heart rate variability: a noninvasive signature of cardiac autonomic function. Crit Rev Biomed Eng 1993;21:245-311. Kamen PW. Heart rate variability. Aus Fam Phys 1996;25:1087-94.

Kamen PW, Krum H, Tonkin AM. Poincaré plot of heart rate variability allows quantitative display of parasympathetic nervous activity. Clin Sci 1996:91:201-8. Kamen PW, Tonkin AM. Application of the Poincaré plot to heart rate variability: a new measure of functional status in heart failure. Aust NZ J Med 1995;25:18-26.

Karterud HN, Knizek BL, Nakken KO. Changing the diagnosis from epilepsy to PNES: patient's experiences and understanding of their new diagnosis. Seizure 2010;19:40-6.

Katayama H, Gianotti LR, Isotani T, et al. Classes of multichannel EEG microstates in light and deep hypnotic conditions. Brain Topogr 2007;20:7-14.

Kemp B, OLivan J. European data format 'plus'(EDF+), and EDF alike standard format for the exchange of physiological data. Clin Neurophysiol 2003;1 14:1755-61.

Kihlstrom JF. Dissociations and dissociation theory in hypnosis: comment on Kirsch and Lynn (1998). Psychol Bull 1998;123:186-91.

Kikuchi $\mathrm{H}$, Fujii T, Abe $\mathrm{N}$, et al. Memory repression: brain mechanisms underlying dissociative amnesia. J Cogn Neurosci 2010;22:602-13.

Kirmayer L, Robbins J. Three forms of somatization in primary care: prevalence, cooccurrence, and sociodemographic characteristics. J Nerv Ment Dis 1991;179:647-55.

Kirsch I, Lynn SJ. Dissociation theories of hypnosis. Psychol Bull 1998;123:100-15.

Klein TA, Ullsperger M, Danielmeier C. Error awareness and the insula: links to neurological and psychiatric diseases. Front Hum Neurosci 2013;7:14.

Knyazeva MG, Jalili M, Frackowiak RS, et al. Psychogenic seizures and frontal disconnection: EEG synchronisation study. J Neurol Neurosurg Psychiatry $2011 ; 82: 505-11$. 
Koenig T, Prichep L, Lehmann D, et al. Millisecond by millisecond, year by year: normative EEG microstates and developmental stages. Neurolmage 2002;16:41-8.

Krawitz A, Braver TS, Barch DM, et al. Impaired error-likelihood prediction in medial prefrontal cortex in schizophrenia. Neurolmage 201 1;54:1506-17.

Kriegeskorte N, Simmons WK, Belgowan PS, et al. Circular analysis in systems neuroscience: the dangers of double dipping. Nature Neurosci 2009;12:535-40.

Kuyk J, Leijten F, Meinardi $\mathrm{H}$, et al. The diagnosis of psychogenic nonepileptic seizures: a review. Seizure 1997;6:243-53.

Kuyk J, Spinhoven P, Van Emde Boas W, et al. Dissociation in temporal lobe epilepsy and pseudo-epileptic seizure patients. J Nerv Ment Dis 1999;12:713-20.

Laakmann G, Wittmann M, Gugath $M$, et al. Effects of psychotropic drugs (desimipramine, chlorimipramine, sulpiride and diazepam) on the human HPA axis. Psychopharmacology (Berl) 1984;84:66-70.

Labate A, Cerasa A, Mula $M$, et al. Neuroanatomic correlates of psychogenic nonepileptic seizures: A cortical thickness and VBM study. Epilepsia 2012;53:37785.

LaFrance WC, Barry JJ. Update on treatments of psychological nonepileptic seizures. Epilepsy Behav 2005;7:364-74.

LaFrance W, Devinsky O. Treatment of nonepileptic seizures. Epilepsy Behav 2002;3:19-23.

LaFrance WC, Devinsky $O$. The treatment of nonepileptic seizures: historical perspectives and future directions. Epilepsia 2004;45:15-21.

Lafrance WC Jr, Keitner GI, Papandonatos GD, et al. Pilot pharmacologic randomized controlled trial for psychogenic nonepileptic seizures. Neurology 2010;75:1166-73.

Lally N, Spence W, McCusker C, et al. Psychological processes and histories associated with nonepileptic versus epileptic seizure presentations. Epilepsy Behav 2010;17:360-5.

Landgrebe M, Barta W, Rosengarth K, et al. Neuronal correlates of symptom formation in functional somatic syndromes: a fMRI study. Neurolmage 2008;41:1336-44. 
Langers DRM, Jansen JFA, Backes WH. Enhanced signal detection in neuroimaging by means of regional control of the global false discovery rate. Neurolmage 2007;38:43-56.

Lanius RA, Bluhm $R$, Lanius $U$, et al. A review of neuroimaging studies in PTSD: heterogeneity of response to symptom provocation. J Psychiatr Res 2006;40:709-29.

Lanius R, Williamson P, Boksman K, et al. Brain activation during script-driven imagery induced dissociative responses in PTSD: a functional magnetic resonance imaging investigation. Biol Psychiatry 2002;52:305-11.

Latalova K, Prasko J, Diveky T, et al. Autonomic nervous system in euthymic patients with bipolar affective disorder. Neuro Endocrinol Lett 2010;31:829-36.

Lawton G, Baker GA, Brown JB. Comparison of two types of dissociation in epileptic and nonepileptic seizures. Epilepsy Behav 2008;13:333-6.

Lee JS, Koo BH. Fractal analysis of EEG upon auditory stimulation during waking and hypnosis in healthy volunteers. Int J Clin Exp Hypn 2012;60:266-85.

Lee JS, Spiegel D, Kim SB, et al. Fractal analysis of EEG in hypnosis and its relationship with hypnotizability. Int J Clin Exp Hypn 2007;55:14-31.

Leis AA, Ross MA, Summers AK. Psychogenic seizures: ictal characteristics and diagnostic pitfalls. Neurology 1992;42:95-9.

Lenze EJ, Mantella RC, Shi P, et al. Elevated cortisol in older adults with generalized anxiety disorder is reduced by treatment: A placebo-controlled evaluation of escitalopram. Am J Geriatr Psychiatry 2011;19:482-90.

Leonard KN, Telch MJ, Harrington PJ. Dissociation in the laboratory: a comparison of strategies. Behav Res Ther 1999;37:49-61.

Lesser RP. Psychogenic seizures. Neurology 1996;46:1499-507.

Leutmezer F, Schernthaner C, Lurger S, et al. Electrocardiographic changes at the onset of epileptic seizures. Epilepsia 2003;44:348-54.

Lipowski ZJ. Somatization: the concept and its clinical application. Am J Psychiatry 1988;145: 1358-68.

Luteijn F, Kok AR. Handleiding Nederlandse Verkorte MMPI Herziene uitgave, 7. Swets and Zeitlinger Test Services, The Netherlands, 1985.

Maaranen P, Tanskanen A, Haatainen $K$, et al. The relationship between psychological and somatoform dissociation in the general population. J Nerv Ment Dis 2005; 193:690-2. 
Maesschalk C, Vertommen H. Nederlandse Verkorte Temperament en Karakter Vragenlijst (VTCI). Tijdschr Klin Psychol 2001;31:10-5.

Magaudda A, Gugliotta SC, Tallarico R, et al. Identification of three distinct groups of patients with both epilepsy and psychogenic nonepileptic seizures. Epilepsy Behav 2011;22:318-23.

Malik M, Camm AJ, Kleiger RE. Heart rate variability. Standards of measurement, physiological interpretation, and clinical use. Task Force of the European Society of Cardiology and the North American Society of Pacing and Electrophysiology. Eur Heart J 1996;17:354-81.

Malliani A, Pagani M, Lombardi F, et al. Cardiovascular neural regulation explored in the frequency domain. Circulation 1991;84:1482-92.

Mantella RC, Butters MA, Amico JA, et al. Salivary cortisol is associated with diagnosis and severity of late-life generalized anxiety disorder. Psychoneuroendocrinology 2008;33:773-81.

Maquet $\mathrm{P}$, Faymonville $\mathrm{ME}$, Degueldre $\mathrm{C}$, et al. Functional neuroanatomy of hypnotic state. Biol Psychiatry 1999:45:327-33.

Marciano F, Migaux ML, Acanfora D, et al. Quantification of Poincare maps for the evaluation of heart rate variability. Comp cardiol 1994;557-80.

Martin RC, Gilliam FG, Kilgore M, et al. Improved health care resource utilization following video-EEG-confirmed diagnosis of nonepileptic psychogenic seizures. Seizure 1998;7:385-90.

Mathalon DH, Fedor M, Faustman WO, et al. Response-monitoring dysfunction in schizophrenia: an event-related brain potential study. J Abn Psychol 2002;111:22-41.

Matthews PM, Jezzard P. Functional magnetic resonance imaging. J Neurol Neurosurg Psychiatry 2004;75:6-12.

Mazza M, Della Marca G, Martini A, et al. Non-epileptic seizures (NES) are predicted by depressive and dissociative symptoms. Epilepsy Res 2009;84:91-6.

McEwen BS. Physiology and neurobiology of stress and adaptation: Central role of the brain. Physiol Rev 2007;87:873-904.

McGeown WJ, Mazzoni G, Venneri A, et al. Hypnotic induction decreases anterior default mode activity. Conscious Cogn 2009;18:848-55.

Mclsaac SA, Young AH. The role of hypothalamic pituitary-adrenal axis dysfunction in the etiology of depressive disorders. Drugs Today (Barc). 2009;45:127-33. 
McKenzie PS, Oto M, Graham CD, et al. Do patients whose psychogenic nonepileptic seizures resolve, 'replace' them with other medically unexplained symptoms? Medically unexplained symptoms arising after a diagnosis of psychogenic non-epileptic seizures. J Neurol Neurosurg Psychiatry 201 1;18:1-3.

McKenzie P, Oto M, Russell A, et al. Early outcome and predictors in 260 patients with psychogenic nonepileptic attacks. Neurology 2010;74:64-9.

Mead LA, Mayer AR, Bobholz JA, et al. Neural basis of the Stroop interference task: Response competition or selective attention? JINS 2002;8:735-42.

Mechelli A, Price CJ, Friston KJ, et al. Voxel-based morphometry of the human brain: methods and applications. Curr Med Imaging Rev 2005;1:105-13.

Mellers JD. The approach to patients with "non-epileptic seizures". Post Med J 2005;81:498-504.

Mitchell JW, Ali F, Cavanna AE. Dissociative experiences and quality of life in patients with non-epileptic attack disorder. Epilepsy Behav 2012;25: 307-12.

Miu AC, Heilman RM, Miclea M. Reduced heart rate variability and vagal tone in anxiety: trait versus state, and the effects of autogenic training. Auton Neurosci 2009; 145:99-103.

Montano N, Ruscone TG, Porta A, et al. Power spectrum analysis of heart rate variability to assess the changes in sympathovagal balance during graded orthostatic tilt. Circulation 1994;90:1826-31.

Moore PM, Baker GA. Non-epileptic attack disorder: a psychological perspective. Seizure 1997;6:429-34.

Moore PM, Baker GA, McDade G, et al. Epilepsy, pseudoseizures and perceived family characteristics: a controlled study. Epilepsy Res 1994;18:75-83.

Mueser KT, Rosenberg SD, Goodman LA, et al. Trauma, PTSD and the course of severe illness: an interactive model. Schizophr Res 2002;53:123-43.

Nair DG. About being BOLD. Brain Res Brain Res Rev 2005;50:229-43.

Nardo D, Högberg G, Lanius RA, et al. Gray matter volume alterations related to trait dissociation in PTSD and traumatized controls. Acta Psychiatr Scand 2013;128:222-33.

Näring G, Nijenhuis ER. Relationships between self-reported potentially traumatizing events, psychoform and somatoform dissociation, and absorption, in two nonclinical populations. Aust N Z J Psychiatry 2005;39:982-8. 
Nater UM, Bohus M, Abbruzzese $E$, et al. Increased psychological and attenuated cortisol and alpha-amylase responses to acute psychosocial stress in female patients with borderline personality disorder. Psychoneuroendocrinology 2010;35:1565-72.

Nijenhuis ER. Somatoform dissociation. Phenomena, measurement, and theoretical issues. Van Gorcum, The Netherlands, 1999.

Nijenhuis ER, Spinhoven P, Van Dyck R, et al. The development and the psychometric characteristics of the Somatoform Dissociation Questionnaire (SDQ-20). J Nerv Ment Dis 1996;184:688-94.

Nijenhuis ERS, Spinhoven P, van Dyck R, et al. Degree of somatoform and psychological dissociation in dissociative disorders is correlated with reported trauma. J Trauma Stress 1998;11:711-30.

Nijenhuis ER, Spinhoven P, Van Dyck R, et al. Psychometric characteristics of the Somatoform Dissociation Questionnaire: a replication study. Psychother Psychosom 1998;67:17-23.

Nijenhuis ER, van der Hart $O$. Dissociation in trauma: a new definition and comparison with previous formulations. J Trauma Dissociation 2011;12:416-45.

Nijenhuis ER, Van der Hart O, Kruger K. The psychometric characteristics of the Traumatic Experiences Checklist (TEC): first findings among psychiatric outpatients. Clin Psychol Psychother 2002;9:200-10.

Ogawa S, Lee TM, Nayak AS, et al. Oxygenation-sensitive contrast in magnetic resonance image of rodent brain at high magnetic fields. Magn Reson Med 1990;14:68-78.

Ogden P, Pain C, Fisher J. A sensorimotor approach to the treatment of trauma and dissociation. Psych Clin North Am 2006;29:263-79.

Pérez-Fabello MJ, Campos A. Dissociative experiences and creativity in fine arts students. Nordic Psychology 2011;63:72-81.

Perlini AH, Spanos NP. EEG alpha methodologies and hypnotizability: a critical review. Int J Psychophysiol 1991;28:511-30.

Persson H, Ericson M, Tomson T. Carbamazepine affects autonomic cardiac control in patients with newly diagnosed epilepsy. Epilepsy Res 2003;57:69-75.

Pervanidou P, Chrousos GP. Neuroendocrinology of post-traumatic stress disorder. Prog Brain Res 2010;182:149-60. 
Pieper S, Brosschot JF, van der Leeden R, et al. Cardiac effects of momentary assessed worry episodes and stressful events. Psychosom Med 2007;69:901-9.

Pomeranz M, Macaulay RJB, Caudill MA, et al. Assessment of autonomic function in humans by heart rate spectral analysis. Am J Physiol 1985;248:H151-3.

Ponnusamy A, Marques JL, Reuber M. Heart rate variability measures as biomarkers in patients with psychogenic nonepileptic seizures: Potential and limitations. Epilepsy Behav $2011 ; 22: 685-91$.

Ponnusamy A, Marques JL, Reuber M. Comparison of heart rate variability parameters during complex partial seizures and psychogenic nonepileptic seizures. Epilepsia 2012;53:1314-21.

Pradhan C, Sinha S, Thennarasu K, et al. Quantitative analysis of heart rate variability in patients with absence epilepsy. Neurol India 2011;59:25-9.

Prigatano GP, Stonnington CM, Fisher RS. Psychological factors in the genesis and management of nonepileptic seizures: clinical observations. Epilepsy Behav 2002;3:343-9.

Prueter C, Schulz-Venrath U, Rimpau W. Dissociative and associated psychopathological symptoms in patients with epilepsy, pseudoseizures and both seizure forms. Epilepsia 2002;43:188-92.

Pyka M, Burgmer $M$, Lenzen T, et al. Brain correlates of hypnotic paralysis-a restingstate fMRI study. Neurolmage 2011:56:2173-82.

Raij TT, Numminen J, Narvanen S, et al. Strength of prefrontal activation predicts intensity of suggestion-induced pain. Hum Brain Mapp 2009;30:2890-7.

Rainville P, Hofbaver RK, Bushnell MC, et al. Hypnosis modulates activity in brain structures involved in the regulation of consciousness. J Cogn Neurosci 2002; 14:887-901.

Raj SR, Roach DE, Koshman ML, et al. Activity-responsive pacing produces long-term heart rate variability. J Cardiovasc Electrophysiol 2004;15:179-83.

Raven J, Raven JC, Court JH. Manual for Raven's progressive matrices and vocabulary scales. Harcourt Assessment, USA, 2003.

Ray WJ. EEG concomitants of hypnotic susceptibility. Int J Clin Exp Hypn 1997;45:30113.

Raz A, Fan J, Posner Ml. Hypnotic suggestion reduces conflict in the human brain. Proc Natl Acad Sci USA 2005;102:9978-83. 
Reinders AA, Nijenhuis ER, Quak J, et al. Psychobiological characteristics of dissociative identity disorder: a symptom provocation study. Biol Psychiatry 2006;60:730-40.

Reitan RM. The validity of the Trail Making Test as an indicator of organic brain damage. Percept Mot Skills 1958;8:271-6.

Reitan RM. Trail making test. Manual for administration and scoring. Reitan Neuropsychology Laboratory, USA, 1992.

Reuber M. The etiology of psychogenic non-epileptic seizures: towards a biopsychosocial model. Neurol Clin 2009;27:909-24.

Reuber M, Baker $G$, Gill R, et al. Failure to recognize psychogenic nonepileptic seizures may cause death. Neurology 2004a;62:834-5.

Reuber M, Elger CE. Psychogenic nonepileptic seizures: review and update. Epilepsy Behav 2003;4:205-216.

Reuber M, Fernandez G, Helmstaedter C, et al. Evidence of brain abnormality in patients with psychogenic nonepileptic seizures. Epilepsy Behav 2002;3:249-54.

Reuber $M$, House AO. Treating patients with psychogenic non-epileptic seizures. Curr Opin Neurol 2002;15:207-11.

Reuber M, House AO, Pukrop R, et al. Somatization, dissociation and general psychopathology in patients with psychogenic non-epileptic seizures. Epilepsy Res 2003;27:159-67.

Reuber M, Howlett S, Khan A, et al. Non-epileptic seizures and other functional neurological symptoms: predisposing, precipitating, and perpetuating factors. Psychosomatics 2007;48:230-8.

Reuber M, Jamnadas-Khoda J, Broadhurst $M$, et al. Psychogenic nonepileptic seizure manifestations reported by patients and witnesses. Epilepsia $2011 ; 52: 2028-35$.

Reuber M, Pukrop R, Baver J, et al. Multidimensional assessment of personality in patients with psychogenic non-epileptic seizures. J Neurol Neurosurg Psychiatry 2004b;75:743-8.

Riley KC. Measurement of dissociation. J Nerv Ment Dis 1988;176:449-50.

Rimoldi O, Pierini S, Ferrari A, et al. Analysis of short-term oscillations of R-R and arterial pressure in conscious dogs. Am J Physiol 1990;258:H967-76.

Roach D, Sheldon A, Wilson W, et al. Temporally localized contributions to measures of large-scale heart rate variability. Am J Physiol 1998;274:H1 465-71. 
Roach D, Wilson W, Ritchie D, et al. Dissection of long-range heart rate variability: controlled induction of prognostic measures by activity in the laboratory. J Am Coll Cardiol 2004;43:2271-7.

Roder $\mathrm{CH}$, Michal M, Overbeck $\mathrm{G}$, et al. Pain response in depersonalization: a functional imaging study using hypnosis in healthy subjects. Psychother Psychosom 2007;76:115-21.

Rogers BP, Morgan VL, Newton AT, et al. Assessing functional connectivity in the human brain by fMRI. Magn Reson Imaging 2007;25:1347-1357.

Rorden C, Brett M. Stereotaxic display of brain lesions. Behav Neurol 2000;12:191-200. Rosenbaum M. Psychogenic seizures-why women? Psychosomatics 2000;41:147-9.

Rusch N, Weber M, Il'yasov KA, et al. Inferior frontal white matter microstructure and patterns of psychopathology in women with borderline personality disorder and comorbid attention-deficit hyperactivity disorder. Neurolmage 2007;35:738-47.

Salinsky M, Spencer D, Boudreau E, et al. Psychogenic nonepileptic seizures in US veterans. Neurology $2011 ; 77: 945-50$.

Salmon P, Al-Marzooqi SM, Baker G, et al. Childhood family dysfunction and associated abuse in patients with nonepileptic seizures: towards a causal model. Psychosom Med 2003;65:695-700.

Sanderman R, Ormel J. DeUtrechtse Coping Lijst (UCL): validiteit en betrouwbaarheid. Gedrag Gezond 1992;20:32-7.

Sanders S. The perceptual alteration scale: a scale measuring dissociation. Am J Clin Hypn 1986;29:95-102.

Sar $V$, Kundakci T, Kiziltan E, et al. Differentiating dissociative disorders from other diagnostic groups through somatoform dissociation in Turkey. J Trauma Dissociation 2000;1:67-80.

Sar V, Unal SN, Ozturk E. Frontal and occipital perfusion changes in dissociative identity disorder. Psychiatry Res 2007;156:217-23.

Schachar RJ, Chen S, Logan GD, et al. Evidence for an error monitoring deficit in attention deficit hyperactivity disorder. J Abn Child Psychol 2004;32:285-93.

Schlamann M, Naglatzki R, de Greiff A, et al. Autogenic training alters cerebral activation patterns in fMRI. Int J Clin Exp Hypn 2010;58:444-56.

Schneider F, Bermpohl F, Heinzel A, et al. The resting brain and our self: Selfrelatedness modulates resting state neural activity in cortical midline structures. J Neurosci 2008;157:120-31. 
Schreurs PJ, Van deWillige G, Brosschot JF, et al. De Utrechtse Copinglijst: UCL; omgaan met problemen en gebeurtenissen. Herziene handleiding. Swets en Zeitlinger Test Services, The Netherlands, 1993.

Schulz-Stubner S, Krings T, Meister IG, et al. Clinical hypnosis modulates functional magnetic resonance imaging signal intensities and pain perception in a thermal stimulation paradigm. Reg Anesth Pain Med 2004;29:549-56.

Selkirk $M$, Duncan $R$, Oto $M$, et al. Clinical differences between patients with nonepileptic seizures who report antecedent sexual abuse and those who do not. Epilepsia 2008;49:1446-50.

Selwa LM, Geyer J, Nikakhtar N, et al. Nonepileptic seizure outcome varies by type of spell and duration of illness. Epilepsia 2000;41:1330-4.

Shah AJ, Lampert R, Goldberg J, et al. Posttraumatic stress disorder and impaired autonomic modulation in male twins. Biol Psychiatry 2013;73:1 103-10.

Sigurdardottir KR, Olafsson E. Incidence of psychogenic seizures in adults: a population-based study in Iceland. Epilepsia 1998;39:749-52.

Sirven Jl, Glosser DS. Psychogenic nonepileptic seizures: theoretic and clinical considerations. Neuropsychiatry Neuropsychol Behav Neurol 1998;1 1:225-35.

Smith SM, Fox PT, Miller KL, et al. Correspondence of the brain's functional architecture during activation and rest. Proc Natl Acad Sci USA 2009;106:130405.

Smith SM, Miller KL, Salimi-Khorshidi G, et al. Network modelling methods for FMRI. Neurolmage 2011;54:875-91.

Sno HN. Meetinstrumenten bij dissociatieve stoornissen. Tijdschr Psychiatr 2004;46:697700.

Sokhadze E, Baruth J, El-Baz A, et al. Impaired error monitoring and correction function in autism. J Neurother 2010;14:79-95.

Spitzer C, Spelsberg B, Grabe $\mathrm{H}-\mathrm{J}$, et al. Dissociative experiences and psychopathology in conversion disorders. J Psychosom Res 1999;46:291-294.

Stam CJ. Characterization of anatomical and functional connectivity in the brain: A complex networks perspective. Int J Psychophysiol 2010;77:186-194.

Stam CJ, Reijneveld JC. Graph theoretical analysis of complex networks in the brain. Nonlinear Biomed Phys 2007;1:3.

Stein PK, Bosner MS, Kleiger RE, et al. Heart rate variability: a measure of cardiac autonomic tone. Am Heart J 1994;127:1376-81. 
Stern DB. Handedness and the lateral distribution of conversion reactions. J Nerv Ment Dis 1997; 164:122-128.

Stone J, Carson A. The unbearable lightheadedness of seizing: wilful submission to dissociative (non-epileptic) seizures. Neurol Neurosurg Psychiatry 2013;84:822-4.

Stone J, Carson A, Sharpe M. Functional symptoms and signs in neurology: assessment and diagnosis. J Neurol Neurosurg Psychiatry 2005;76:S1i2-12.

Stone J, Sharpe M, Binzer M. Motor conversion symptoms and pseudoseizures: a comparison of clinical characteristics. Psychosomatics 2004;45:492-9.

Stroop JR. Studies of interference in serial verbal reactions. J Exp Psychol 1935;18:64362.

Strutt AM, Hill SW, Scott BM, et al. A comprehensive neuropsychological profile of women with psychogenic nonepileptic seizures. Epilepsy Behav 201 1;20:24-8.

Sun FT, Miller LM, D'Esposito M. Measuring interregional functional connectivity using coherence and partial coherence analyses of $\mathrm{fMRl}$ data. Neurolmage 2004;21:647-58.

Surges R, Thijs RD, Tan HL, et al. Sudden unexpected death in epilepsy: risk factors and potential pathomechanisms. Nat Rev Neurol 2009;5:492-504.

Syed TU, LaFrance WC, Kahriman ES, et al. Can semiology predict psychogenic nonepileptic seizures? A prospective study. Ann Neurol 201 1;69:997-1004.

Szaflarski JP, Szaflarski M, Hughes C, et al. Psychopathology and quality of life: psychogenic non-epileptic seizures versus epilepsy. Med Sci Monit 2003;9:CR 1 13-8.

Taylor VA, Grant J, Daneault V, et al. Impact of mindfulness on the neural responses to emotional pictures in experienced and beginner meditators. Neurolmage $2011 ; 57: 1524-33$.

Terhune DB, Cardena E, Lindgren M. Differential frontal-parietal phase synchrony during hypnosis as a function of hypnotic suggestibility. Int J Psychophysiol 2011;48:1444-7.

Testa SM, Krauss GL, Lesser RP, et al. Stressful life event appraisal and coping in patients with psychogenic seizures and those with epilepsy. Seizure 2012;21:2827.

Thayer JF, Brosschot JF. Psychosomatics and psychopathology: looking up and down from the brain. Psychoneuroendocrinology 2005;30:1050-8. 
Thayer JF, Hansen AL, Saus-Rose E, et al. Heart rate variability, prefrontal neural function, and cognitive performance: the neurovisceral integration perspective on self-regulation, adaptation, and health. Ann Behav Med 2009;37:141-53.

Thompson PM, Batzel LW, Wilkus RJ. Millon clinical multiaxial inventory assessments of patients manifesting either psychogenic or epileptic seizures. J Epilepsy 1992;5:226-30.

Tofts P. Quantitative MRI of the brain measuring changes caused by disease. John Wiley \& Sons Ltd., USA, 2003.

Tojek TM, Lumley M, Barkley $G$, et al. Stress and other psychosocial characteristics of patients with psychogenic nonepileptic seizures. Psychosomatics 2000;41:221-6.

Tomson T, Ericson M, Ihrman C, et al. Heart rate variability in patients with epilepsy. Epilepsy Res 1998;30:77-83.

Tomson T, Nashef L, Ryvlin P. Sudden unexpected death in epilepsy: current knowledge and future directions. Lancet Neurol 2008;7:1021-31.

Tsakiris M, Longo MR, Haggard P. Having a body versus moving your body: neural signatures of agency and body-ownership. Neuropsychologia 2010;48:2740-9.

Tulppo M, Makikallio TH, Takala TE, et al. Quantitative beat-to-beat analysis of heart rate dynamics during exercise. Am J Physiol 1996;271:H244-52.

Vaitl D, Birbaumer N, Gruzelier J, et al. Psychobiology of Altered States of Consciousness. Psychol Bull 2005;131:98-127.

Van Beilen $M$, de Jong BM, Gieteling EW, et al. Abnormal parietal function in conversion paresis. PLoS One 2011;6:e25918.

Van der Boom KJ, van den Hout MA, Huntjens R. Psychoform and somatoform dissociation, traumatic experiences, and fantasy proneness in somatoform disorders. Pers Individ Differ 2010;48:447-51.

Van der Hart O, Van Dijke A, Van Son MJM, et al. Somatoform dissociation in traumatized World War I combat soldiers: a neglected clinical heritage. J Trauma Dissociation 2000;1:33-66.

Vanderlinden J, Van Dyck R, Vandereycken W, et al. Dissociative experiences in the general population in The Netherlands and Belgium: a study with the Dissociative Questionnaire (DIS-Q). Dissociation 1991:180-4.

Vanderlinden J, Van Dyck R, Vandereycken W, et al. Dissociatieve ervaringen bij Vlamingen en Nederlanders; een studie met de Dissociation Questionnaire. Dir Ther 1993;13:57-77. 
Van der Kruijs SJ, Bodde NM, Aldenkamp AP. Psychophysiological biomarkers of dissociation in psychogenic non-epileptic seizures. Acta Neurol Belg 2011;111:99-103.

Van der Kruijs SJ, Bodde NM, Carrette E, et al. Neurophysiological correlates of dissociative symptoms. J Neurol Neurosurg Psychiatry 2014a;85:174-9.

Van der Kruijs SJ, Bodde NM, Vaessen MJ, et al. Functional connectivity of dissociation in patients with psychogenic non-epileptic seizures. J Neurol Neurosurg Psychiatry 2012;83:239-47.

Van der Kruijs SJ, Vonck KE, Langereis GR, et al. Autonomic nervous system functioning associated with psychogenic non-epileptic seizures: Analysis of heart rate variability. Submitted for publication, $2014 \mathrm{~b}$.

VandeVusse L, Hanson L, Berner MA, et al. Impact of self-hypnosis in women on select physiologic and psychological parameters. J Obstet Gynecol Neonatal Nurs 2010;39:159-68.

Vanhaudenhuyse A, Boly $M$, Balteau $E$, et al. Pain and non-pain processing during hypnosis: a thulium-YAG event-related fMRI study. Neurolmage 2009;47:1047-54.

Veltman DJ, de Ruiter MB, Rombouts SA, et al. Neurophysiological correlates of increased verbal working memory in high-dissociative participants: a functional MRI study. Psychol Med 2005;35:175-85.

Vincentiis S, Valente KD, Thomé-Souza S, et al. Risk factors for psychogenic nonepileptic seizures in children and adolescents with epilepsy. Epilepsy Behav 2006;8:294-8.

Vingerhoets AJ, Jeninga AJ, Menges LJ. Het meten van chronische en alledaagse stressoren: Eerste onderzoeksbevindingen met de Alledaagse Problemen Lijst (APL) II. Gedrag Gezond 1989;17:10-7.

Vingerhoets AJ, Van Tilburg MA. Alledaagse Problemenlijst (APL). Swets en Zeitlinger Test Services, The Netherlands, 1994.

Vlamings $\mathrm{PH}$, Jonkman LM, Hoeksma MR, et al. Reduced error monitoring in children with autism spectrum disorder: an ERP study. Eur J Neurosci 2008;28:399-406.

Vlooswijk MC, Jansen JF, Jeukens CR, et al. Memory processes and prefrontal network dysfunction in cryptogenic epilepsy. Epilepsia 2011:52:1467-75.

Vlooswijk MC, Jansen JF, Majoie HJ, et al. Functional connectivity and language impairment in cryptogenic localization-related epilepsy. Neurology 2010;75:395402. 
Voon V, Brezing C, Gallea C, et al. Emotional stimuli and motor conversion disorder. Brain 2010b;133:1526-36.

Voon V, Brezing C, Gallea C, et al. Aberrant supplementary motor complex and limbic activity during motor preparation in motor conversion disorder. Mov Disord $2011 ; 26: 2396-403$.

Voon V, Gallea C, Hattori N, et al. The involuntary nature of conversion disorder. Neurology 2010a;74:223-8.

Waites $A B$, Briellmann RS, Saling $M M$, et al. Functional connectivity networks are disrupted in left temporal lobe epilepsy. Ann Neurol 2006;59:335-43.

Ward NS, Oakley DA, Frackowiak RS, et al. Differential brain activations during intentionally simulated and subjectively experienced paralysis. Cogn Neuropsychiatry 2003;8:295-312.

Wiersema JR, Van der Meere JJ, Roeyers H. ERP correlates of error monitoring in adult ADHD. J Neural Transm 2009;1 16:371-9.

Wik G, Fischer H, Bragee B, et al. Functional anatomy of hypnotic analgesia: a PET study of patients with fibromyalgia. Eur J Pain 1999;3:7-12.

Wilkus RJ, Dodrill C, Thompson PM. Intensive EEG monitoring and psychological studies of patients with pseudoepileptic seizures. Epilepsia 1984;25:100-7.

Witgert ME, Wheless JW, Breier JI. Frequency of panic symptoms in psychogenic nonepileptic seizures. Epilepsy Behav 2005;6:174-8.

Wolf RC, Sambataro F, Vasic N, et al. Aberrant connectivity of resting-state networks in borderline personality disorder. J Psychiatry Neurosci 201 1;36:402-11.

Wolf RC, Thomann PA, Sambataro F, et al. Orbitofrontal cortex and impulsivity in borderline personality disorder: an MRI study of baseline brain perfusion. Eur Arch Psychiatry Clin Neurosci 2012;262:677-85.

Wyllie $\mathrm{E}$, Friedman D, Lüders $\mathrm{H}$, et al. Outcome of psychogenic seizures in children and adolescents compared with adults. Neurology 1991;41:742-4.

Zaatreh MM, Quint SR, Tennison MB, et al. Heart rate variability during interictal epileptiform discharges. Epilepsy Res 2003;54:85-90. 

